Felipe Ptak Lemos

\title{
Nanotribologia em grafeno e outros materiais atomicamente finos
}

Tese de Doutorado

Tese apresentada como requisito parcial para obtenção do grau de Doutor em Física pelo Programa de Pós-graduação em Física, do Departamento de Física da PUC-Rio.

Orientador

Prof. Rodrigio Prioli Menezes

Coorientadora: Dra. Clara Muniz da Silva de Almeida 


\section{Nanotribologia em grafeno e outros materiais atomicamente finos}

Tese apresentada como requisito parcial para obtenção do grau de Doutor em Física pelo Programa de Pós-graduação em Física da PUC-Rio. Aprovada pela Comissão Examinadora abaixo:

Prof. Rodrigio Prioli Menezes

Orientador

Departamento de Física - PUC-Rio

Dra. Clara Muniz da Silva de Almeida

Coorientadora

INMETRO

Prof. Bernardo Ruegger Almeida Neves

UFMG

Prof. Rodrigo Barbosa Capaz

UFRJ

Prof. Benjamin Fragneaud UFJF

Prof. Omar Ginoble Pandoli Departamento de Química - PUC-Rio

Rio de Janeiro, 9 de setembro de 2020 
Todos os direitos reservados. A reprodução, total ou parcial do trabalho, é proibida sem a autorização da universidade, do autor e do orientador.

\section{Felipe Ptak Lemos}

Graduado em física pela Pontifícia Universidade Católica do Rio de Janeiro em 2014. Obteve o título de Mestre em Física pela mesma universidade em 2016, com ênfase em instrumentação científica. Em seu projeto de doutorado, trabalhou com nanotribologia e materiais bidimensionais.

Ficha Catalográfica

Lemos, Felipe Ptak

Nanotribologia em grafeno e outros materiais atomicamente finos / Felipe Ptak Lemos; orientador: Rodrigio Prioli Menezes; coorientadora: Clara Muniz da Silva de Almeida. 2020.

119 f: il. color. ; $30 \mathrm{~cm}$

Tese (doutorado) - Pontifícia Universidade Católica do Rio de Janeiro, Departamento de Física, 2020.

Inclui bibliografia

1. Física - Teses. 2. Fricção. 3. Materiais bidimensionais. 4. Grafeno. 5. TMD. 6. Modelo de Prandtl-Tomlinson. I. Menezes, Rodrigo Prioli. II. Almeida, Clara Muniz da Silva de. III. Pontifícia Universidade Católica do Rio de Janeiro. Departamento de Física. IV. Título. 


\section{Agradecimentos}

Ao meu orientador, Prof. Rodrigo Prioli, pela paciência e dedicação durante o desenvolvimento do trabalho. Pelas discussões frutíferas, e pela transmissão de conhecimento.

À minha co-orientadora, Dra. Clara Almeida, pela disponibilidade em usar os Laboratório de Fenômenos de Superfícies (LAFES) do INMETRO. Pelas discussões do trabalho, pelas medidas, pela ajuda com o Nanowizard e pelas amostras.

Ao Prof. Victor Carôzo e seu aluno Syed Hamza, pelas amostras de $\mathrm{MoS}_{2}$ e $\mathrm{WS}_{2}$ cedidas.

Aos companheiros do Laboratório de Nanoscopia, Dra. Paula Galvão e em especial ao Dr. Douglas Lacerda, pela amizade e apoio. Por todas as ajudas, desde equipamentos e programas no Matlab às mais triviais resoluções físicas, além das discussões sobre música e a natureza da vida.

Aos grupo do LAFES no INMETRO, Igor, Thiago e Pietro, pela ajuda com o laboratório.

Ao Prof. Daniele Fulvio, pela ajuda com as medidas em FTIR.

Aos amigos do vdG, por tornar o ambiente de trabalho mais leve e tornar esta árdua tarefa um pouco mais suportável.

Aos funcionários do vdG, Edson, Nilton, Sérgio e Suellen, sempre solícitos.

Aos professores e funcionários do Departamento de Física. Em especial à Giza, sempre disposta à ajudar nas questões mais complicadas da burocracia envolvida no curso do doutorado.

À minha família, com a qual sempre posso contar nos bons e maus momentos. À CAPES, ao CNPq, à FAPERJ e à PUC-Rio, pelas bolsas e auxílios concedidos, sem os quais a realização deste trabalho não seria possível.

O presente trabalho foi realizado com apoio da Coordenação de Aperfeiçoamento de Pessoal de Nível Superior - Brasil (CAPES) - Código de Financiamento 001. 


\section{Resumo}

Lemos, Felipe Ptak; Menezes, Rodrigo Prioli; Almeida, Clara Muniz da Silva de. Nanotribologia em grafeno e outros materiais atomicamente finos. Rio de Janeiro, 2020. 119p. Tese de Doutorado - Departamento de Física, Pontifícia Universidade Católica do Rio de Janeiro.

Neste trabalho foi estudado o atrito em escala nanométrica em materiais atomicamente finos, como o grafeno e os dicalcogenetos de metais de transição (TMD) como o dissulfeto de molibdênio $\left(\mathrm{MoS}_{2}\right)$ e o dissulfeto de tungstênio $\left(\mathrm{WS}_{2}\right)$. Para tanto, foi utilizado um microscópio de força atômica (AFM), de modo que uma ponta de nitreto de silício suportada por uma haste (cantiléver) é deslizada sob a superfície do material em análise, e o atrito é quantificado de acordo com a deformação lateral da haste. Diferentes parâmetros foram alterados durante a varredura para verificar suas influências, tais como a força normal aplicada durante a varredura e a velocidade relativa em que o sistema ponta-amostra desliza. Parâmetros relativos às superfícies, como número de camadas, rugosidade e adesão também foram investigados. Com a variação da velocidade de deslizamneto, verificamos uma dependência linear com o logaritmo da velocidade, até um ponto de saturação. Esta dependência é amplificada de acordo com o número de camadas do grafeno, de modo que numa monocamada essa inclinação é mais acentuada do que nas demais camadas. Usando o modelo de Prandtl-Tomlinson termicamente ativo, conseguiu-se determinar o potencial de interação entre a ponta do AFM e a superfície analisada, as forças críticas em que a saturação do atrito ocorre e a frequência estipulada com que os eventos de superação da barreira de pontecial acontecem. Com a variação da força normal aplicada, os resultados mostram que grafeno e $\mathrm{MoS}_{2}$ seguem o modelo Johnson-Kendall-Roberts (JKR) de mecânica de contato, enquanto o $\mathrm{WS}_{2}$ segue o modelo Derjaguin-Muller-Toporov (DMT). Para explicar tal diferença, uma hipótese associada ao efeito piezoelétrico é estipulada. Ademais, foi observado que a contaminação das superfícies de grafeno por adsorção de hidrocarbonetos pela exposição ao ar aumenta o atrito medido, e altera sua relação à carga aplicada. Os estágios iniciais da contaminação foram observados, e notou-se que esta se propaga da monocamada para as demais camadas da folha de grafeno, com diferentes taxas de área contaminada por tempo.

\section{Palavras-chave}

Fricção; Materiais bidimensionais; Grafeno; TMD; Modelo de PrandtlTomlinson. 


\section{Abstract}

Lemos, Felipe Ptak; Menezes, Rodrigo Prioli (Advisor); Almeida, Clara Muniz da Silva de (Co-Advisor). Nanotribology of graphene and other atomically thin materials. Rio de Janeiro, 2020. 119p. Tese de Doutorado - Departamento de Física, Pontifícia Universidade Católica do Rio de Janeiro.

In this work, the friction mechanism at the nanoscale of atomically thin materials such as graphene, transition metal dichalcogenides (TMD) such as molybdenum disulfide $\left(\mathrm{MoS}_{2}\right)$ and tungsten disulfide $\left(\mathrm{WS}_{2}\right)$, and muscovite mica was studied with the use of an atomic force microscope (AFM). The AFM scans these materials surfaces with a silicon nitride tip which is attached at the end of a cantilever. The tips slides through the surface and friction is measured by the torsional deflection of the cantilever. Parameters such as applied normal load and sliding speed were varied in order to verify their influences. Surfaces properties such as number of layers, roughness and tip-sample adhesion were also analyzed. The sliding speed experiment shows a linear dependence with the logarithm of the scanning velocity, until friction reaches a saturation point, where it remains the same even at higher velocities. Such dependence is amplified with the number of graphene layers, as a monolayer presents a steeper curve than few layers graphene. The data was fitted using the thermally active Prandtl-Tomlinson model and the tip-sample interaction potential was estimated, as well as the critical forces at which friction saturation occurs and the hop frequency at which a potential barrier is surpassed. In the applied normal load experiment, results shows that both graphene and $\mathrm{MoS}_{2}$ follow the Johnson-Kendall-Roberts (JKR) model, while $\mathrm{WS}_{2}$ and mica follows the Derjaguin-Muller-Toporov (DMT) model. In order to explain the different behavior in both TMDs samples, a hypothesis associated with the piezoelectric effect is proposed. Furthermore, the influence of airborne contamination in the friction of graphene was studied. Results shows that the contact mechanics is altered due to adsorbed hydrocarbon molecules on the graphene flakes. Initial stages of contamination shows that it propagates from the monolayer to subsequent layers, with a different contaminated area over time rate.

\section{Keywords}

Friction; 2D Materials; Graphene; TMD; Prandtl-Tomlinson Mode. 


\section{Sumário}

1 Introdução 14

2 Modelos para fricção em escala atômica 20

2.1 Mecânica de Contato 21

2.2 Modelo de Prandtl-Tomlinson 23

2.3 Modelo de Prandtl-Tomlinson Térmicamente Ativado 27

3 Materiais e Métodos $\quad 31$

3.1 Obtenção e preparação das amostras 31

3.1.1 Grafeno 31

$\begin{array}{lll}3.1 .2 & \text { TMDs } & 33\end{array}$

3.1.3 Mica Muscovita 33

3.2 Microscopia de Força Atômica 34

$\begin{array}{lll}3.2 .1 & \text { Microscopia de Força Lateral } & 38\end{array}$

3.2.2 Curvas de Força-Distância 40

4 Caracterização dos materiais $\quad 42$

4.1 Metodologia $\quad 42$

4.2 Resultados 43

4.2.1 Grafeno 43

4.2.2 TMDs 49

4.2.3 Mica 53

4.2.3.1 Muitas camadas $\quad 53$

4.2.3.2 Poucas camadas $\quad 58$

$\begin{array}{lll}4.3 & \text { Discussão } & 61\end{array}$

4.3.1 Grafeno 61

4.3.2 TMDs 63

$\begin{array}{lll}4.3 .3 \text { Mica } & 65\end{array}$

4.4 Conclusões 66

$5 \quad$ Mecânica de contato em materiais atomicamente finos $\quad 68$

$\begin{array}{lll}5.1 & \text { Metodologia } & 68\end{array}$

$\begin{array}{lll}5.2 & \text { Resultados } & 69\end{array}$

$\begin{array}{lll}5.3 \text { Discussão } & 71\end{array}$

$\begin{array}{lll}\text { 5.3.1 Grafeno } & 71\end{array}$

$\begin{array}{lll}\text { 5.3.2 Comparação entre os TMDs } & 72\end{array}$

$\begin{array}{lll}5.3 .3 \text { Mica } & 75\end{array}$

$\begin{array}{lll}5.4 \text { Conclusões } & 75\end{array}$

6 Influência da velocidade nas medidas de fricção $\quad 77$

6.1 Grafeno $\quad 77$

$\begin{array}{lll}6.1 .1 & \text { Metodologia } & 77\end{array}$

$\begin{array}{lll}6.1 .2 & \text { Resultados } & 78\end{array}$

6.1.3 Discussão 84 
$\begin{array}{lll}6.2 & \text { Outros materiais } & 88\end{array}$

$\begin{array}{lll}6.3 \text { Conclusões } & 90\end{array}$

7 Domínios de fricção por contaminação e exposição ao ar 92

7.1 Métodos 92

$\begin{array}{llr}7.2 & \text { Resultados } & 93\end{array}$

$\begin{array}{lll}7.3 & \text { Discussão } & 101\end{array}$

$\begin{array}{lll}7.4 \text { Conclusões } & 104\end{array}$

8 Conclusões e perspectivas futuras $\quad 105$

$\begin{array}{ll}\text { Referências bibliográficas } & 108\end{array}$ 


\section{Lista de figuras}

Figura 2.1 Esquema de superfícies em contato para os modelos DMT e JKR. As setas indicam o raio de ação da força de adesão entre as superfícies. Imagem adaptada da Referência [30].

Figura 2.2 Simualação para os modelos DMT (azul) e JKR (vermelho) utilizando os mesmos parâmetros em ambas equações.

Figura 2.3 Loops de fricção para um fio de tungstênio numa amostra de grafite com diferentes cargas aplicadas. Figura adaptada da Referência [31].

Figura 2.4 Potencial $V(x, t)$ de interação no Modelo PT.

Figura 2.5 Esquema do fenômeno sitck-slip de transição entre mínimos de potencial com um modelo análogo de sistema massamola. (a) Sistema se encontra num mínimo de potencial, com a mola relaxada; (b) força de atrito provoca estensão na mola (stick); (c) a mola tem energia suficiente para superar a barreira e desliza para o mínimo de potencial adjacente (slip).

Figura 3.1 Rede cristalina do grafeno. Ligação carbono-carbono dada por $a_{C-C}=0,142 \mathrm{~nm}$. Nos vetores de rede, $a=0,246 \mathrm{~nm}$.

Figura 3.2 Processo de esfoliação do grafite. (a) Amostra de HOPG; (b) fita adesiva no HOPG; (c) fita adesiva com HOPG; (d) diversas camadas de grafite espalhados pela fita; (e) fita adesiva no substrato; (f) uma folha de grafite e grafeno em poucas camadas vista por um microscópio ótico.

Figura 3.3 (a) Estrutura de um TMD. Átomos M em preto, e metálicos em amarelo; (b) Estrutura de um TMD vista de cima, revelando um padrão hexagonal. Note que os átomos em preto e amarelo não estão na mesma altura.

Figura 3.4 Estrutura cristalina da mica muscovita. (a) Projeção ao longo da direção [110]; (b) Superfície clivada. Imagem adaptada da Referência [51].

Figura 3.5 AFMs utilizados no trabalho: (a) Multimode; (b) NX-10; (c) NanoWizard.

Figura 3.6 Esquema básico do funcionamento de um AFM.

Figura 3.7 Modos de operação do AFM de acordo com as distâncias e interações sentidas.

Figura 3.8 Esquema das torções do cantiléver num LFM. (a) Torção sofrida pelo cantiléver devido à materiais diferentes e variações topográficas da amostra; (b) Canal de topografia; (c) Canal ida da deflexão lateral; (d) canal volta da deflexão lateral. Imagem adaptada da Referência [55]

Figura 3.9 Ilustração da aproximação e retração do cantiléver na amostra, formando uma curva de força-distância. À direita, a deflexão do cantiléver nos pontos A (longe da superfície), B ( snap to contact), C (limite da aproximação) e D (deflexão pela adesão) é demonstrada. Adaptado da Referência [55] 
Figura 4.1 (a) Micrografia ótica de região contendo mono e multicamada de grafeno; (b) Topografia obtida por AFM da mesma região de itneresse.

Figura 4.2 Espectros Raman para mono, bi e tricamada de grafeno. 44

Figura 4.3 (a) Topografia feita em AFM mostrando diferentes camadas de grafeno; (b) Histograma com distribuição de alturas; (c) Altura em função do intervalo entre camadas. Linha pontilhada representa a altura entre camadas de grafite.

Figura 4.4 Atrito medido em função do número de camadas.

Figura 4.5 Topografia em 3D para (a) $\mathrm{SiO}_{2}$, (b) $1 \mathrm{LG}$, (c) 2LG e (d) 3LG; (e) Rugosidade para os mesmos materiais; (f) Relação entre rugosidade e fricção para diferentes camadas de grafeno.

Figura 4.6 (a) Curva FD para 1LG; (b) Força de adesão em função para diferentes camadas de grafeno; (c) Correlação entre adesão e fricção para diferentes camadas de grafeno.

Figura 4.7 (a) e (c) Imagens em resolução de rede para mono (a) e tricamada (c) de grafeno; (b) e (d) respectivos loops de fricção.

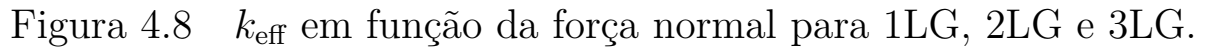

Figura 4.9 (a) Estrutura de $\mathrm{MoS}_{2}$ em forma de estrela; (b) Ampliação da área destacada no quadrado, exibindo resíduos do crescimento; (c) Cristal triangular de $\mathrm{WS}_{2}$; (d) Ampliação da área destacada pelo quadrado.

Figura 4.10 (a) Espectro Raman para $\mathrm{MoS}_{2}$; (b) Espectro PL para $\mathrm{MoS}_{2}$; (c) Espectro Raman para $\mathrm{WS}_{2}$; (d) Espectro PL para $\mathrm{WS}_{2} .51$

Figura 4.11 (a) Topografia da interface entre $\mathrm{SiO}_{2}$ e cristal de $\mathrm{MoS}_{2}$; (b) Linha de perfil demarcada na imagem topográfica, medindo alturas entre cristal e substrato e da barreira entre eles.

Figura 4.12 (a) e (c) Topografia para cristais de $\mathrm{MoS}_{2}$ e $\mathrm{WS}_{2}$, respectivamente; (b) e (d) Mapas de fricção para os mesmos.

Figura 4.13 (a) e (c) Imagens de resolução de rede para $\mathrm{MoS}_{2}$ e $\mathrm{WS}_{2}$, respectivamente. (b) e (d) Perfis stick-slip de força lateral em função do deslocamento da ponta para ambos. Força normal de $120 \mathrm{nN}$ utilizada em ambas as medidas.

Figura 4.14 (a) Folha multicamadas de mica; (b) Linha de perfil mostrada em (a); (c) Outro exemplo de folhas multicamadas apresentando bolhas na superfície; (d) Linha de perfil mostrada na imagem (c).

Figura 4.15 (a) Folha de mica exibindo bolhas na superfície; (b) Área destacada em (a); Bolhas menores na superfície em região ao redor das bolhas em (b).

Figura 4.16 (a) Exemplo de topografia em escala de cinza; (b) Resultado de segmentação pelo método de Otsu.

Figura 4.17 Distribuição de perímetros (a), área (b) e altura(c) das partículas para uma dada força normal.

Figura 4.18 Correlação entre altura e área das partículas segmentadas. Linha vermelha é um ajuste linear. $\bar{R}^{2}=0,69$

Figura 4.19 (a) Mapa de fricção de mica e bolhas na superfície; (b) Histograma do mapa mostrando dois modos. 
Figura 4.20 Gráfico de fricção em função da força normal para bolhas e superfície de mica.

Figura 4.21 (a) Topografia para uma monocamada e poucas camadas adjacentes; (b) Linha de perfil destacada na imagem de topografia. 59

Figura 4.22 Altura das bolhas em poucas camadas em função da área de cada uma. Linha vermelha é um ajuste linear aos dados. $\bar{R}^{2}=0,59$

Figura 4.23 (a) Mapa de fricção de poucas camadas de mica; (b) Resultado da segmentação em função da intensidade dos pixels.

Figura 4.24 (a) Histograma de força lateral para uma área na monocamada de mica sem bolhas; (b) Força lateral média para cada partícula segmentada.

Figura 4.25 Força lateral média em função da área das bolhas.

Figura 5.1 Curvas das medidas de força lateral em função da força normal aplicada pela ponta $F_{k}$. (a) Curva para os quatro materiais; (b) Curvas sem a mica para evidenciar os demais. Linhas sólidas mostram o ajuste pelo modelo JKR, e as linhas pontilhadas pelo modelo DMT.

Figura 5.2 Histograma de forças laterais para $\mathrm{MoS}_{2}$ e $\mathrm{WS}_{2}$ em forças normais similares.

Figura 5.3 Rugosidade RMS média para os materiais estudados.

Figura 5.4 Espectro de fônons para monocamadas de $\mathrm{MoS}_{2}$ (linhas sólidas em vermelho) e $\mathrm{WS}_{2}$ (linhas pontilhadas em azul). Os picos para o $\mathrm{WS}_{2}$ na densidade de estados são identificados pelas setas azuis. Figura adaptada da Referência [86].

Figura 6.1 Fricção medida para diferentes camadas à diferentes velocidades.

Figura 6.2 Medição de força lateral em função do logaritmo da velocidade de varredura para diferentes camadas de grafeno. Linhas sólidas representam as funções do modelo PTT ajustada aos dados.

Figura 6.3 Energia dissipada calculada em função da velocidade de varredura.

Figura 6.4 Probabilidade cumulativa de forças de fricção para (a) 1LG; (b) 2LG; (c) 3LG; e (d) 4LG em diferentes velocidades de varredura. As velocidades são dadas por: $1,0 \mathrm{\mu m} \mathrm{s}^{-1}$ (quadrados pretos), $5,0 \mathrm{\mu m} \mathrm{s}^{-1}$ (círculos vermelhos), $12 \mu \mathrm{m} \mathrm{s}^{-1}$ (triângulos azuis), $22 \mu \mathrm{m} \mathrm{s}^{-1}$ (losangos magenta) e $30 \mathrm{\mu m} \mathrm{s}^{-1}$ (cruzes verdes)

Figura 6.5 Estimativa da amplitude do potencial periódico $V_{0}$ (barras vermelhas) e barreira de potencial $\Delta V$ (barras azuis) para quatro diferentes camadas de grafeno.

Figura 6.6 Espectros de ressonância lateral (linha azul) e vertical (linha vermelha) do cantiléver em contato com a superfície de grafeno. Pico de ressonância lateral em $f_{0}=1,7 \mathrm{MHz}$, e ressonância vertical em $f_{0}=2,1 \mathrm{MHz}$ ).

Figura 6.7 Espectro de ressonância do sistema cantiléver-grafeno. (a) Deflexão lateral; (b) deflexão vertical. 
Figura 6.8 Fricção medida em função do logaritmo da velocidade de varredura para $\mathrm{MoS}_{2}$ (azul) e $\mathrm{WS}_{2}$ (vermelho). Linhas pontilhadas são ajustes lineares.

Figura 6.9 Fricção em função do logaritmo da velocidade de varredura para monocamada de mica.

Figura 7.1 Região contendo mono e multicamada de grafeno em cerca de uma hora após a esfoliação. (a) Topografia obtida por AFM. A seta indica um defeito na folha; (b) Mapa de fricção da mesma região. As setas indicam regiões de maior fricção na monocamada; (c) Perfil de força lateral da linha tracejada em (a) e (b).

Figura 7.2 Topografia (a) e mapa de fricção (b) simultaneamente adquiridos pelo AFM. Perfil das linhas tracejadas de topografia (c) e força lateral (d).

Figura 7.3 Evolução temporal dos domínios de fricção. (a) Topografia após cerca de 30 minutos da esfoliação; (b)-(f) mapas de fricção após cerca de 30 minutos (b), 150 minutos (c), 170 minutos (d), 185 minutos (e) e 190 minutos (f) da esfoliação.

Figura 7.4 (a) Mapa de fricção mostrando área contaminada em mono e bicamada de grafeno; (b) Evolução temporal da área coberta pela contaminação.

Figura 7.5 Esquema demonstrando a cinética de contaminação. (a) Superfície de grafeno e hidrocarbonetos no ar; (b) Moléculas de hidrocarbonetos adosrvidas nas bordas e defeitos da folha de grafneo; (c) Hidrocarbonetos cobrindo a monocamada de grafeno; (d) Após cobertura total da monocamada, a bicamada de grafeno passa também a adosrver moléculas de hidrocarbonetos.

Figura 7.6 Curvas da força lateral medida em função da força normal para regiões limpas (a) e contaminadas (b) do grafeno. Símbolos (círculos e quadrados) preenchidos representam carga de força normal, e símbolos vazios descarga de força normal.

Figura 7.7 Topografia e mapas de fricção após contaminação por exposição ao ar. (a) e (c) Topografia e fricção após 5 horas de exposição; (b) e (d) Topografia e fricção após 29 horas de exposição.

Figura 7.8 Espectro FTIR para um substrato de $\mathrm{SiO}_{2}$ após meses de exposição ao ar. 


\section{Lista de tabelas}

Tabela 5.1 Parâmetros obtidos através dos ajustes dos modelos JKR (grafeno e $\mathrm{MoS}_{2}$ ) e DMT (WSS 2 e mica). $F_{\text {ad }}$ e $\tilde{\mu}$ foram usados como parâmetros livres no ajuste. Energia livre de superfície $\Delta \gamma$ calculada pela relação com a força de adesão. Tensão de cisalhamento calculada com o coeficiente de atrito não linear.

Tabela 5.2 Comparação da força de adesão medida experimentalmente por curvas força-distância com os resultados dos ajustes.

Tabela 6.1 Resultados do ajuste pela eq. (2-36), e frequência de pulos estimada.

Tabela 6.2 Força de friç̧ão com maior probabilidade de pulo entre mínimos de potencial.

Tabela 6.3 Frequências de ressonância normal e lateral do sistema cantiléver-grafeno. 


\section{Introdução}

O grafeno é um material alótropo do carbono, composto por camadas, onde os átomos de carbono são dispostos numa estrutura hexagonal. Devido à este arranjo, uma camada de grafeno possui espessura próximo de um átomo, o que o faz ser considerado um material bidimensional (2D). O grafeno é, na verdade, considerado a base de outros alótropos de carbono. Ao se empilhar diversas camadas de grafeno, obtém-se o grafite altamente ordenado (HOPG); enrolando-o numa esfera, obtém-se o fulereno; e ao dobrá-lo de forma cilíndrica, obtém-se um nanotubo de carbono [1].

Embora a estrutura eletrônica do grafeno já seja conhecida desde 1947, com um estudo usando um modelo tight-binding [2], sua obtenção só foi realizada em 2004, por A. Geim e K. S. Novoselov, pelo método da esfoliação mecânica [3]. Neste método, uma fita adesiva é aderida à um cristal de HOPG. Ao ser retirada, camadas de grafeno são espalhadas pela fita, a qual é então colada num substrato, normalmente de dióxido de silício $\left(\mathrm{SiO}_{2}\right)$, de modo à transferir tais camadas. Ao passar dos anos, métodos de preparo mais confiáveis foram sendo usados para a síntese de grafeno, como o crescimento epitaxial pela desorção de átomos de silício num cristal de carbeto de silício e o crescimento por deposição química em fase vapor (CVD - do inglês chemical vapor depoistion), em que moléculas contendo carbono são aquecidas ao ponto de terem suas ligações quebradas, e os átomos de carbono são então depositados numa superfície metálica.

O estudo do grafeno se tornou atraente para a comunidade científica pois este possui propriedades físicas diferentes de seu equivalente volumétrico, o grafite. Dentre suas propriedades, notou-se que ele possui uma excelente mobilidade eletrônica [4], alta condutividade térmica [5], é transparente [6], e flexível [7], embora seja também rígido [8]. Isso o fez um candidato a ser usado na fabricação de diferentes tipos de dispositivos, como transistores [9], sensores de gás [10] e sistemas nano- e micro-eletromecânicos (NEMS e MEMS, respectivamente - do inglês Nano- e Micro-Electromechanical System) [11].

Porém, com dificuldades de síntese e uso em aplicações, outros materiais bidimensionais além do grafeno vêm sendo propostos para uso na fabricação destes dispositivos. É o caso dos dicalcogenetos de metais de transição (TMD 
- do inglês transition metals dichalcogenides), heteroestruturas do tipo $\mathrm{MX}_{2}$, onde M é um metal de transição (Mo, W, Nb) e X um calcogênio (S, Se e Te), os quais também apresentam uma rede cristalina do tipo hexagonal, organizado em camadas. Dentre os problemas com o grafeno, por exemplo, destaca-se a síntese por CVD, onde o grafeno normalmente é crescido num substrato metálico (em geral cobre) para então ser transferido para um substrato isolante como o $\mathrm{SiO}_{2}$ com a ajuda de um polímero. Esse processo de transferência deixa resíduos do polímero na superfície e pode provocar defeitos [12]. Já os TMDs podem ser crescidos diretamente neste tipo de substrato [13]. Na parte eletrônica, as bandas de valência e condução do grafeno se encontram no chamado Ponto de Dirac, de modo que o gap é nulo, fazendo-o um material semimetálico [1]. Já alguns TMDs, como o dissulfeto de molibdênio $\left(\mathrm{MoS}_{2}\right)$ e o dissulfeto de tungstênio $\left(\mathrm{WS}_{2}\right)$, apresentam gap de energia, sendo estes semicondutores diretos [14]. Além de materiais semicondutores, o estudo de isolantes atomicamente finos como a mica também pode ser interessante [15].

Uma outra proposta de aplicação desses é o uso como lubrificantes sólido. De fato, materiais laminares como grafite e $\mathrm{MoS}_{2}$ são usados na área tribológica há anos. Esses materiais tem uma ligação fraca entre as camadas, do tipo van der Waals, de modo que as camadas possam deslizar entre si, ou mesmo serem desfeitas, provocando uma situação de baixo atrito. Ademais, em sistemas como NEMS e MEMS, é necessário um controle da força de interação entre superfícies, e, para tanto, lubrificantes sólidos como o grafeno e outros materiais bidimensionais são propostos para serem usados nesses sistemas. Assim como acontece em propriedades físicas destes materiais bidimensionais, as propriedades tribológicas são diferentes de suas versões macroscópicas, e o estudo dos mecanismos de básico de fricção e dissipação de energia nesses materiais acontece desde então.

Entre os empenhos para se investigar a fricção nesses nanomateriais, destacam-se estudos experimentais e teóricos, os quais mostram que o atrito em nanoescala é influenciado por uma diversidade de parâmetros, tais como número de camadas $[16,17]$, interação com o substrato $[17,18,19]$, rugosidade da superfície $[20,21,22]$, orientação cristalográfica $[23,24,25,26]$ e temperatura [27, 28, 29]. Vale ressaltar que a friç̧ão em nanoescala se difere consideravelmente da fricção em macroescala, a qual estamos acostumados a lidar no dia-a-dia. Nela, parâmetros como área de contato entre as superfícies, velocidade relativa de deslizamento são importantes, e a dependência com a força normal apresenta uma forma não-linear [30].

Experimentalmente, a forma mais usual de se medir fricção em nanomateriais é com o uso de um microscópio de força atômica (AFM - do inglês Atomic 
Force Microscope), atuando no modo de contato, denominado microscópio de força de fricção (FFM - do inglês Friction Force Microscope) ou microscópio de força lateral (LFM - do inglês Lateral Force Miscroscope) [31]. O instrumento consistente numa ponta, em geral de nitreto de silício $\left(\mathrm{Si}_{3} \mathrm{~N}_{4}\right)$, presa na extremidade de uma haste (cantiléver ${ }^{1}$ ). Essa ponta entra em contato com a superfície a ser analisada e passa então a deslizar sobre ela. O atrito entre ponta e superfície causa uma deflexão lateral no cantiléver, a qual é quantificada para que se possa obter a força de atrito entre as superfícies em movimento. Quanto aos métodos teóricos, estes consistem de simulações computacionais, usando diferentes métodos como Método dos Elementos Finitos (FEM - do inglês Finite Element Method) [17], dinâmica molecular [20] e até mesmo modelos com aprendizado de máquinas [32].

No grafeno em especial, o número de camadas apresenta um papel importante, uma vez que resultados experimentais mostram que o atrito é maior quanto menor for o número de camadas. Uma primeira explicação para este fenômeno foi dada por T. Filleter e colaboradores, num trabalho publicado em 2009 [16]. Os autores mediram o atrito em filmes mono e bicamada de grafeno epitaxial com um FFM, e atribuem a diferença no atrito entre as camadas ao acoplamento elétron-fônon $(e-f)$ entre as camadas durante o movimento relativo entre as superfícies. Estudos posteriores mostram que a diferença no atrito medido em diferentes camadas se deve à deformação flexural (chamado de efeito puckering) da folha de grafeno [17, 18], o qual ocorre quando asperezas das superfícies entram em contato. Essa deformação se deve à interação da folha de grafeno com o substrato sob o qual está depositado. Assim, quanto menos camadas, menor a interação com o substrato e maior liberdade para a folha se deformar na direção fora do plano. Essa deformação causa um aumento na área de contato entre ponta e superfície, o que consequentemente aumenta o atrito medido. Simulações de dinâmica molecular reportadas recentemente apresentam indícios de que o aumento das forças de fricção durante o estágio inicial do movimento pode ser resultado da deformação elástica sofrida pelos átomos em contato [33]. Esta deformação, resultante de tensões cisalhantes oriundas do movimento induzido por uma força externa faz com que as superfícies se adaptem melhor uma a outra

1

O termo usado na literatura internacional é o inglês cantilever, cuja tradução é uma adaptação para o português cantiléver. Embora pouco usual, o verbete está registrado nos dicionários da lingua portuguesa. Trata-se de uma estrutura rígida em forma de viga com uma extremidade fixa num ponto de apoio e a outra livre. Ao decorrer desta tese, os termos cantiléver e haste serão usados de forma equivalente. 
aumentando o número de átomos em uma posição de equilíbrio mecânico. Este maior equilíbrio mecânico proporciona o aumento nas forças de fricção durante o movimento.

Seguindo o argumento da interação com o substrato, a rugosidade também exerce influência na friç̧ão medida. Quando essas nanoestruturas 2D são depositadas em outros materiais atomicamente finos e lisos, como a mica e o nitreto de boro hexagonal (h-BN), há uma interação tipo van der Waals, como ocorre nas próprias camadas das nanoestruturas. A interação entre a superfície em análise e o substrato é, portanto, mais forte, diminuindo a possibilidade do enrugamento da superfície $2 \mathrm{D}$, fazendo com que o atrito medido seja praticamente idêntico mesmo com diferentes números de camadas medidas. Em outras palavras, não existe uma distinção significativa entre o material 2D em poucas camadas para o de muitas camadas, como se o material se aproximasse de seu equivalente macroscópico. Este efeito também foi estudado com simulações computacionais [17, 22]. É importante ressaltar, porém, que estes efeitos de rugosidade, interação com substrato e deformação da folha analisada não descartam necessariamente a contribuição do acoplamento $e-f$ como mecanismo de atrito em materiais 2D.

A orientação cristalográfica também mostrou-se ser um importante parâmetro quando M. Dienwiebel e colaboradores mediram o atrito numa amostra de HOPG variando o ângulo de orientação da amostra em relação à posição do cantiléver. A medida mostrou um aumento na fricção com uma periodicidade de $\sim 60^{\circ}$. Os autores ainda afirmam que este efeito se dá pela adesão de pedaços de grafite na ponta, tendo portanto, um deslizamento entre duas camadas de grafite no processo de varredura do microscópio. Em outro estudo, C. M. Almeida e colaboradores verificaram que numa monocamada de grafeno, o atrito medido chega a ser $\sim 80 \%$ maior ao longo da direção armchair do que ao longo da direção zigzag, dependendo da força normal aplicada [24]. Além dessa discrepância entre direções cristalinas, a orientação pode dar origem à diferentes domínios de fricção, os quais podem ser causados por deformações mecânicas, podendo apresentar periodicidade em relação à orientação [34], ou mesmo uma direção preferencial para ocorrer [25]. Outro fator contribuinte em tais domínios de fricção é a contaminação ambiente da amostra [35].

A influência da velocidade relativa de deslizamento entre as superfícies é um dos fatores que mais diferem a fricção da nanoescala para a fricção em macroescala. Enquanto na última não há dependência explícita do atrito com a velocidade, em nanoescala essa dependência costuma ser linear com o logaritmo da velocidade [36] e pode depender do tipo de terminação química do material em análise [37]. A dependência da velocidade relativa entre as 
superfícies tem particular importância e sua análise pode dar informações sobre o potencial de interação presente. Para baixas velocidades, da ordem de $\mathrm{nm} \mathrm{s}^{-1}$ à dezenas de $\mu \mathrm{ms}^{-1}$, as quais ocorrem nos experimentos envolvendo FFM, flutuações térmicas na barreira de potencial, responsável pela resistência ao movimento, afetam a probabilidade dos átomos das superfícies em contato se movimentarem de um mínimo de potencial a outro, influenciando então as forças de atrito observadas. Apesar dessa influência ter sido amplamente estudada num âmbito geral [36, 38, 39, 40], ainda há poucos estudos referentes à materiais 2D [41, 42]. Simulações computacionais em grafeno mostraram resultados contraditórios, apontando tanto para uma dependência não-linear com o logaritmo da velocidade [43], quanto à nenhuma influência da velocidade [33]. Simulações com h-BN mostram uma dependência exponencial num regime de baixas velocidades [29].

Neste tese, pretendemos estudar mecanismos de fricção em nanoescala em estruturas 2D, tais como o grafeno, o $\mathrm{MoS}_{2}$, o $\mathrm{WS}_{2}$ e a mica. Para tanto, utilizamos um AFM para a medida de atrito entre uma ponta de $\mathrm{Si}_{3} \mathrm{~N}_{4}$ e as supracitadas nanoestruturas. Parâmetros como força normal e velocidade de deslizamento foram variados, para estudarmos os diferentes tipos de mecânica de contato e potencial de interação envolvidos, respectivamente. Fatores como rugosidade e adesão da ponta na superfície também são brevemente explorados. Ademais, um estudo sobre a contaminação da superfície de grafeno e sua influência no atrito medido é apresentado.

No Capítulo 2 da tese, apresentamos modelos para a fricção em nanoescala, como o Modelo de Prandtl-Tomlinson (Modelo PT), o Modelo de Prandtl-Tomlinson térmicamente ativado (Modelo PTT), e diferentes modelos de mecânica de contato, como os modelos Derjaguin-Muller-Toporov (DMT) e Johnson-Kendall-Roberts (JKR).

No Capítulo 3 apresentamos os materiais utilizados no estudo, suas características físicas, como a estrutura cristalina, e os métodos de obtenção das amostras. Ademais, explicamos brevemente o funcionamento de um FFM.

No Capítulo 4 mostraremos a caracterização dos materiais estudados. Resultados quanto ao número de camadas no grafeno, altura entre camadas, rugosidade e força de adesão serão discutidos, assim como o estado da superfície dos materiais, revelando fenômenos como oxidação e contaminação das mesmas. Medidas de fricção em resolução de rede também serão reportadas.

No Capítulo 5 discutimos a mecânica de contato nos materiais. Veremos como grafeno e $\mathrm{MoS}_{2}$ seguem o modelo JKR, enquanto o $\mathrm{WS}_{2}$ e a mica seguem o modelo DMT. Com o ajuste do modelo, parâmetros como a resistência ao cisalhamento são estimados. Ademais, uma proposta relacionada ao efeito 
piezoelétrico é proposta para explicar a diferença de comportamento entre os dois TMDs.

No Capítulo 6 abordamos os resultados referentes à influência da velocidade relativa entre as superfícies no mecanismo de fricção. Para o caso do grafeno, um ajuste dos dados ao modelo PTT foi feito em função do número de camadas. Resultados como força de fricção crítica, barreira de potencial entre ponta e superfície e frequências mecânicas do sistema serão discutidos.

No Capítulo 7 será apresentada a influência da contaminação ambiente nas folhas de grafeno. Um estudo da taxa de contaminação por área da folha é feito, e a natureza dos contaminantes é discutida.

Por fim, no Capítulo 8, temos as conclusões finais e perspectivas para futuros trabalhos a serem realizados. 


\section{2}

\section{Modelos para fricção em escala atômica}

A friç̧ão em escala atômica ou nanométrica se difere em muito da fricção em macroescala a qual estamos acostumados no dia-a-dia. De fato, a fricção é dos fenômenos mais antigos conhecidos pela humanidade, e seu uso é registrado desde a Idade da Pedra, com a dissipação de energia em forma de calor para se criar fogo, aos egípcios usando água como lubrificante em areia para melhor transportar peças de madeira. Do estudo macroscópico do atrito, alguns resultados são bem conhecidos como a independência com a área de contato e com a velocidade, e a Lei de Amonton, em que o atrito ${ }^{1}$ é proporcional à força normal aplicada, e a constante de proporcionalidade é o coeficiente de atrito [30]. A Lei de Amonton é expressada como:

$$
F_{F}=\mu F_{n},
$$

onde $\mu$ é o coeficiente de atrito. Entretanto, a invenção do AFM e o modo FFM abriu caminhos para uma nova área de conhecimento, a da nanotribologia [31]. Na nanotribologia, interações de asperezas simples ocorrem, e a contribuição de um único átomo pode ser relevante. Parâmetros como área de contato, velocidade de deslizamento das superfícies ou temperatura passam a ter importância nesse novo cenário.

Neste capítulo, iremos abordar modelos para a fricção em escala atômica ou nanométrica, começando pelo contato de dois sólidos, descrevendo os modelos Derjaguin-Muller-Toporov (DMT) e Johnson-Kendall-Roberts (JKR). Em seguida, abordaremos a interação entre ponta e superfície, começando pelo Modelo de Prandtl-Tomlinson (PT) e depois descrevendo sua extensão, Modelo de Prandtl-Tomlinson térmicamente ativado (PTT), o qual leva em conta o papel da temperatura no processo de fricção.

1

No decorrer desta tese, os termos força de atrito, força de fricção e força lateral, assim como suas representações $f_{L}$ e $F_{F}$ são usados de forma equivalente. 


\section{1}

\section{Mecânica de Contato}

A área de contato é um importante parâmetro para a fricção em escala nanométrica. Ao entrar em contato, tanto ponta quanto superfície podem sofrer pequenas deformações. O tipo de deformação, assim como sua extensãp, pode depender do formato dos objetos em contato e da força de adesão $F_{a d}$ entre eles. No caso de um AFM, em geral se considera um contato entre uma esfera e um plano, representando ponta e superfície, respectivamente.

Neste tipo de contato, é caracterizado uma distância $\delta$ entre os objetos, e a deformação deixa uma impressão circular de raio $r$. Um primeiro modelo foi proposto por Hertz, tal que o raio $r$ seja muito menor que o raio da ponta, i.e., $r \ll R$. Este raio $r$ é dado por:

$$
r=\left(\frac{3 R}{4 E_{r}}\right)^{1 / 3} F_{N}^{1 / 3}
$$

enquanto a distância é caracterizada por:

$$
\delta=\frac{r^{2}}{R}
$$

$\mathrm{Na}$ eq. (2-2), $E_{r}$ é o módulo elástico reduzido, definido como:

$$
\frac{1}{E_{r}}=\frac{1-\nu_{p}^{2}}{E_{p}}+\frac{1-\nu_{a}^{2}}{E_{a}},
$$

onde $\nu_{i}$ são as razões de Poisson para ponta $(p)$ e amostra (a), e $E_{i}$ são os módulos elásticos correspondentes.

Entretanto, o modelo de Hertz não considera a adesão entre os dois corpos. Porém, na escala nanométrica, a adesão proveniente de forças atrativas tem relevância no contato. Entre os modelos em que a adesão é considerada, destacam-se os modelos Derjaguin-Muller-Toporov (DMT) e Johnson-KendallRoberts [30].

O modelo JKR costuma descrever contatos em que a deformação elástica causada pela forças de adesão é grande comparada ao raio de ação desta última. Isto é, contatos em que a força de adesão é alta, seja pelo tipo de material ou pelo tamanho do raio da ponta. Já o modelo DMT costuma descrever contatos em que esta deformação é pequena, normlamente entre superfícies mais rígidas, com menor adesão entre elas [30,44]. Um esquema de superfícies em contato de acordo com os modelos pode ser visto na Figura 2.1. 

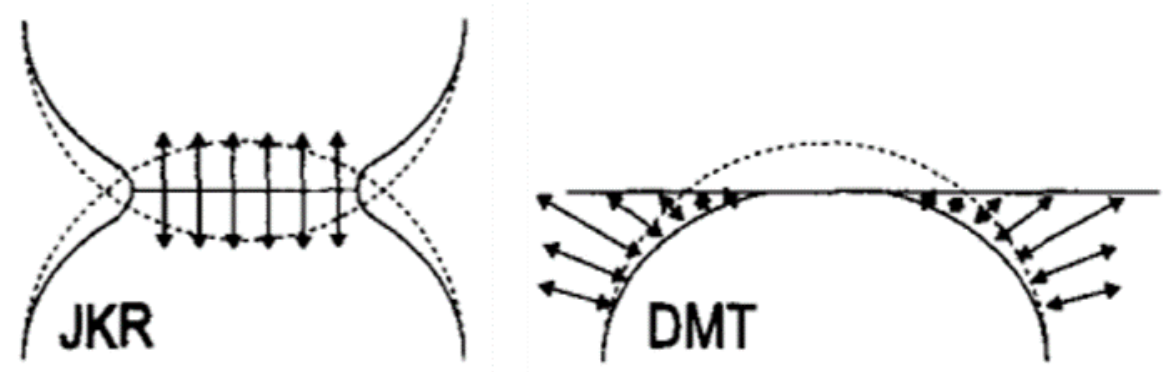

Figura 2.1: Esquema de superfícies em contato para os modelos DMT e JKR. As setas indicam o raio de ação da força de adesão entre as superfícies. Imagem adaptada da Referência [30].

Sendo assim, modificações ao modelo de Hertz foram feitas em função do trabalho e da força de adesão.O raio $r$ de deformação no modelo DMT é dado por:

$$
r^{\mathrm{DMT}}=\left(\frac{3 R}{4 E_{r}}\right)^{1 / 3}\left(F_{N}+F_{a d}\right)^{1 / 3},
$$

enquanto a força de adesão é descrita como:

$$
F_{a d}^{\mathrm{DMT}}=2 \pi R \Delta \gamma
$$

Para o modelo JKR temos as seguintes equações:

$$
r^{\mathrm{JKR}}=\left(\frac{3 R}{4 E_{r}}\right)^{1 / 3}\left(\sqrt{F_{a d}}+\sqrt{F_{N}+F_{a d}}\right)^{2 / 3},
$$

e, para a adesão:

$$
F_{a d}^{\mathrm{JKR}}=\frac{3}{2} \pi R \Delta \gamma
$$

A transição entre os limites para cada modelo é dada por um parâmetro adimensional, chamado parâmetro de Tabor, $\mu_{T}$, dado por [44]:

$$
\mu_{T}=\frac{1}{z_{0}}\left(\frac{16 R \Delta \gamma}{9 E_{r}^{2}}\right)
$$

onde $\Delta \gamma$ é a energia livre da superfície (o trabalho da adesão), e $z_{0}$ é a distância de equilíbrio entre as duas superfícies.

A força de fricção $F_{F}$ é relacionada com a área de contato pela relação de Bowden-Tabor:

$$
F_{F}=\tau A,
$$

onde $\tau$ é a resistência de cisalhamento, e $A=\pi r^{2}$ a área de contato. Sendo assim, conseguimos escrever a força de fricção para ambos os modelos: 


$$
\begin{gathered}
F_{F}^{\mathrm{DMT}}=\tilde{\mu}\left(F_{N}+F_{a d}\right)^{2 / 3} ; \\
F_{F}^{\mathrm{JKR}}=\tilde{\mu}\left(\sqrt{F_{a d}}+\sqrt{F_{N}+F_{a d}}\right)^{4 / 3},
\end{gathered}
$$

onde $\tilde{\mu}$ é o coeficiente não linear de atrito, em ambos casos descrito como:

$$
\tilde{\mu}=\pi \tau\left(\frac{3 R}{4 E_{r}}\right)^{2 / 3}
$$

Uma simulação dos dois modelos é exibida na Figura 2.2. Ambas as curvas foram feitas utilizando os mesmos parâmetros para $\tilde{\mu}$ e $F_{a d}$ e as mesmas forças normais aplicadas.

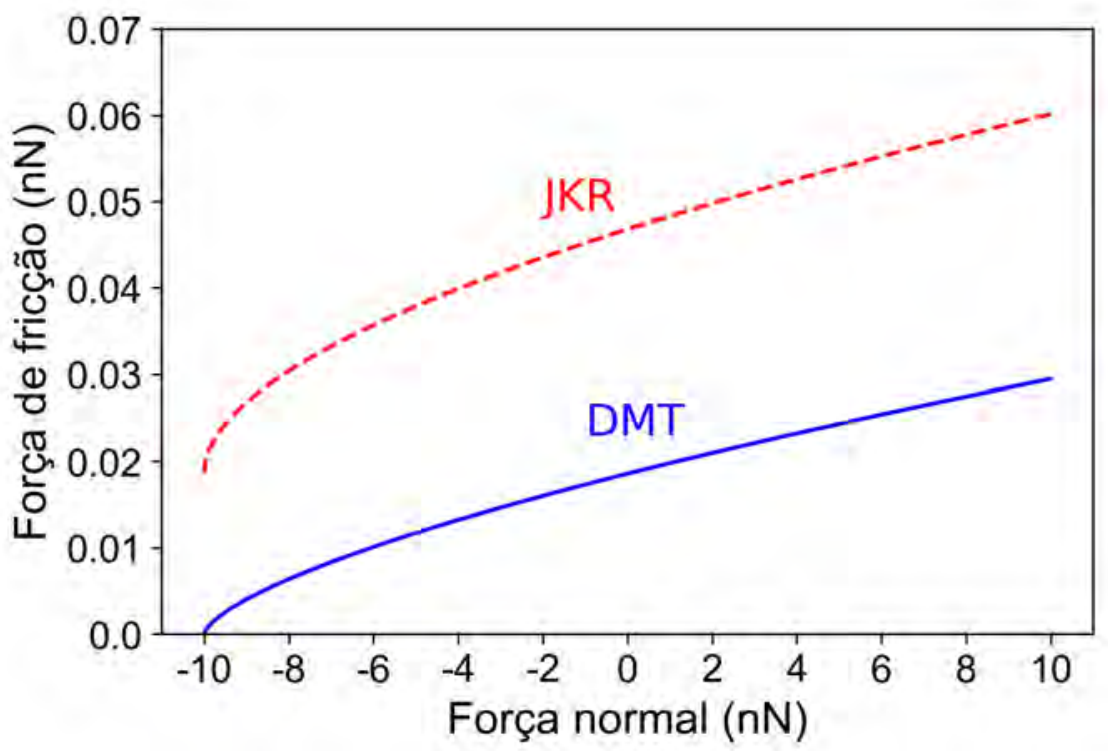

Figura 2.2: Simualação para os modelos DMT (azul) e JKR (vermelho) utilizando os mesmos parâmetros em ambas equações.

Vale ressaltar que a área de contato é muito difícil de ser medida com deformações tão pequena, assim como a resistência de cisalhamento. Em ambos os casos, esses parâmetros são estimados, portanto, com experimentos medindo a fricção em função da força normal aplicada.

\section{2}

\section{Modelo de Prandtl-Tomlinson}

No primeiro experimento de fricção em nanoescala usando um FFM, Mate e colaboradores movimentaram um fio de tungstênio numa superfície de grafite. Entre os resultados, observou-se um padrão do tipo dente de serra para a força lateral medida pelo microscópio. Este padrão é chamado de stick-slip e está associado à barreiras de energia no potencial de interação entre ponta e superfície. Juntando os gráficos dos canais de ida e volta, nota-se histerése na 
força lateral, o que é chamado de loop de fricção, e a área entre as duas curvas nos dá a energia dissipada no processo. O primeiro loop de fricção publicado pode ser visto na Figura 2.3.

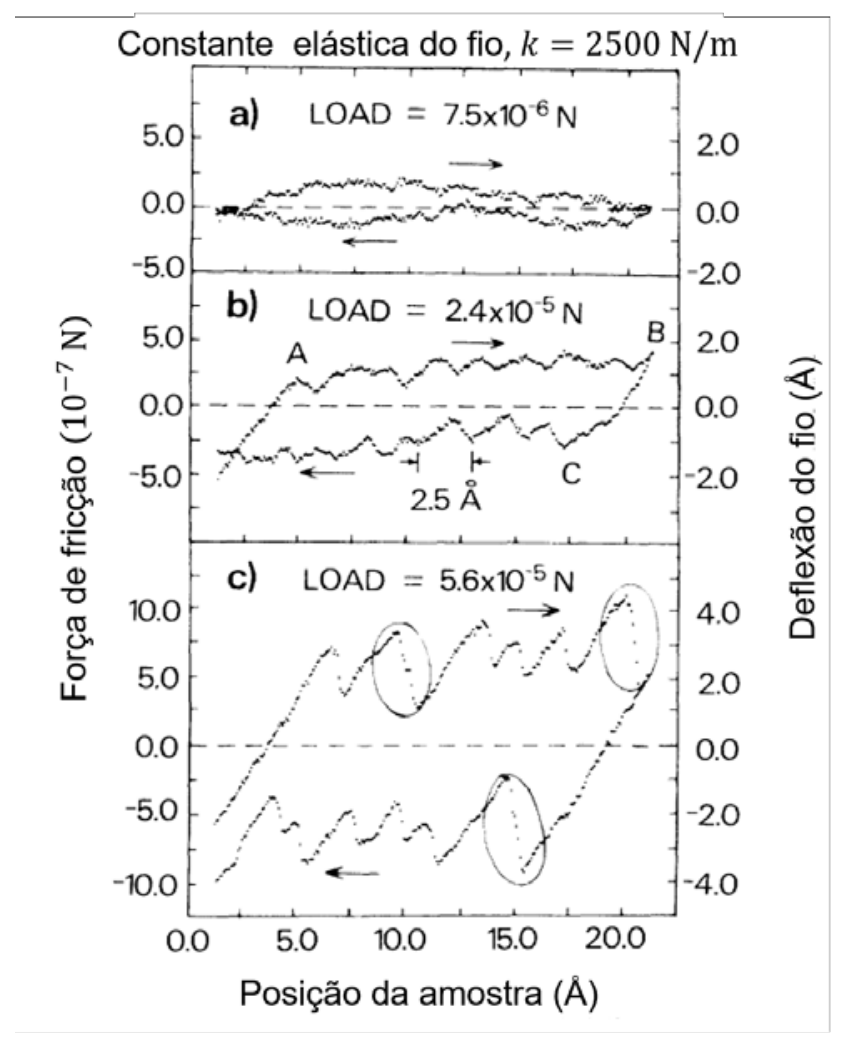

Figura 2.3: Loops de fricção para um fio de tungstênio numa amostra de grafite com diferentes cargas aplicadas. Figura adaptada da Referência [31].

No modelo PT, ponta e cantiléver ao deslizarem sobre uma superficie plana são modelados como um sistema massa-mola, o qual obedece à uma equação de movimento como a Equação de Langevin:

$$
m^{*} \ddot{x}_{t}=-\frac{\partial V}{\partial x_{t}}\left(x_{t}, t\right)-m^{*} \gamma \dot{x}_{t}+\xi(t),
$$

onde $x_{t}$ é o movimento da ponta, $m^{*}$ é a massa efetiva do cantiléver, $V\left(x_{t}, t\right)$ é o potencial de interação, $\gamma$ é o fator de amortecimento devido ao atrito, e $\xi(t)$ é um termo referente ao ruído térmico.

O potencial $V\left(x_{t}, t\right)$ é dado pela combinação da energia elástica armazenada pelo cantiléver e um potencial periódico devido à natureza cristalina da superfície.

$$
V\left(x_{t}, t\right)=-\frac{1}{2} V_{0} \cos \left(\frac{2 \pi x}{a}\right)+\frac{1}{2} k_{\mathrm{eff}}\left(v t-x_{t}\right)^{2},
$$

onde $v t$ é o movimento da superfície em relação à ponta.

$\mathrm{Na}$ eq. (2-15), $V_{0}$ é a amplitude do potencial periódico, $k_{\text {eff }}$ é a constante elástica efetiva do contato entre ponta e superfície, $v$ é a velocidade de 
deslizamento e $a$ é a periodicidade do potencial, dado pelo parâmetro de rede do material observado. Um esboço de $V(x, t)$ é mostrado na Figura 2.4.

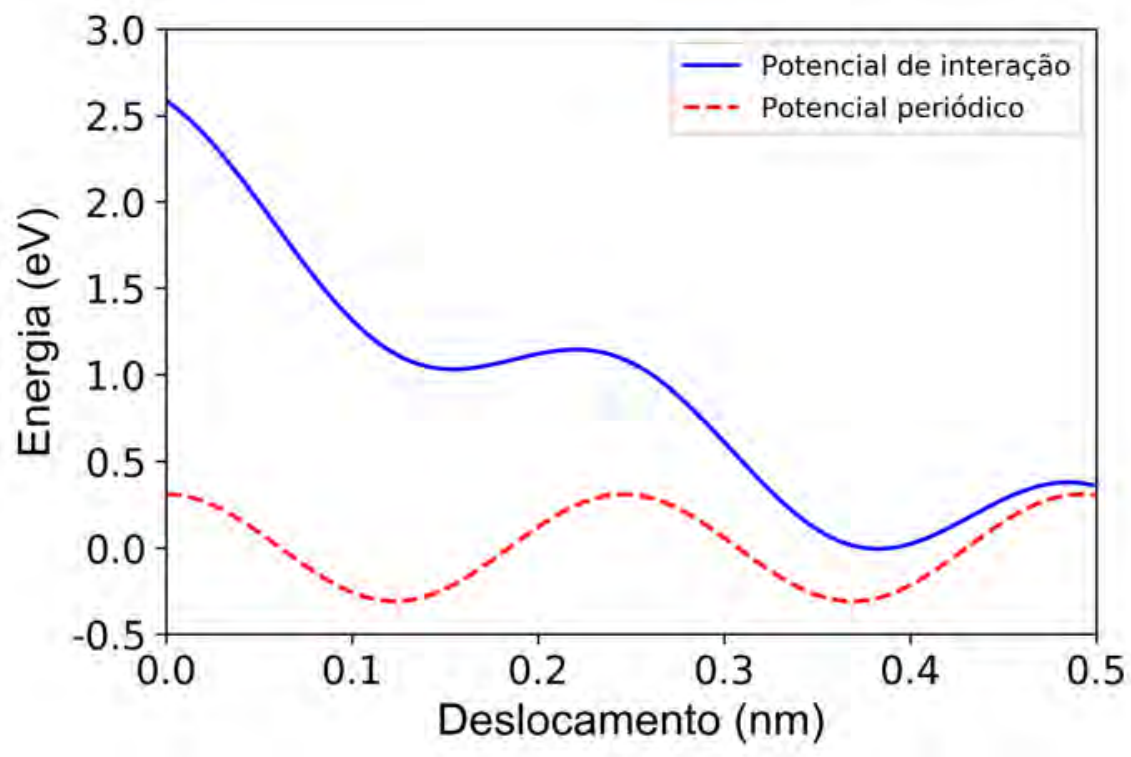

Figura 2.4: Potencial $V(x, t)$ de interação no Modelo PT.

Como dito anteriormente, ao deslizar sob a superfície, o sistema apresenta um padrão stick-slip. Ao movimentar a amostra, eventualmente a ponta se encontra num mínimo de potencial, isto é, $\partial V / \partial x=0$. Enquanto se move, as forças de fricção atuam estendendo a mola, a qual é esticada até um limite em que a energia armazenada pelo sistema ponta-cantiléver é maior do que a barreira de potencial à qual está sujeita, deslizando para o mínimo mais próximo. Esta barreira é dada pela expressão $\Delta V=V\left(x_{\max }, t\right)-V\left(x_{\min }, t\right)$, onde $x_{\max }$ e $x_{\min }$ são os máximos e mínimos de $V(x, t)$ num dado tempo $t$. Um esquema do processo stick-slip, com o análogo do sistema massa-mola sob interação de um potencial periódico e o efeito sobre a curva de força por deslocamento regitrada pelo microscópio é mostrado na Figura 2.5.

Derivando o potencial descrito na eq. (2-15), obtemos:

$$
\frac{\partial V}{\partial x_{t}}=-\frac{\pi V_{0}}{a} \sin \left(\frac{2 \pi x}{a}\right)-k_{\mathrm{eff}}\left(v t-x_{t}\right)
$$

onde aplicando a condição de mínimo de potencial, $\partial V / \partial x=0$, obtemos uma expressão para a força lateral $f_{L}$ máxima, a qual denominaremos força crítica, $F_{c}$ :

$$
F_{c}=\frac{\pi V_{0}}{a},
$$

a qual ocorre no ponto $x^{*}=a / 4[45,46]$.

Pode-se notar que, ao aparecer diretamente na expressão para o potencial de interação, como na eq. (2-15), o parâmetro $k_{\text {eff }}$ é importante para o 


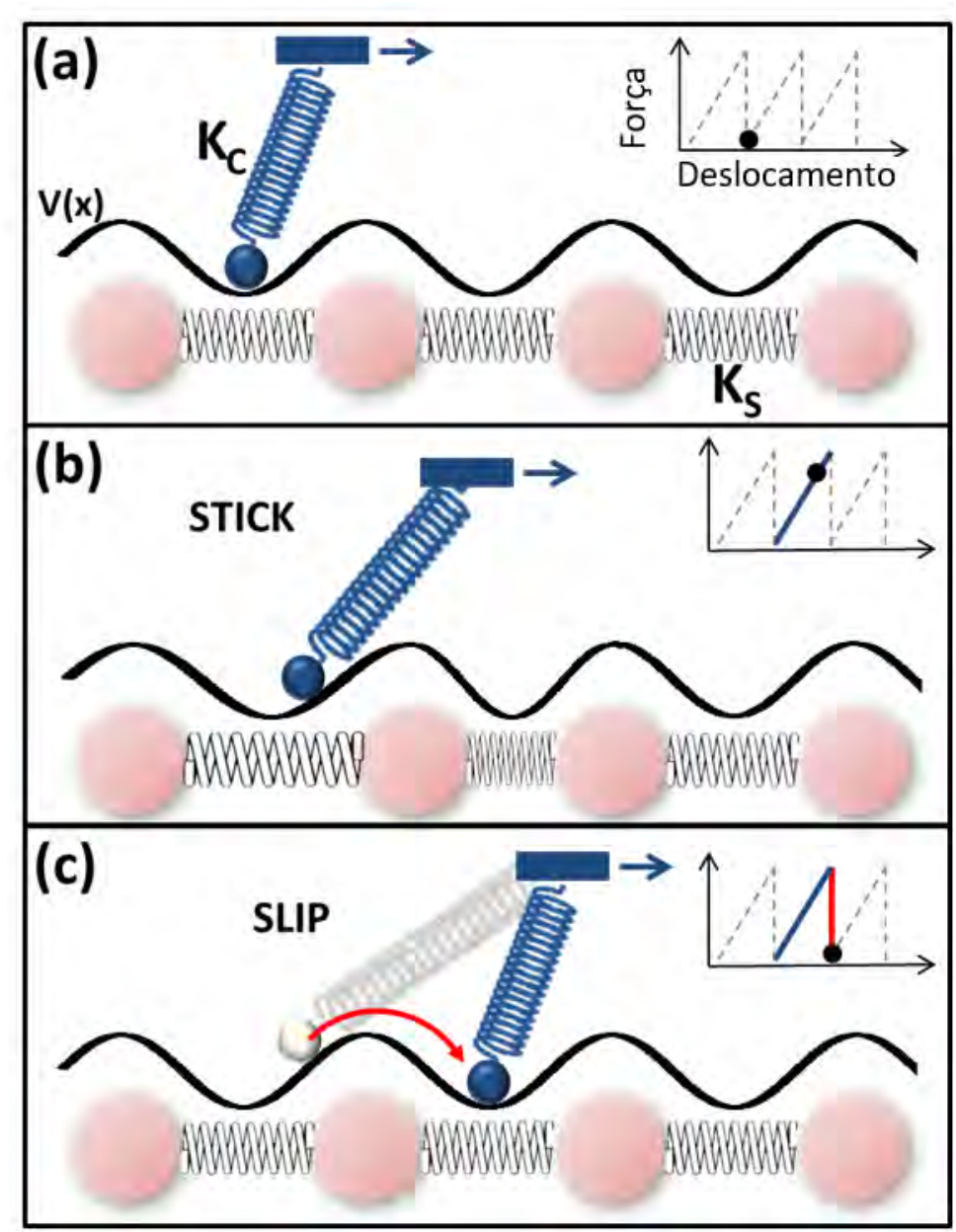

Figura 2.5: Esquema do fenômeno sitck-slip de transição entre mínimos de potencial com um modelo análogo de sistema massa-mola. (a) Sistema se encontra num mínimo de potencial, com a mola relaxada; (b) força de atrito provoca estensão na mola (stick); (c) a mola tem energia suficiente para superar a barreira e desliza para o mínimo de potencial adjacente (slip).

modelo PT, e representa a conformidade entre ponta e superfície, podendo ser modelado como uma série de molas [46, 47].

$$
\frac{1}{k_{\text {eff }}}=\frac{1}{k_{\text {contato }}}+\frac{1}{k_{\varphi}}+\frac{1}{k_{\text {ponta }}},
$$

onde $k_{\varphi}$ é a constante de mola lateral do cantiléver, e $k_{\text {contato }}$ e $k_{\text {ponta }}$ representam a rigidez do contato lateral do contato ponta-superfície e da ponta, respectivamente. O parâmetro $k_{\text {contato }}$ é definido pelo contato entre uma esfera e uma superfície, dado como $k_{\text {contato }}=8 r G^{*}$, onde $r$ é o raio de contato e $G^{*}$ é o módulo de cisalhamento efetivo, dado por [47]:

$$
\frac{1}{G^{*}}=\frac{1-\nu_{1}^{2}}{G_{1}}+\frac{1-\nu_{2}^{2}}{G_{2}},
$$

onde $\nu_{i}$ são as razões de Poisson da esfera e da superfície, e $G_{i}$ são os módulos de cisalhamento correspondentes. 
A constante elástica efetiva $k_{\text {eff }}$ pode ser determinada pela inclinação do padrão dente-de-serra das curvas stick-slip nas medidas de fricção, sendo, portanto, definido também como:

$$
k_{\mathrm{eff}}=\frac{d f_{L}}{d x} .
$$

\section{3}

\section{Modelo de Prandtl-Tomlinson Térmicamente Ativado}

Apesar de simples, o modelo PT explica bem o padrão da força lateral em escala atômica. Porém, flutuações térmicas são importantes nessa escala, de modo que a ponta possa ter energia para superar a barreira de potencial apenas por influência da temperatura. A força lateral máxima $F_{c}$ dada pela eq. (2-17) é condicionada à temperatura $T=0$. Numa temperatura $T$ finita qualquer, transições entre mínimos implicam em uma força lateral menor do que $F_{c}$. A probabilidade $p(t)$ para que a ponta pule de um mínimo de potencial para outro é dada por [39]:

$$
\frac{d p}{d t}=-f_{0} \exp \left(-\frac{\Delta V(t)}{k T}\right) p(t)
$$

onde $f_{0}$ é a frequência do pulo, $\Delta V(t)$ a barreira de potencial e $k$ é a constante de Boltzmann.

Porém, estamos interessados no domínio de força lateral $f_{L}$, e não do tempo. Para passar de um para outro, fazemos:

$$
\frac{d p}{d t}=\frac{d p}{d f_{L}} \frac{d f_{L}}{d t}=\frac{d p}{d f_{L}} \frac{d f_{L}}{d x} \frac{d x}{d t} .
$$

Notando, pela eq. (2-20), que $d f_{L} / d x=k_{\text {eff }}$, isto é, a constante elástica do contato entre ponta e superfície, e $\dot{x}=v$, a velocidade de varredura do sistema, temos, então:

$$
\frac{d p}{d t}=\left(k_{\mathrm{eff}} v\right) \frac{d p}{d f_{L}}
$$

o que resulta na probabilidade:

$$
\frac{d p}{d f_{L}}=-\frac{f_{0}}{k_{\mathrm{eff}} v} \exp \left(-\frac{\Delta V\left(f_{L}\right)}{k T}\right) p\left(f_{L}\right)
$$

Buscando a condição de maior probabilidade, isto é,

$$
\frac{d^{2} p}{d f_{L}^{2}}=0
$$

calculamos a derivada da transição: 


$$
\begin{aligned}
& \frac{d^{2} p}{d F_{L}^{2}}=-\frac{f_{0}}{k_{\text {eff }} v} \exp \left(-\frac{\Delta V\left(f_{L}\right)}{k T}\right) \frac{d p}{d f_{L}}+ \\
& +\frac{f_{0}}{k_{\text {eff }} v} \frac{1}{k T} \frac{\partial\left(\Delta V\left(f_{L}\right)\right)}{\partial f_{L}} \exp \left(-\frac{\Delta V\left(f_{L}\right)}{k T}\right) p\left(f_{L}\right) .
\end{aligned}
$$

Substituindo a Eq. (2-24) na Eq. (2-26), ficamos com:

$$
\begin{aligned}
& \frac{d^{2} p}{d f_{L}^{2}}=-\frac{f_{0}}{k_{\mathrm{eff}} v} \exp \left(-\frac{\Delta V\left(f_{L}\right)}{k T}\right)\left[-\frac{f_{0}}{k_{\mathrm{eff}} v} \exp \left(-\frac{\Delta V\left(f_{L}\right)}{k T}\right) p\left(f_{L}\right)\right]+ \\
& +\frac{f_{0}}{k_{\mathrm{eff}} v} \frac{1}{k T} \frac{\partial\left(\Delta V\left(f_{L}\right)\right)}{\partial f_{L}} \exp \left(-\frac{\Delta V\left(f_{L}\right)}{k T}\right) p\left(f_{L}\right)
\end{aligned}
$$

e aplicando a condição (2-25), temos:

$$
\begin{aligned}
& -\frac{f_{0}}{k_{\mathrm{eff}} v} \exp \left(-\frac{\Delta V\left(f_{L}\right)}{k T}\right)\left[\frac{f_{0}}{k_{\mathrm{eff}} v} \exp \left(-\frac{\Delta V\left(f_{L}\right)}{k T}\right) p\left(f_{L}\right)\right]= \\
& =\frac{f_{0}}{k_{\mathrm{eff}} v} \frac{1}{k T} \frac{\partial\left(\Delta V\left(f_{L}\right)\right)}{\partial f_{L}} \exp \left(-\frac{\Delta V\left(f_{L}\right)}{k T}\right) p\left(f_{L}\right),
\end{aligned}
$$

o que pode ser simplificado como:

$$
-\frac{f_{0}}{k_{\mathrm{eff}} v} \exp \left(-\frac{\Delta V\left(f_{L}\right)}{k T}\right)=\frac{1}{k T} \frac{\partial\left(\Delta V\left(f_{L}\right)\right)}{\partial f_{L}},
$$

chegando à uma expressão geral para qualquer barreira de potencial.

A barreira de potencial em geral é descrita como [46]:

$$
\Delta V=\frac{\Delta V_{0}}{k T}\left(1-\frac{f_{L}}{F_{c}}\right)^{\alpha}
$$

onde $\Delta V_{0}$ é a barreira com temperatura $T=0, F_{c}$ é o valor máximo que a força de fricção pode atingir, sendo também a força com $T=0$, e o expoente $\alpha$ pode depender do regime analisado, podendo ser linear [36], $\alpha=3 / 2[38,39]$ ou ainda maior que $3 / 2$ [48].

Substituindo o potencial (2-30) na Eq. (2-29), obtemos:

$$
-\frac{f_{0}}{k_{\text {eff }} v} \exp \left[-\frac{\Delta V_{0}}{k T}\left(1-\frac{f_{L}}{F_{c}}\right)^{\alpha}\right]=\frac{\alpha \Delta V_{0}}{F_{c} k T}\left(1-\frac{f_{L}}{F_{c}}\right)^{\alpha-1} .
$$

Tomando o logaritmo, ficamos com: 


$$
\begin{aligned}
& \ln \left(\frac{f_{0}}{k_{\mathrm{eff}} v}\right)-\frac{\Delta V_{0}}{k T}\left(1-\frac{f_{L}}{F_{c}}\right)^{\alpha}=\ln \left(\frac{\alpha \Delta V_{0}}{F_{c} k T}\right)+(\alpha-1) \ln \left(1-\frac{f_{L}}{F_{c}}\right) \\
& \ln \left(\frac{f_{0}}{k_{\mathrm{eff}} v}\right)-\ln \left(\frac{\alpha \Delta V_{0}}{F_{c} k T}\right)=\frac{\Delta V_{0}}{k T}\left(1-\frac{f_{L}}{F_{c}}\right)^{\alpha}+(\alpha-1) \ln \left(1-\frac{f_{L}}{F_{c}}\right),
\end{aligned}
$$

onde usamos as propriedades $\ln x y=\ln x+\ln y$ e $\ln x^{y}=y \ln x$.

Reorganizando, então, chegamos a relação entre velocidade de varredura e força lateral o qual governa os processos de transição entre minimos de potencial:

$$
\ln \frac{v}{v_{0}}=-\frac{\Delta V_{0}}{k T}\left(1-\frac{f_{L}}{F_{c}}\right)^{\alpha}-(\alpha-1) \ln \left(1-\frac{f_{L}}{F_{c}}\right),
$$

onde $v_{0}$ é uma velocidade crítica dada por:

$$
v_{0}=\frac{F_{c} k T}{\alpha \Delta V_{0} k_{\mathrm{eff}}} f_{0}
$$

Uma primeira aproximação para a eq. (2-33) foi feita por E. Gnecco e colaboradores, os quais consideraram uma relação linear do potencial entre a barreira de potencial e a força de atrito. Isto é, na eq. (2-30), o expoente é $\alpha=1$, o que reduz a equação para [36]:

$$
f_{L}=F_{c}+\left(\frac{k T F_{C}}{\Delta V_{0}}\right) \ln \frac{v}{v_{0}}
$$

Pouco depois, Sang e colaboradores [38] estabeleceram uma relação em que $\alpha=3 / 2$, a qual é ainda hoje a relação mais aceita. Usando este valor para o expoente $\alpha$, obtemos a seguinte equação relacionando fricção com a velocidade de varredura $v$ :

$$
\ln \frac{v}{v_{0}}=-\frac{\Delta V_{0}}{k T}\left(1-\frac{f_{L}}{F_{c}}\right)^{3 / 2}-\frac{1}{2} \ln \left(1-\frac{f_{L}}{F_{c}}\right) .
$$

O argumento utilizado para o expoente $\alpha$ se dá por uma aproximação do potencial $V\left(x_{t}, t\right)$. Localmente, podemos considerar dois pontos de mínimo, como visto na Figura 2.4. Uma analogia com a nucleação numa transição de fase em primeira ordem é feita. Uma primeira aproximação, com o potencial infinitesimalmente pequeno, considera a energia descrita por $V=F x_{t}+x_{t}^{2}-x_{t}^{4}$, onde $F$ é a fricção e $x_{t}$ o deslocamento da ponta, resultando numa barreira $\Delta V \sim(C-F)$, onde $C$ é uma constante. Isso é equivalente à $\alpha=1$. Com barreiras mais altas, a ponta ao ser arrastada ao longo da superfície causa um aumento no potencial. Flutuações térmicas provocam pulos superando a barreira de potencial principalmente quando a ponta está próxima de transicionar de um mínimo para outro, no topo da barreira. Nesse ponto, o 
potencial pode ser descrito como $V=F x_{t}-x_{t}^{3}$, de modo que a barreira seja $\Delta V \sim(C-F)^{3 / 2}$, correspondendo à $\alpha=3 / 2[38]$.

Nas eqs. (2-35) e (2-36), é possível perceber que estamos limitados numa determinada faixa de velocidades, uma vez que a função logarítimica diverge nos limites $v \rightarrow 0$ e $v \rightarrow \infty$ para $-\infty$ e $\infty$, respectivamente. De fato, análises em relação aos limites de velocidade nos modelos PT e PTT são normalmente feitos em função da equação de movimento, como na eq. (2-14). No limite $v \rightarrow 0$, o fenômeno stick-slip é reproduzido, com o sistema fixado caso a força de friç̧ão seja maior do que a força externa, no caso exercida pelo cantiléver. Em analogia com o sistema massa-mola, a mola continua a ser esticada até uma distância crítica $D_{p}$, exercendo uma força limítrofe $f_{p}$. Após esse limite, é possível ter movimento do sistema com forças médias $f_{L}$ menores que $f_{p}$ [49]. Já nos casos em que $v$ é muito grande, há previsão de ressonâncias na fricção e até mesmo movimentos caóticos do sistema [49]. 


\section{3 \\ Materiais e Métodos}

Neste capítulo, descreveremos os materiais analisados na tese, sendo eles o grafeno, os TMDs e a mica; além de explicar os métodos usados para análise de fricção em nanoescala. Métodos como espectroscopia Raman e espectroscopia no infravermelho por transformada de Fourier (FTIR - do inglês Fourier Transform Infrared Spectroscopy) foram usadas para a identificação do número de camadas no grafeno e detecção de contaminantes nas folhas de grafeno, respectivamente. Porém, como o foco da tese é o estudo tribológico dos materiais 2D, tais métodos não serão descritos aqui.

\section{1}

\section{Obtenção e preparação das amostras}

Neste tese utilizamos quatro amostras diferentes, sendo elas o grafeno, a mica, o $\mathrm{MoS}_{2}$ e o $\mathrm{WS}_{2}$.

\subsection{1 \\ Grafeno}

O grafeno consiste numa fina camada de átomos de carbono arranjados numa estrutura hexagonal. Em sua configuração eletrônica, o orbital $2 \mathrm{~s}$ interage com os orbitais $2 \mathrm{p}_{\mathrm{x}}$ e $2 \mathrm{p}_{\mathrm{z}}$, formando três orbitais híbridos tipo $s p^{2}$. A interação desses orbitais formam três ligações covalentes tipo sigma $(\sigma)$. A distância dessas ligações $\sigma$ do grafeno, $a_{C-C}$ é de $0,142 \mathrm{~nm}$. Essas ligações são responsáveis à propriedades mecânicas do grafeno [1]. Os elétrons remanescentes da última camada eletrônica ocupam orbitais $2 \mathrm{p}_{\mathrm{z}}$, formando ligações covalentes tipo pi $(\pi)$, onde a nuvem eletrônica é distribuída perpendicularmente ao plano. Os elétrons nos orbitais $2 \mathrm{p}_{\mathrm{z}}$ são fracamente ligados e relativamente delocalizados, sendo responsáveis pelas propriedades eletrônicas do grafeno [1]. Sua célula unitária possui dois átomos na base, e o parâmetro de rede é dado por $a=0,246 \mathrm{~nm}$. A rede do grafeno, assim como seus vetores de rede, pode ser vista na figura 3.1 . 


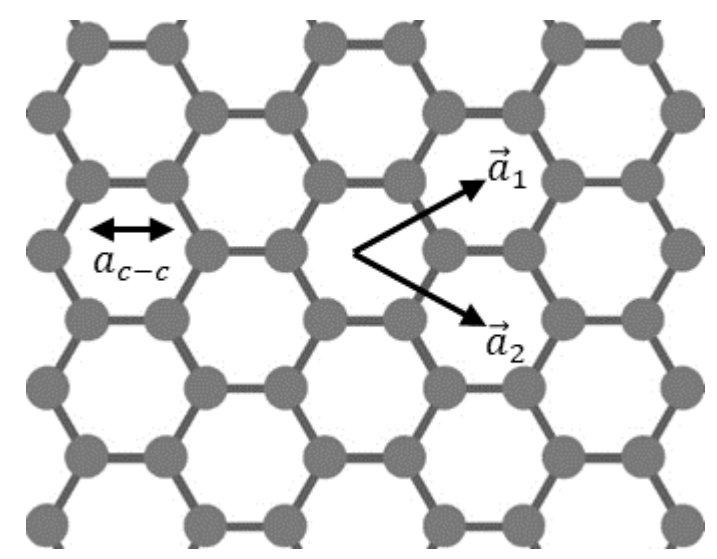

Figura 3.1: Rede cristalina do grafeno. Ligação carbono-carbono dada por $a_{C-C}=0,142 \mathrm{~nm}$. Nos vetores de rede, $a=0,246 \mathrm{~nm}$.

As amostras de grafeno foram obtidas pela esfoliação de HOPG [3]. Neste método, cola-se uma fita adesiva, usualmente do tipo blue tape, na superfície do cristal, e então a fita é puxada abruptamente na direção vertical. Esse processo transfere camadas de grafite e grafeno para para a fita. Então, a fita é colada na superfície de um substrato de $\mathrm{SiO}_{2}$. Neste trabalho, os substratos possuem uma camada de óxido nominal de $300 \mathrm{~nm}$. Com a fita colada no substrato, o conjunto é aquecido à uma temperatura de $100^{\circ} \mathrm{C}$. A fita é então retirada da mesma forma abrupta com que é feita no grafite. Este processo transfere camadas de grafeno, seja monocamada ou poucas-camadas, e ainda camadas de grafite. A amostra é então levada à um microscópio ótico para a localização e mapeamento das regiões de interesse. O processo é descrito na figura 3.2.
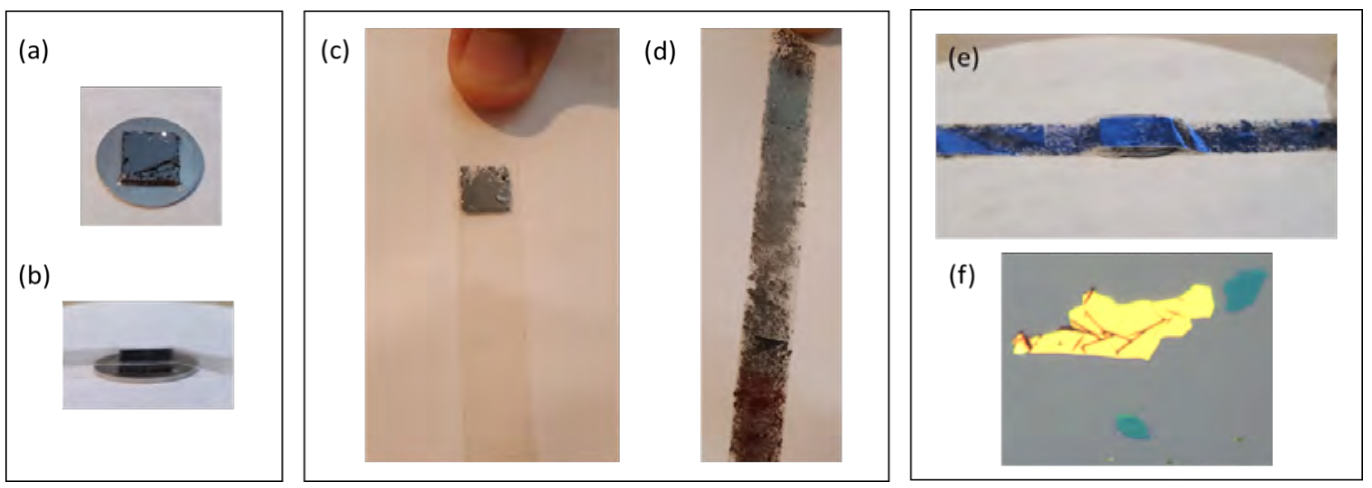

Figura 3.2: Processo de esfoliação do grafite. (a) Amostra de HOPG; (b) fita adesiva no HOPG; (c) fita adesiva com HOPG; (d) diversas camadas de grafite espalhados pela fita; (e) fita adesiva no substrato; (f) uma folha de grafite e grafeno em poucas camadas vista por um microscópio ótico. 


\subsection{2}

\section{TMDs}

Os TMDs são heteroestruturas que apresentam rede cristalina hexagonal, porém uma monocamada de um TMD não possui apenas um átomo de espessura, mas sim três, sendo um átomo M localizado entre dois átomos metálicos, como visto na Figura 3.3.

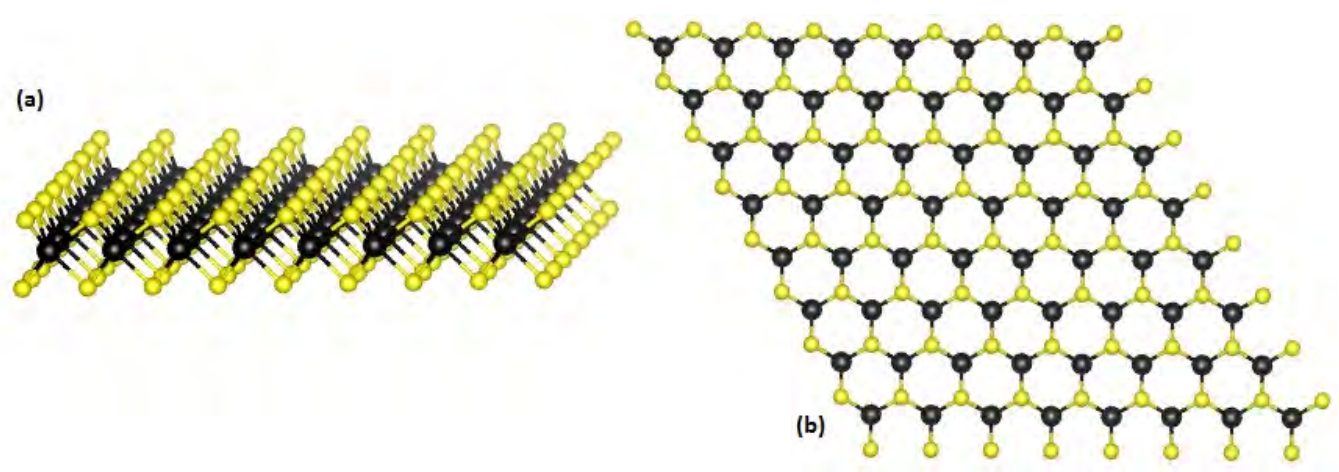

Figura 3.3: (a) Estrutura de um TMD. Átomos $M$ em preto, e metálicos em amarelo; (b) Estrutura de um TMD vista de cima, revelando um padrão hexagonal. Note que os átomos em preto e amarelo não estão na mesma altura.

Os TMDs usados neste trabalho foram crescidos por deposição química em fase vapor (CVD). Este processo consiste de um tubo de quartzo localizado dentro de um forno. Dentro do tubo, colocam-se duas barcas de cerâmica, uma contendo enxofre em pó (S), e outra contendo óxido de molibdênio $\left(\mathrm{MoO}_{3}\right)$, também em pó, para o caso do crescimento de $\mathrm{MoS}_{2}$, ou óxido de tungstênio $\left(\mathrm{WO}_{3}\right)$ para o crescimento de $\mathrm{WS}_{2}$. Um substrato de $\mathrm{SiO}_{2}$ é colocado em cima do óxido dos metais de transição, com a face virada para o precursor. A temperatura e pressão do sistema são controlados, assim como o fluxo de argônio (Ar), usado como gás de transporte, de modo que a síntese seja completa e otimizada. O controle da temperatura e pressão faz com que os pós sejam evaporados e as moléculas são dessorvidas, enquanto o gás de arraste transporta átomos de S até a barca contendo os metais de transição [50]. As amostras de TMD obtidas neste trabalho foram crescidas pelo grupo do Prof. Victor Carôzo, do Departamento de Física da PUC-Rio.

\subsection{3}

\section{Mica Muscovita}

A mica muscovita é um mineral isolante, composto por potássio $(\mathrm{K})$, alumínio $(\mathrm{Al})$, silício $(\mathrm{Si})$, oxigênio $(\mathrm{O})$ e moléculas de hidróxido $(\mathrm{OH})$, formando a estrutura $\mathrm{KAl}_{3} \mathrm{Si}_{3} \mathrm{O}_{10}(\mathrm{OH})_{2}$ [51]. Ao contrário dos outros materiais analisados nesta tese, sua estrutura macroscópica em geral é do tipo monoclínica, 
com um parâmetro de rede $a=0,52 \mathrm{~nm}$. Porém, como os outros materiais citados, ela também é constituída de camadas cuja interação é do tipo van der Waals, o que a faz ser facilmente clivada. Ao ser clivada, apresenta uma forma pseudo-hexagonal. Sua estrutura cristalina é apresentada na figura 3.4. Assim como o grafeno, as amsotras de mica utilizadas aqui foram obtidas pelo método de micro-esfoliação mecânica.

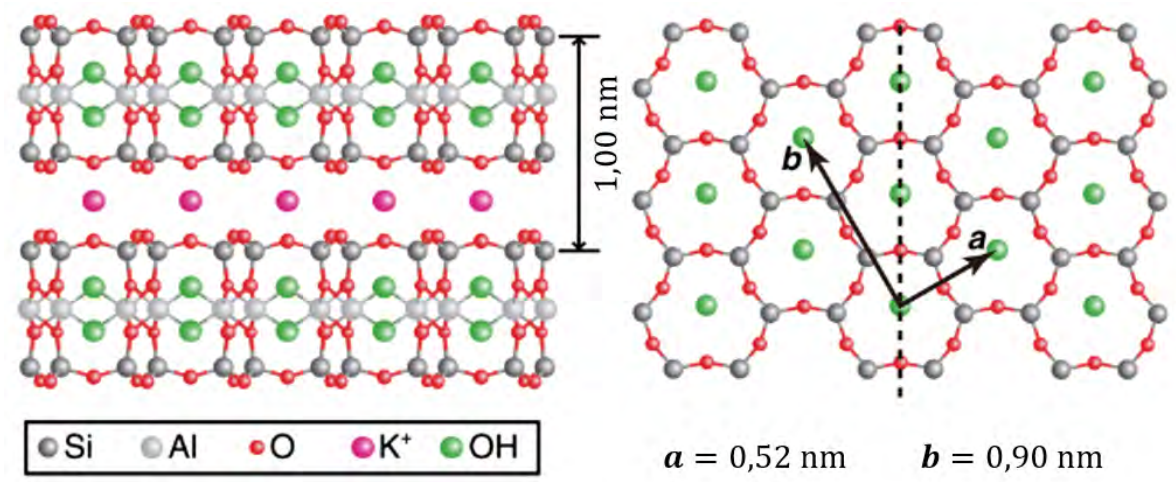

Figura 3.4: Estrutura cristalina da mica muscovita. (a) Projeção ao longo da direção [110]; (b) Superfície clivada. Imagem adaptada da Referência [51].

\section{2 \\ Microscopia de Força Atômica}

O AFM é um instrumento da família da Microscopia por Ponta de Prova (SPM - do inglês Scanning Probe Microscopy), utilizado para caracterização da superfície de materiais. O AFM se destaca por permitir caracterização em três dimensões do material em análise e por não precisar de uma grande preparação de amostras, ao contrário de outros instrumentos normalmente usados em física de superfícies, como microscópios eletrônicos, por exemplo.

Durante o desenvolvimeneto desta tese, foram usados três AFMs diferentes: um MultiMode equipado com uma eletrônica Nanoscope IIIa (Bruker, Santa Barbara, CA), disponível no Laboratório de Nanoscopia da PUC-Rio; um NanoWizard (Bruker, Santa Barbara, CA), localizado no Laboratório de Fenômenos de Superfícies no INMETRO; e um NX-10 (Park Systems AFM, Korea), também localizado no Laboratório de Nanoscopia da PUC-Rio. Os dois primeiros foram usados para medidas tribológicas, enquanto o último foi usado para algumas medidas complementares em outros modos. A Figura 3.5 mostra uma foto de cada um dos três AFMs utilizados.

A medição no AFM é feita por uma ponta, presa ao cantiléver. Essa ponta é aproximada da superfície, permitindo a detecção de forças interatômicas entre ponta e superfície. A detecção é feita ao longo de uma varredura, em 
que a amostra é coloca sobre uma cerâmica piezoelétrica com liberdade de movimentação em três dimensões, sendo o movimento induzido por tensões elétricas enviadas por um sistema de controle.

A interação entre ponta e superfície provoca uma deflexão vertical no cantiléver, o qual é modelado como uma mola, obedecendo à Lei de Hooke:

$$
F_{n}=k_{n} \Delta z
$$

onde $F$ é a força entre ponta e superfície, $k_{n}$ é a constante elástica do cantiléver e $\Delta z$ é a deflexão vertical do mesmo. A deflexão em primeira aproximação, pode ser interpretada como produzida por variações topográficas e, portanto, permite a formação de imagens da superfície da amostra medida. Esta deflexão do cantilever é muito pequena, normalmente da ordem de ångströms (A), e é medida com a ajuda de um laser.

Esse sistema pode ser visto na Figura 3.6. O feixe de laser incide na haste e é refletido para um espelho, o qual então o reflete para um fotodetector, o qual possui quatro quadrantes, dito detector PSPD (Position Sensitive PhotoDiode). Durante a varredura, a posição no fotodetector varia, gerando uma corrente elétrica, a qual é convertida em tensão elétrica pelo controlador. A variação de posição do laser no PSPD permite gravar as variações verticais e laterais do cantiléver.

(a)

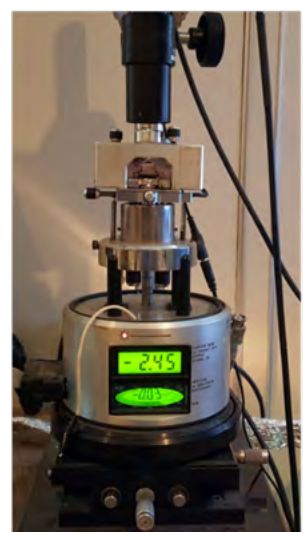

(b)

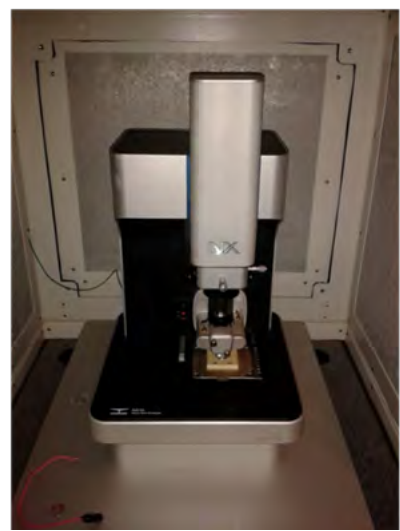

(c)

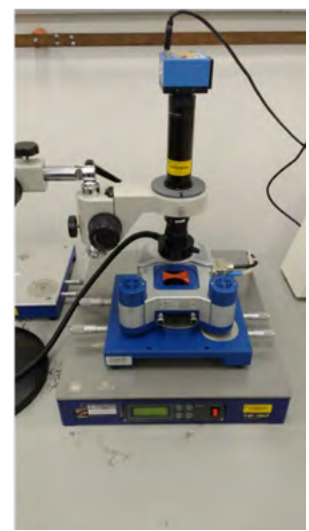

Figura 3.5: AFMs utilizados no trabalho: (a) Multimode; (b) NX-10; (c) NanoWizard. 


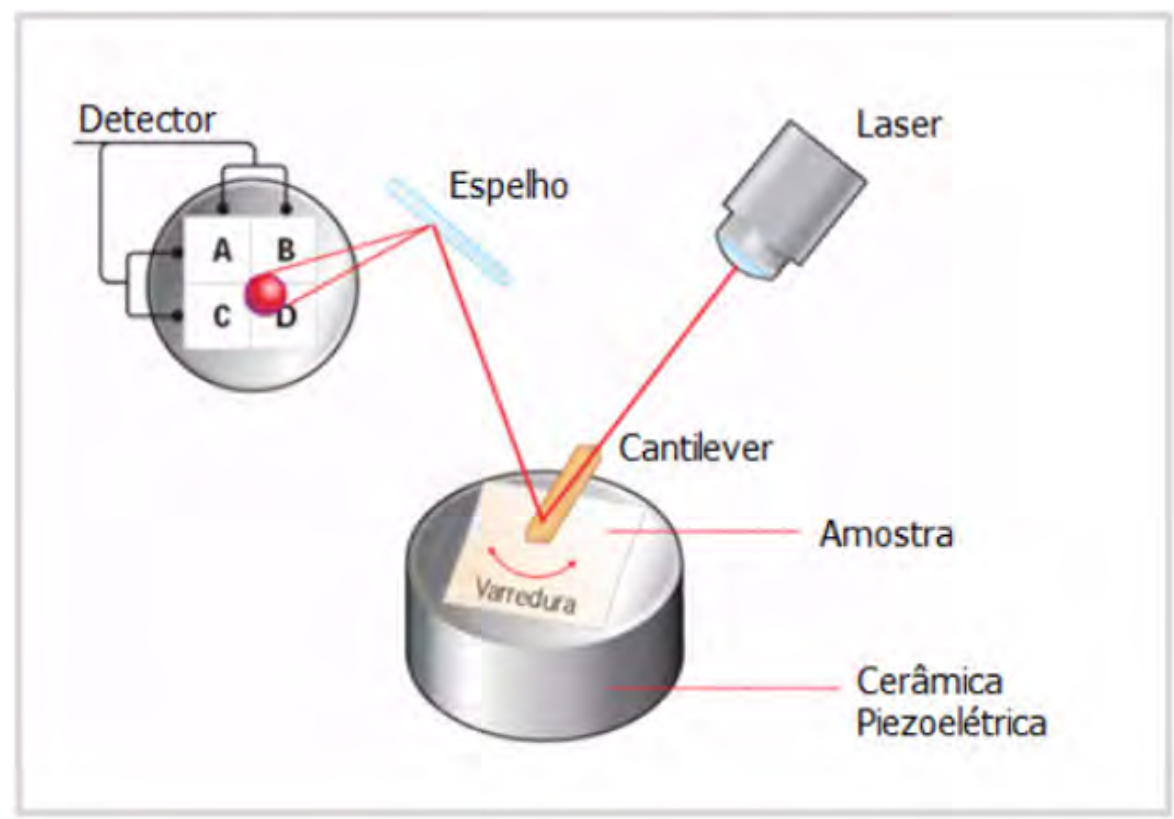

Figura 3.6: Esquema básico do funcionamento de um AFM.

Os quadrantes do PSPD são denominados A, B, C e D, como visto na Figura 3.6. A deflexão vertical do cantiléver é dada pela diferença do sinal entre os quadrantes superiores e inferiores, e dividida pela soma de todos os quadrantes. Ou seja, dada pela seguinte equação:

$$
V_{z}=\frac{\left(V_{A}+V_{B}\right)-\left(V_{C}+V_{D}\right)}{V_{A}+V_{B}+V_{C}+V_{D}}
$$

onde $V_{i}$, para $i=A, B, C, D$, é a tensão registrada em cada quadrante, e $V_{z}$ a tensão pela deflexão vertical do cantiléver.

Porém, para quantificação dessa deflexão vertical, é necessária uma calibração do microscópio. Dada uma constante de calibração $S_{z}$, a deflexão pode ser quantificada por:

$$
\Delta z=S_{z} V_{z}
$$

e a força normal pode então ser quantificada como:

$$
F_{n}=k_{n} \Delta z=k_{n} S_{z} V_{z}
$$

A constante $S_{z}$ pode ser obtida por curvas de força-distância (F-D), as quais serão explicadas em seção mais adiante.

A distância entre ponta e superfície determina o tipo de interação sentida. Essas forças pertencem à dois regimes diferentes, forças repulsivas e atrativas. As forças repulsivas acontecem à curta distância, resultantes o Princiípio de Exclusão de Pauli, com uma forte superposição da função de onda dos elétrons da ponta e da superfície [52]. Já forças atrativas acontecem predominantemente em distâncias longas, tendo interação tipo van der Waals, causada por dipolos 
induzidos por flutuações instantâneas na densidade eletrônica ao redor dos átomos.

Com isso, um AFM trabalha em dois modos principais: um modo estático e um modo dinâmico. No modo estático, a ponta entra em contato com a superfície, sofrendo interações repulsivas, e a deflexão do cantiléver é medida. No modo dinâmico, há dois modos de operação, o modo de contato intermitente (também chamado tapping mode AFM - TM-AFM) e o modo não contato (non-contact AFM - NC-AFM).

Nestes modos dinâmicos, a haste é posta para oscilar numa frequência de referência, perto da ressonância, e as interações provocam uma mudança na frequência de trabalho. Essa frequência de trabalho é comparada com a frequência de referência, e a medição se dá pela diferença entre as duas. No modo TM-AFM, a ponta oscila entre longas e curtas distâncias, sentindo tanto interação repulsiva como atrativa. Já no modo NC-AFM, a ponta permanece à longas distâncias, sentindo apenas interações atrativas. A Figura 3.7 mostra os regimes de operação do AFM de acordo com as interações sentidas.

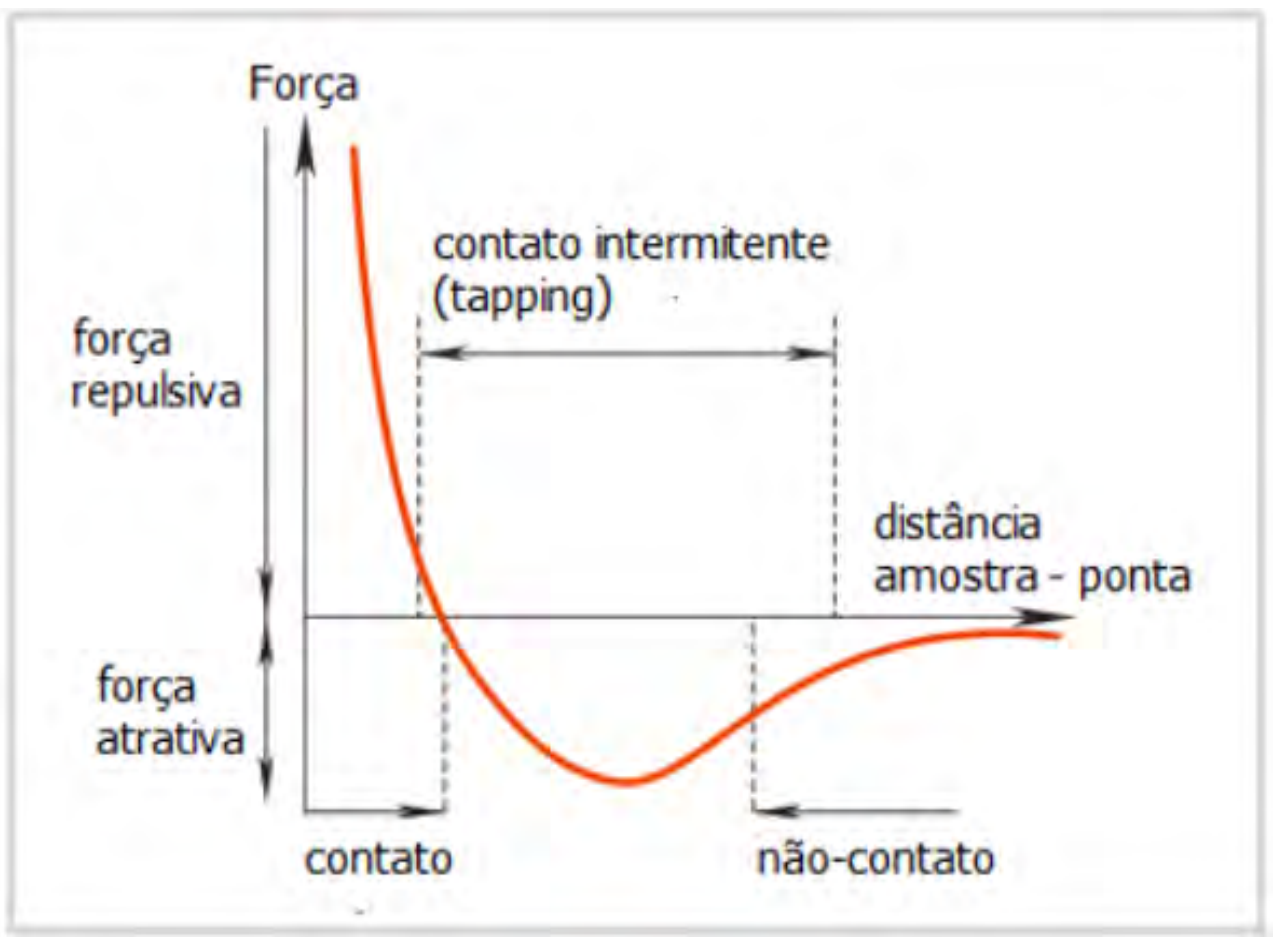

Figura 3.7: Modos de operação do AFM de acordo com as distâncias e interações sentidas.

Como o foco da tese está na caracterização tribológica, com a ponta em contato com a superfície, os modos dinâmicos não serão explicados em mais detalhes. 


\subsection{1}

\section{Microscopia de Força Lateral}

No modo LFM, a ponta é posta em contato com a superfície, varrendo a amostra em direção perpendicular ao eixo maior do cantiléver. A varredura é feita numa mesma linha em dois sentidos, normalmente dados como canais de $i d a$ e volta. Ao varrer a superfície, as forças de atrito causam uma torção no cantiléver. Simultaneamente com a deflexão vertical, o microscópio é capaz de gravar também essas deflexões laterais do cantiléver devido às forças de atrito. Para isto, o PSPD é gravada a diferença entre a soma dos dois lados do detector, e também dividida pela soma. Isto é, a deflexão lateral é dada por:

$$
V_{L}=\frac{\left(V_{A}+V_{C}\right)-\left(V_{B}+V_{D}\right)}{V_{A}+V_{B}+V_{C}+V_{D}}
$$

onde $V_{L}$ é a deflexão lateral do cantiléver.

Tal qual a deflexão normal, também é necessária uma calibração para quantificação das forças de atrito pela torção do cantiléver. Temos então que a força de atrito está relacionada com uma constante de proporcionalidade $S_{\varphi}$, tal que:

$$
F_{F}=k_{\varphi} \Delta \varphi=k_{\varphi} S_{\varphi} V_{L},
$$

onde $F_{F}$ é a força de fricção, $k_{\varphi}$ e $\Delta \varphi$ são a constante torcional do cantiléver e a torção sofrida pelo cantiléver, respectivamente. A calibração do AFM foi feita anteriormente de acordo com o artigo de E. Liu e colaboradores [53]. Brevemente explicando, esta depende da geometria dos cantilévers utilizados e do caminho ótico do laser refletido até o fotodiodo, de modo que a torção do cantiléver é monitorada de acordo com a voltagem gerada pelo fotodetetor. Ao final, encontra-se um fator de conversão $C_{L}$, dado por:

$$
C_{L}=k_{\varphi} \frac{(h+t / 2) S_{\text {input }} k_{n}}{S_{z} \eta C_{n}}
$$

onde $h$ é a altura da ponta, $t$ a expessura do cantiléver, $S_{\text {input }}$ a sensibilidade lateral do fotodetetor $\left(S_{\text {input }}=1\right)$ e $C_{n}$ é uma constante torcional do cantiléver, dada em $\mathrm{N} \mathrm{rad}^{-1}$. O processo de calibração pode ser encontrado na tese de Robert Zamora [54].

Uma vez que a força de atrito depende da força normal na superfície, para realizar este tipo de medida, o AFM (ou LFM) precisa de um sistema para controlar a força total aplicada. Para tanto, o microscópio se utiliza de um sistema de controle baseado num amplificador do tipo ProporcionalDiferencial-Integral (PID). Antes de realizar a medida, é necessário definir uma tensão de referência, chamada setpoint. Variações topográficas da amostra podem alterar o valor da força aplicada, o que consequentemente altera o valor 
de $V_{L}$ medido pelo detetor PSPD. O controlador PID, portanto, está sempre tentando corrigir estas variações, enviando tensões elétricas à cerâmica para que esta se adéque ao valor de referência, forçando com que toda a varredura seja feita com uma mesma força normal. A força normal total é dada pela soma da força aplicada pelo cantilever com a adesão entre ponta e superfície.

$$
F_{n}=F_{k}+F_{\text {ad }},
$$

onde $F_{k}$ é a carga devido ao cantilever e $F_{\text {ad }}$ é a força de adesão entre ponta e superfície. $F_{\text {ad }}$ é obtida através das curvas F-D.

Variações topográficas da amostra, como um degrau ou um vale, também alteram a posição de $V_{L}$ no detetor diretamente. Ao contrário do atrito, no movimento relativo entre as duas superfícies, essas variações de topografia independem da direção de varredura. Para eliminar esse efeito, é preciso calcular um mapa de fricção, subtraindo as imagens dos canais de $i d a$ e volta da força lateral. Isto é, para se calcular o mapa, precisamos fazer:

$$
V_{L}^{\text {mapa }}=\frac{1}{2}\left(V_{L}^{\text {ida }}-V_{L}^{\text {volta }}\right),
$$

onde novamente $V_{L}$ denota a deflexão pela torção do cantiléver e os índices superiores indicam o canal de onde a imagem foi extraída.

A Figura 3.8 exibe um esquema de como os mapas de fricção são obtidos. A ponta varre uma superfície contendo dois materiais, aqui chamados de 1 e 2 , da esquerda para a direita, no canal de $i d a$. Uma primeira torção no cantiléver é registrada pela mudança de material, indicando diferentes coeficientes de atrito. Este segundo material não altera o registro topográfico medido. Ao subir um degrau, a ponta sofre outra torção, e outra de igual proporção com sentido inverso ao descer o degrau. Na varredura de volta, nota-se que as torções pela topografia da amostra seguem o mesmo registro no PSPD, enquanto a torção pelo Material 2 continua oposta ao sentido de varredura da ponta. A subtração dos canais $i d a$ e volta, portanto, eliminam a influência da topografia e o resultado é dado em função apenas dos dois materiais componentes da amostra analisada [55]. 
(a)

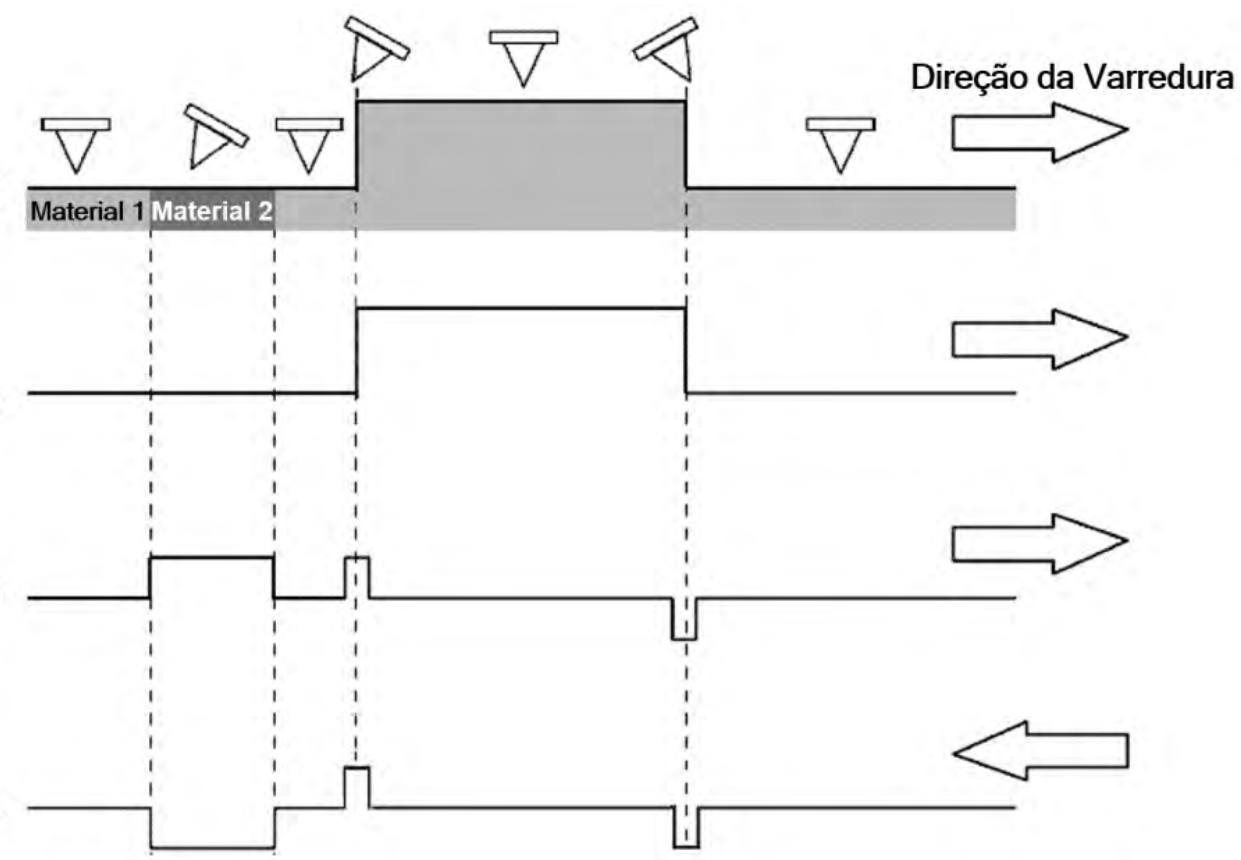

Figura 3.8: Esquema das torções do cantiléver num LFM. (a) Torção sofrida pelo cantiléver devido à materiais diferentes e variações topográficas da amostra; (b) Canal de topografia; (c) Canal ida da deflexão lateral; (d) canal volta da deflexão lateral. Imagem adaptada da Referência [55]

\subsection{2}

\section{Curvas de Força-Distância}

As curvas F-D medem a deflexão do cantiléver em função do deslocamento na direção $\hat{z}$ da cerâmica piezoelétrica. Essas curvas são divididas em aproximação e retração da ponta na superfície. O processo é mostrado na Figura 3.9 Inicialmente, a ponta está distante da superfície, de modo que a deflexão do cantiléver é nula (Ponto A). Ao ser aproximada, o gradiente de força $\frac{\partial F}{\partial z}$ é alterado, e quando este se torna maior que a constante elástica $k_{n}$ do cantiléver, a ponta entra abruptamente em contato com a superfície (Ponto B). A cerâmica continua se movendo, aproximando ponta e superfície, de modo que a força de interação seja do tipo repulsiva, e a carga continua a aumentar, até chegar à um limite de aproximação (Ponto C). A partir deste ponto, começa a retração da ponta, e a adesão entre ponta e superfície causa uma deflexão negativa do cantiléver, até que este se solte da superfície, e a deflexão volte a ser nula (Ponto D). 

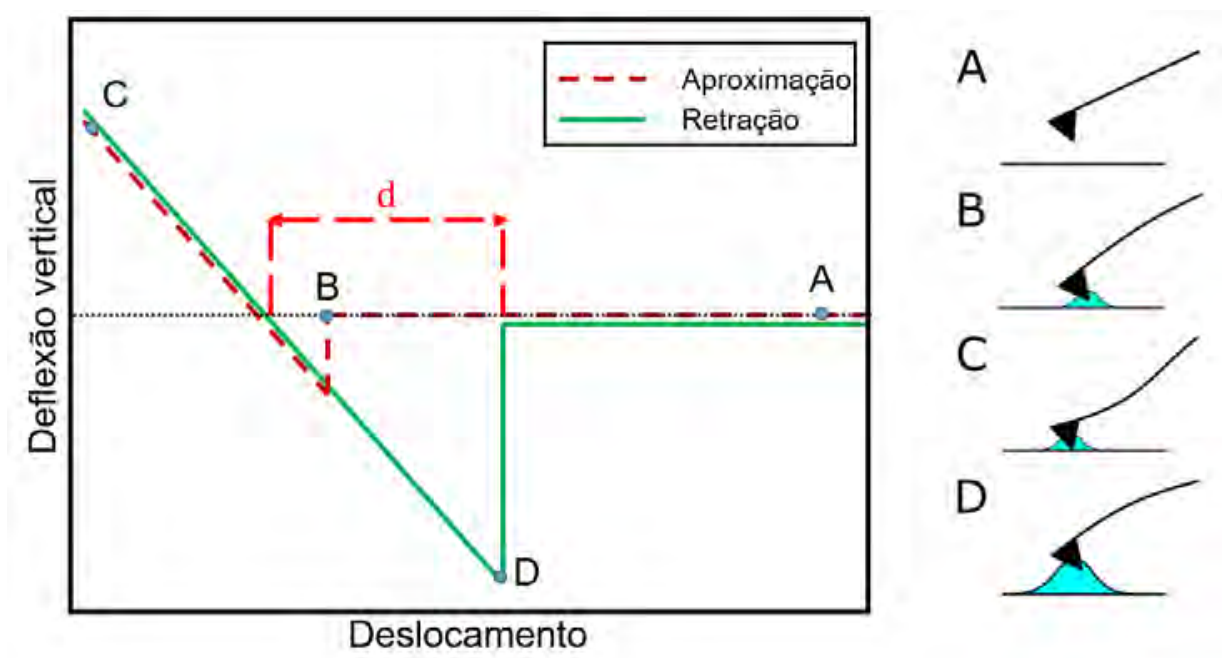

Figura 3.9: Ilustração da aproximação e retração do cantiléver na amostra, formando uma curva de força-distância. À direita, a deflexão do cantiléver nos pontos A (longe da superfície), B (snap to contact), C (limite da aproximação) e D (deflexão pela adesão) é demonstrada. Adaptado da Referência [55]

Com as curvas F-D podemos obter a sensibilidade $S_{z}$ mencionada na eq. (3-3), medida na inclinação da curva F-D. Como o valor registrado no PSPD é dado em volts, multiplicando-o por $S_{z}$ e pela constante $k_{n}$ temos então a força $F_{k}$ devido ao cantiléver. Ademais, a força de adesão $F_{\text {ad }}$ entre ponta e superfície é extraída na curva de retração. Ela é calculada multiplicando a distância $d$ mostrada na Figura 3.9 pela constante elástica do cantiléver.

$$
F_{\text {ad }}=k_{n} d .
$$

Portanto, com curvas F-D temos a força normal $F_{n}$ total, descrita na eq. (3-8), aplicada durante uma varredura do LFM. 


\section{4}

\section{Caracterização dos materiais}

Neste capítulo apresentaremos a caracterização dos materiais analisados. Serão exibidas as superfícies dos materiais, identificando número de camadas, resíduos da síntese, estado de oxidação e, para o caso da mica, uma análise sobre bolhas na superfície. Medidas de atrito em relação à rugosidade e força de adesão do grafeno serão mostradas, assim como em função do número de camadas.

\section{1}

\section{Metodologia}

As amostras foram obtidas de acordo com os métodos descritos no Capítulo 3. No caso do grafeno, após a obtenção das amostras, regiões de interesse contendo uma ou poucas camadas foram observadas num microscópio ótico, e após a identificação das regiões, foi feito espectroscopia Raman para ajudar a identificar o número de camadas, assim como determinar a qualidade do grafeno. No caso dos TMDs, além da identificação de regiões de interesse por microscopia ótica, também foram feitos espectros de fotoluminescência para identificar camadas dos materiais. Para a mica, nenhuma das espectroscopias foi feita.

Tendo as regiões de interesse identificadas por microscopia ótica, as amostras são então imageadas por AFM, operado no modo contato. Por ter uma grande variação de tamanho de folhas e regiões de interesse para cada uma das amostras, não há um padrão nos tamanhos de varreduras feitos. Apenas tentou-se obter boas imagens das regiões. Medidas de rugosidade foram estimadas em áreas de 1,0 $\mathrm{m} \times 1,0 \mu \mathrm{m}$. Já os mapas de fricção em resolução de rede são feitos com imagens de área de 5,0 $\mathrm{nm} \times 5,0 \mathrm{~nm}$, com o auxílio de um sistema para filtração de ruído mecânico.

Para a medida de altura entre camadas, ou entre substrato e camada, um plano foi traçado ao longo de uma região de interesse, funções gaussianas foram ajustadas à histogramas de distribuição de alturas. A diferença entre os picos das gaussianas é a diferença de altura entre camadas.

Uma análise de bolhas presentes nas superfícies de mica esfoliada foi feita usando o software de processamento de imagem FIJI [56]. Imagens de 
fricção nos canais ida e volta foram aliadas usando o plugin StackReg [57]. Partículas pequenas foram segmentadas automaticamente usando o método de Otsu [58], enquanto partículas maiores presentes em camadas mais finas foram segmentadas arbitrariamente. Após a segmentação, foi feito um processo de erosão (remover pixeis nas bordas das partículas selecionadas), e, para a análise, partículas nas bordas das imagens foram excluídas, uma vez que podem fornecer resultados incompletos.

\section{2}

\section{Resultados}

\subsection{1}

\section{Grafeno}

A Figura 4.1a mostra uma folha de grafeno esfoliada depositada em $\mathrm{SiO}_{2}$, exibindo várias camadas de grafeno (denominadas $N L G$, onde $N$ é a quantidade de camadas), assim como uma grande região de grafite. A monocamada pode ser identificada pelo contraste, sendo este muito parecido com o do substrato. Quanto maior o número de camadas, mais opaco é o contraste. A Figura 4.1b mostra uma imagem de topografia da mesma região obtida por AFM.

(a)

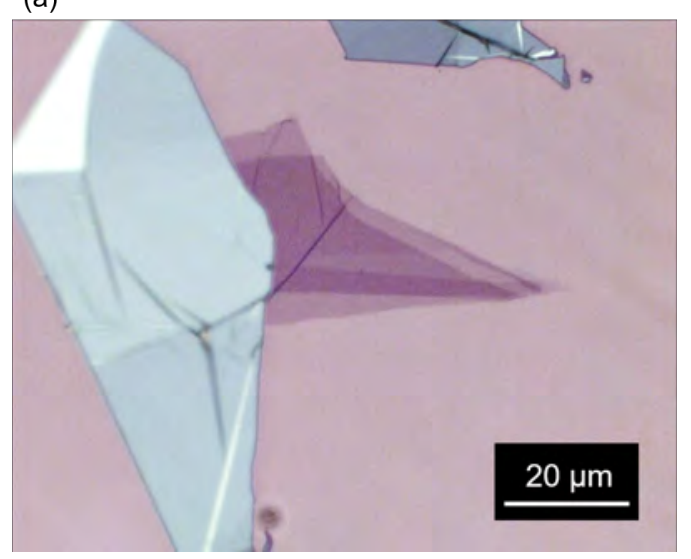

(b)

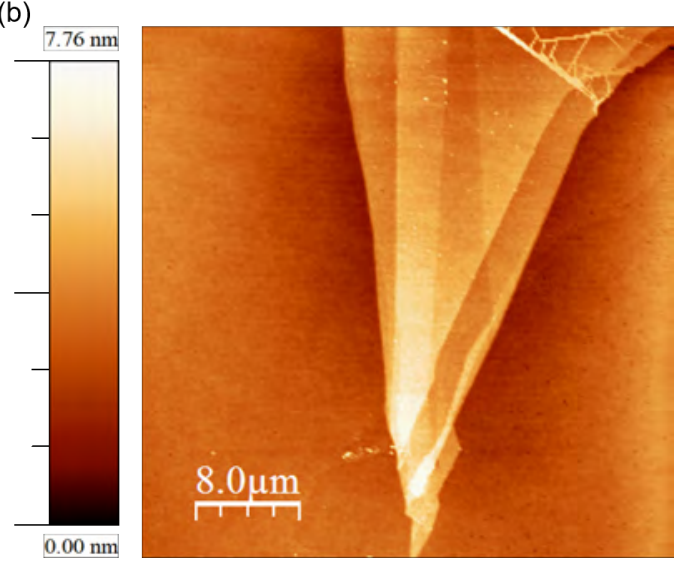

Figura 4.1: (a) Micrografia ótica de região contendo mono e multicamada de grafeno; (b) Topografia obtida por AFM da mesma região de itneresse.

A Figura 4.2 mostra espectros Raman para uma, duas e três camadas de grafeno. Picos característicos nas bandas $G$ e $2 D$ são identificados em $\Delta \omega \sim 1580 \mathrm{~cm}^{-1}$ e $\Delta \omega \sim 2700 \mathrm{~cm}^{-1}$, respectivamente. É possível notar que o pico $2 D$ se torna mais largo e menos intenso com o aumento do número de camadas, enquanto o pico $G$ ganha intensidade. 


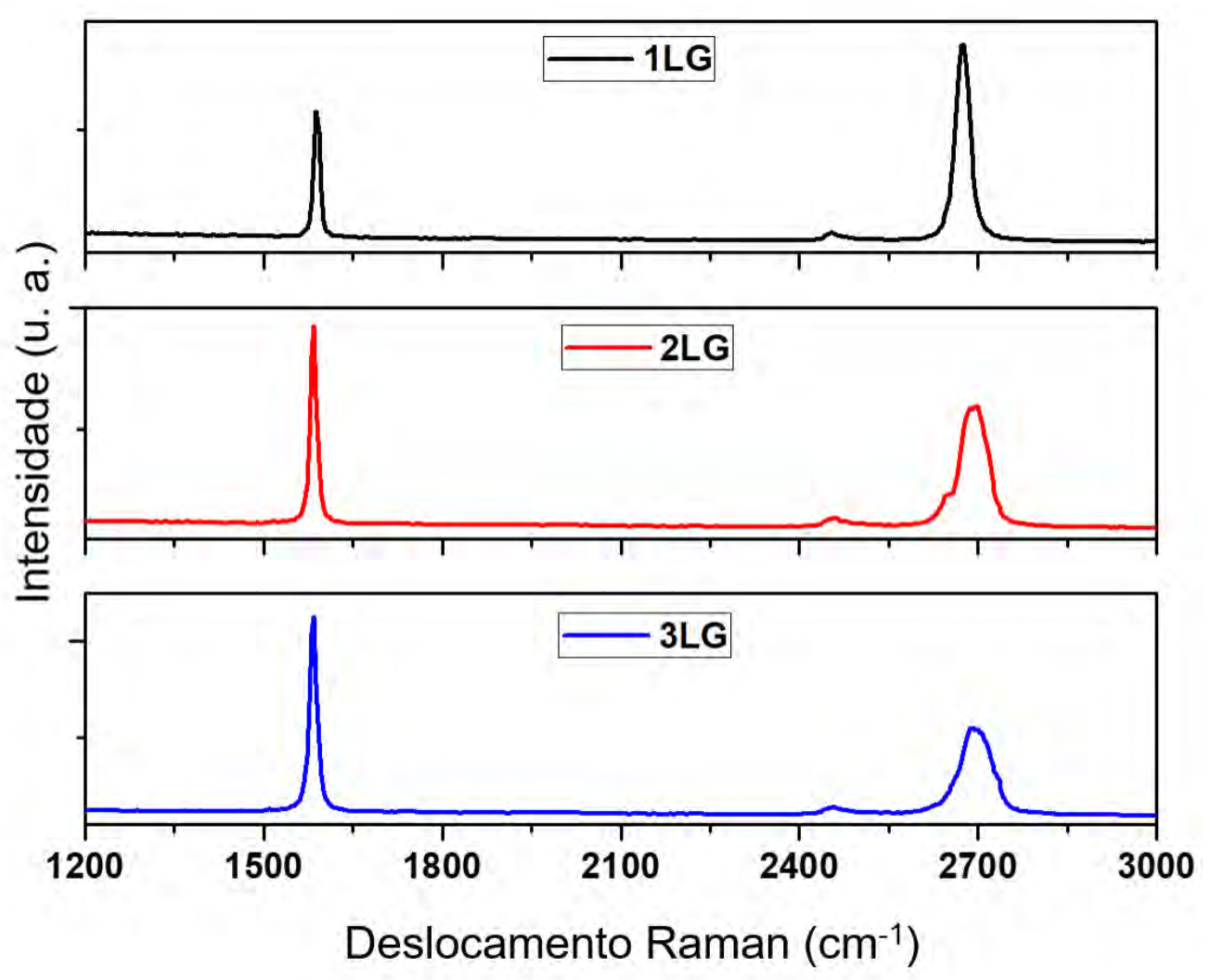

Figura 4.2: Espectros Raman para mono, bi e tricamada de grafeno.

A quantificação da variação de altura é exibida na Figura 4.3. Na Figura 4.3a uma amostra com quatro camadas de grafeno em sequência é mostrada. Na Figura 4.3b, um histograma com distribuições de altura, de onde são extraídas as alturas entre camadas. A altura entre o substrato e uma monocamada é medida em $\Delta h \sim 1,0 \mathrm{~nm}$, enquanto para as camadas adjacentes é estimada em $\Delta h \sim 0,5 \mathrm{~nm}$. A altura em função do intervalo entre camadas é vista na Figura 4.3c. Nota-se que entre quatro e cinco camadas, a altura entre essas passa a ser equivalente à altura entre camadas de grafite, em $\Delta h=0,335 \mathrm{~nm}$, enfatizada pela linha pontilhada no gráfico. 


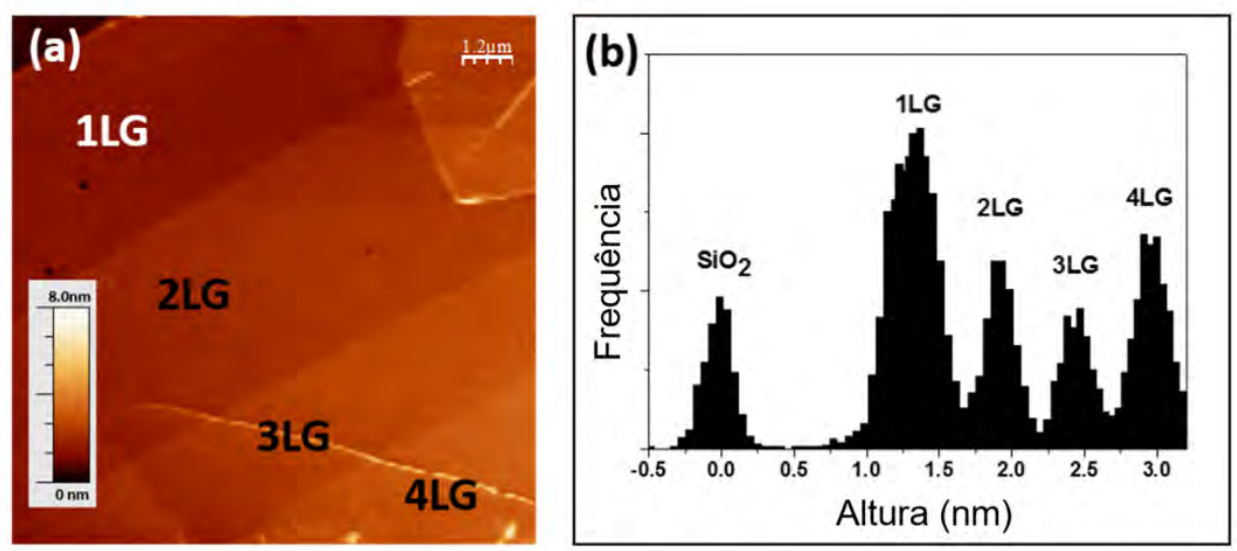

(c)

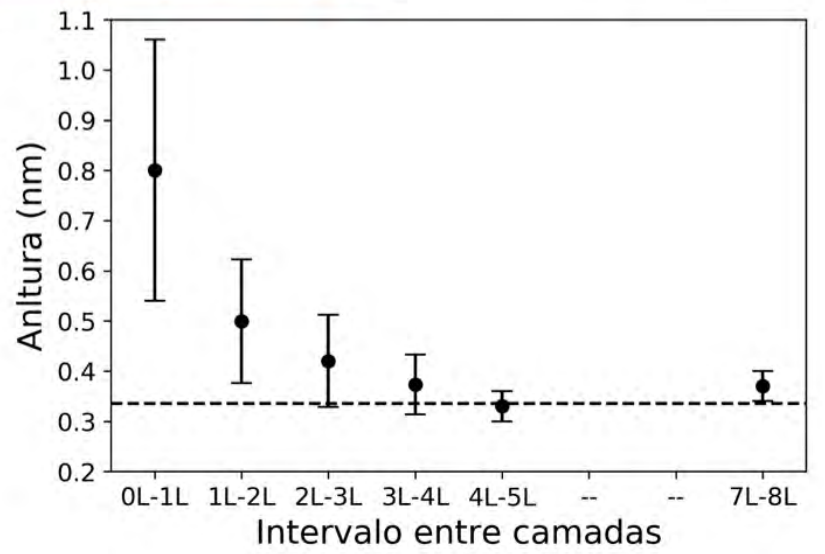

Figura 4.3: (a) Topografia feita em AFM mostrando diferentes camadas de grafeno; (b) Histograma com distribuição de alturas; (c) Altura em função do intervalo entre camadas. Linha pontilhada representa a altura entre camadas de grafite.

Uma medida de atrito em função do número de camadas de grafeno é vista na Figura 4.4. Pode-se notar claramente uma tendência da diminuição do atrito com o aumento do número de camadas. 


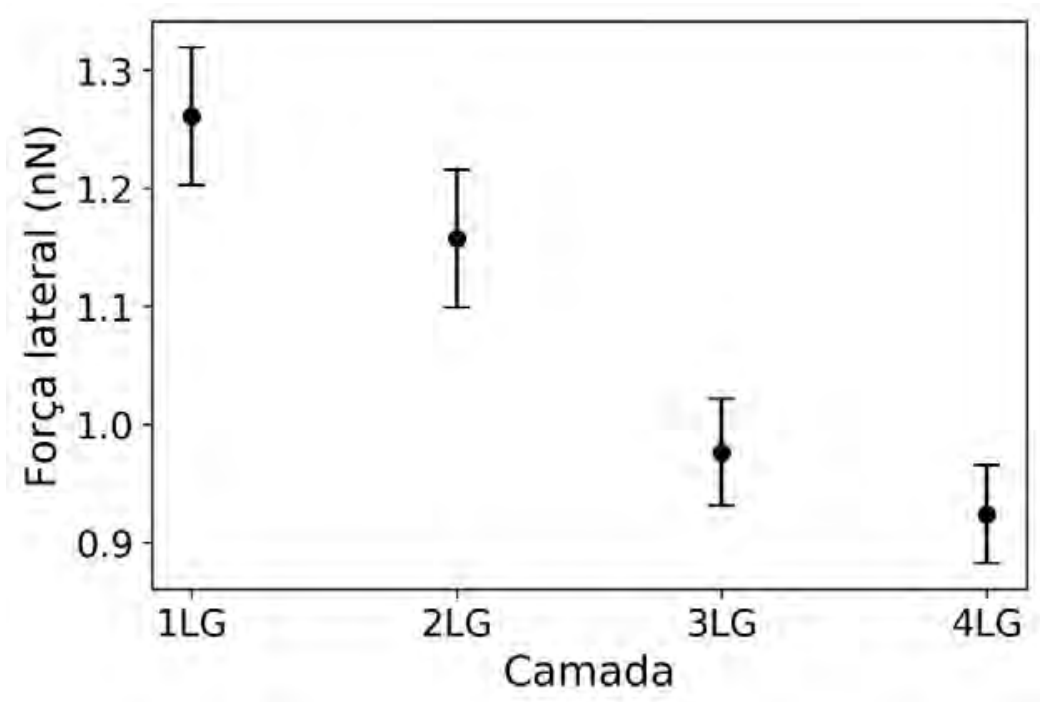

Figura 4.4: Atrito medido em função do número de camadas.

Parâmetros como rugosidade e adesão podem ter influência na medida de atrito. Imagens topográficas em três dimensões para uma, duas e três camadas de grafeno, assim como para o substrato de $\mathrm{SiO}_{2}$, são mostradas na Figura 4.5a, a partir das quais se extraem as rugosidades das amostras, mostrada na Figura 4.5b. Uma associação entre rugosidade e atrito é exibida na Figura $4.5 \mathrm{c}$ para diferentes camadas de atrito. Percebe-se um comportamento inverso entre eles, com a rugosidade crescendo com o número de camadas, enquanto a friç̧ão decresce. As linhas sólidas são apenas guias para os olhos.
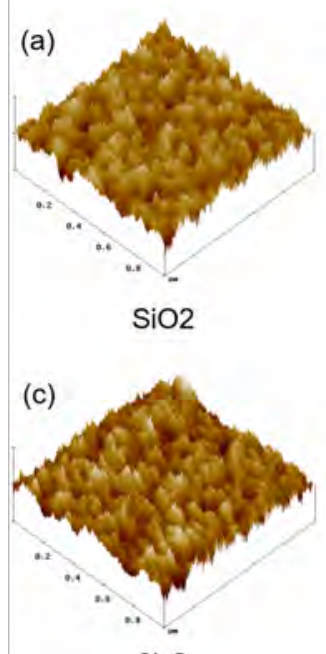

2LG

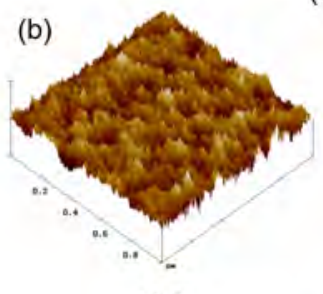

(d)

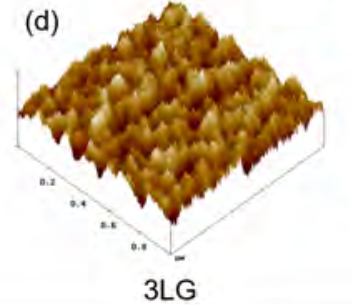

(f) (e)
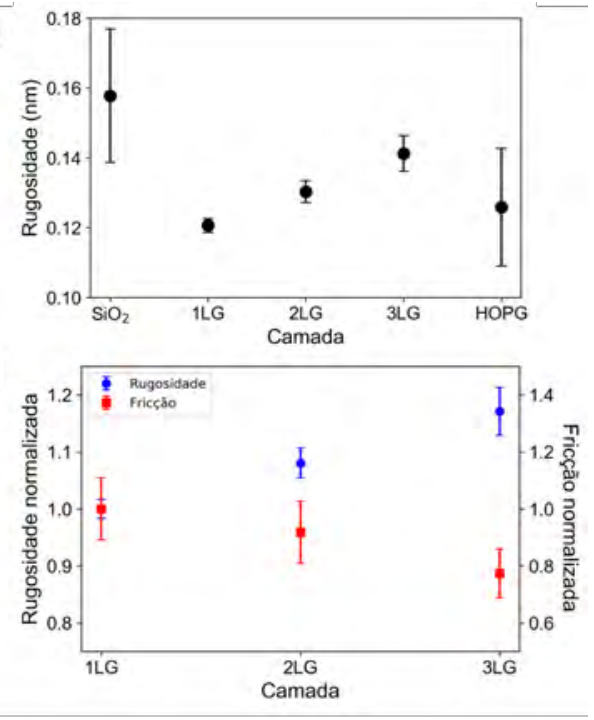

Figura 4.5: Topografia em 3D para (a) $\mathrm{SiO}_{2}$, (b) 1LG, (c) 2LG e (d) 3LG; (e) Rugosidade para os mesmos materiais; (f) Relação entre rugosidade e fricção para diferentes camadas de grafeno. 
Método similar para a adesão é feita em sequência. Na Figura 4.6a, mostramos uma típica curva FD para uma camada de grafeno. A adesão em função do número de camadas é mostrada na Figura 4.6b, e uma correlação enter adesão e fricção é exibida na Figura 4.6c. Novamente, as linhas sólidas são apenas guias para os olhos. Percebe-se que a adesão é similar entre as camadas, praticamente indistinguível dentro do erro estatístico.

(a)

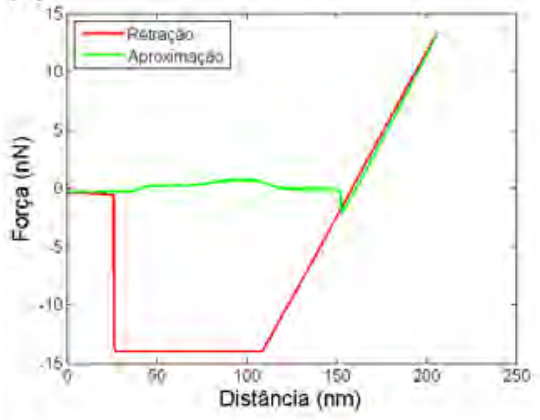

(b)

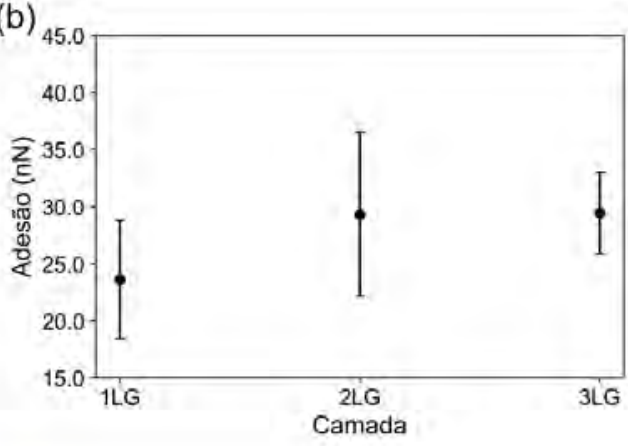

(c)

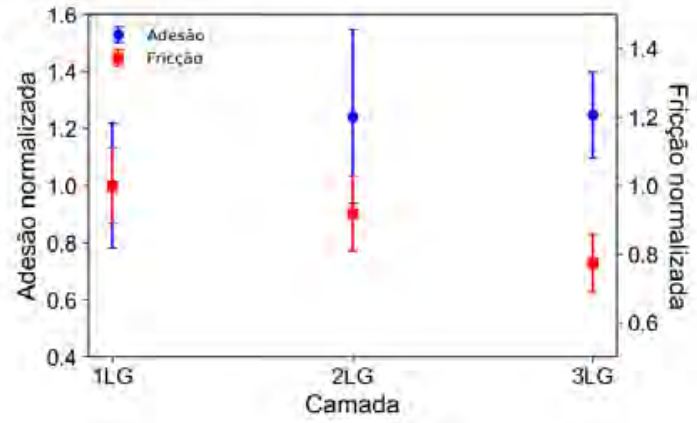

Figura 4.6: (a) Curva FD para 1LG; (b) Força de adesão em função para diferentes camadas de grafeno; (c) Correlação entre adesão e fricção para diferentes camadas de grafeno.

Uma comparação entre mono e tricamada de grafeno é mostrada em imagens força lateral em resolução de rede, nas Figuras 4.7a e b, enquanto as Figuras 4.7c e d mostram loops de friç̧ão nessa escala. Vê-se uma maior área nos loops da monocamada, associada à dissipação de energia. A deformação da amostra também pode ser estimada, ao menos de forma qualitativa, pelos loops. A inclinação destes é associada à deformação fora do plano na folha de grafeno. Pode-se perceber que a inclinação é maior para a monocamada, indicando maior deformação desta. 
(a)

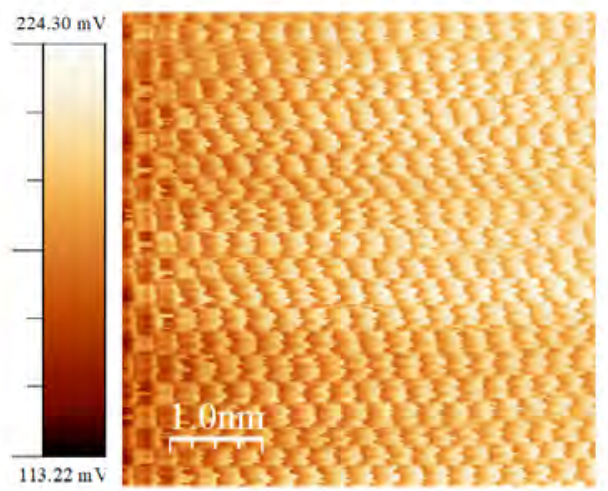

(c)

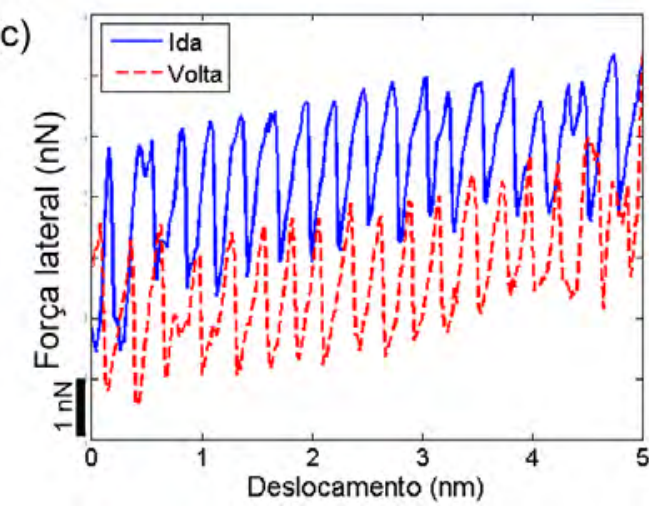

(b)

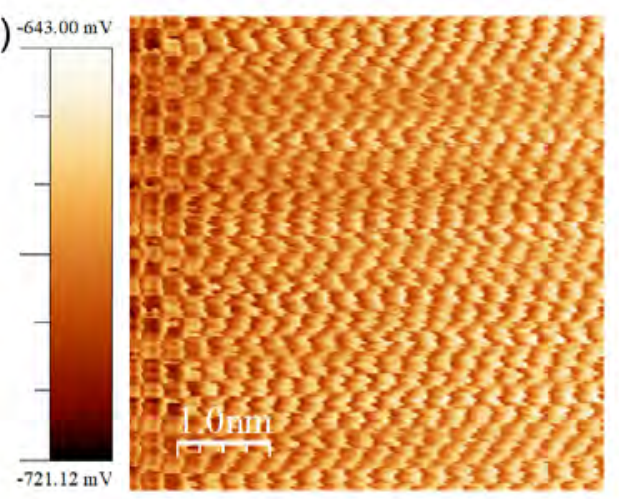

(d)

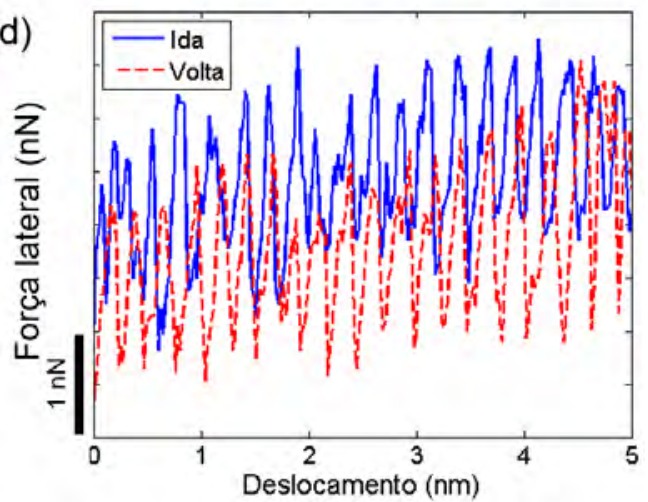

Figura 4.7: (a) e (c) Imagens em resolução de rede para mono (a) e tricamada (c) de grafeno; (b) e (d) respectivos loops de fricção.

Como visto no Capítulo 2, a constante efetiva de contato $k_{\text {eff }}$ é um importante parâmetro para a fricção em escala nanométrica. Medidas de $k_{\text {eff }}$ em função da força normal para diferentes camadas é mostrada na Figura 4.8. Nota-se que a constante não varia com a força, e é igual dentro do erro estatístico para as diferentes camadas. Sendo assim, o valor médio foi estimado em $k_{\text {eff }}=12 \pm 5 \mathrm{~N} \mathrm{~m}^{-1}$. 


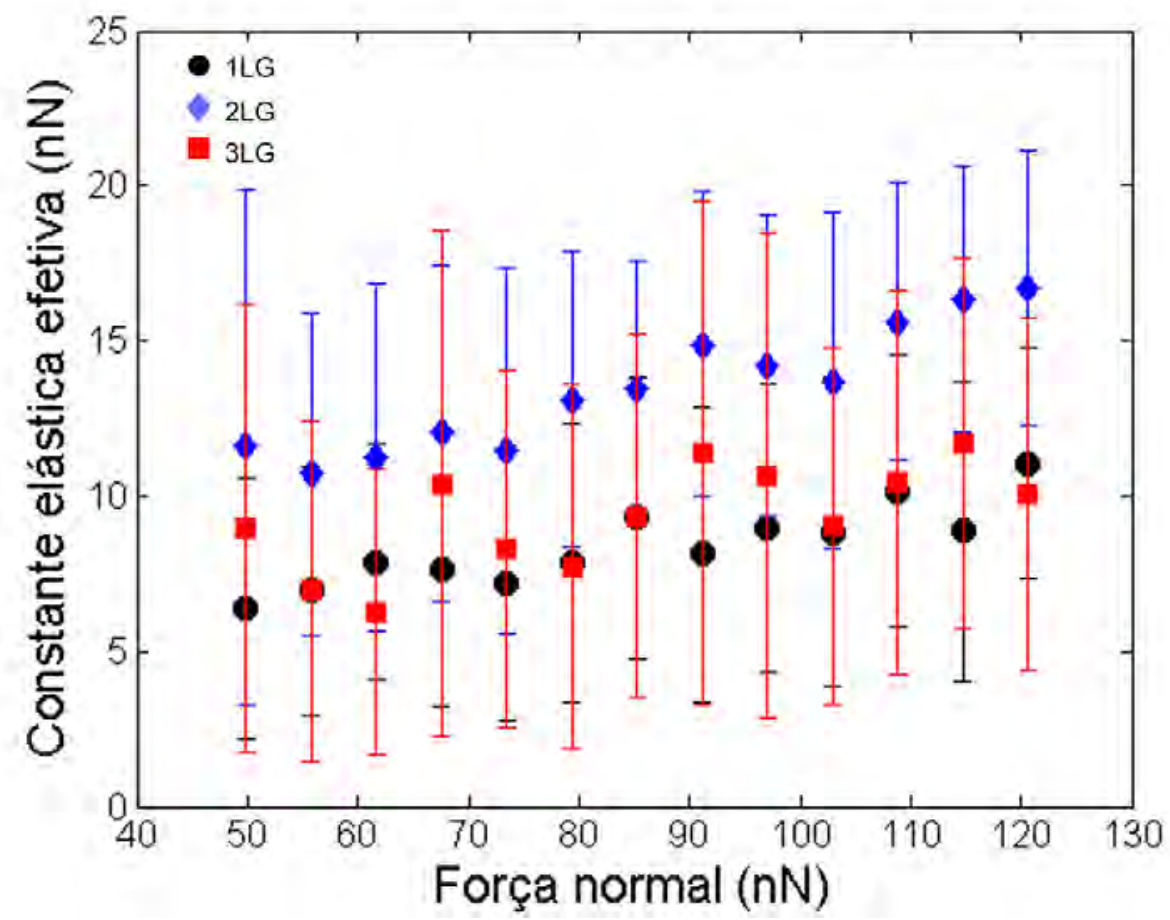

Figura 4.8: $k_{\text {eff }}$ em função da força normal para 1LG, 2LG e 3LG.

\subsection{2 \\ TMDs}

Cristais de $\mathrm{MoS}_{2}$ e $\mathrm{WS}_{2}$ crescidos por CVD costumam apresentar uma forma triangular. Em alguns casos, há fusão de cristais formando estruturas policristalinas, com diferentes formatos. Na Figura 4.9a, podemos ver uma estrutura de $\mathrm{MoS}_{2}$ em forma de estrela. A área destacada pelo quadrado é mostrada na Figura 4.9b. Percebe-se que o interior da estrutura contém pequenas partículas, provavelmente resíduos dos materiais usados no crescimento. A Figura 4.9c mostra um cristal triângular de $\mathrm{WS}_{2}$, e, igualmente, a área destacada é mostrada na Figura 4.9d, contendo resíduos do processo de crescimento. Em ambas amostras nota-se também uma barreira entre a superfície do TMD e o substrato de $\mathrm{SiO}_{2}$. 

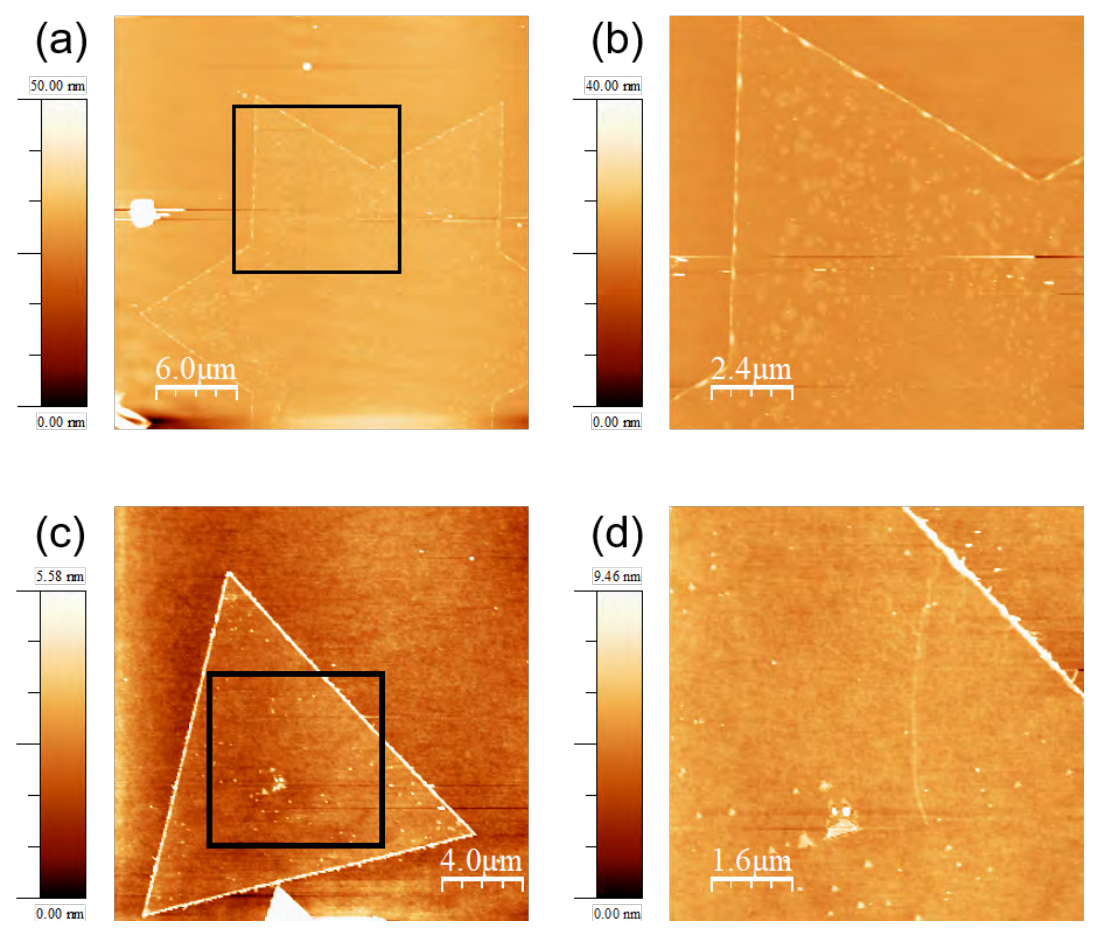

Figura 4.9: (a) Estrutura de $\mathrm{MoS}_{2}$ em forma de estrela; (b) Ampliação da área destacada no quadrado, exibindo resíduos do crescimento; (c) Cristal triangular de $\mathrm{WS}_{2}$; (d) Ampliação da área destacada pelo quadrado.

A Figura 4.10 mostra espectros Raman e de fotoluminescência para monocamadas de $\mathrm{MoS}_{2}$ e $\mathrm{WS}_{2}$. Nos espectros Raman, vemos as bandas $E_{2 g}^{1}=382 \mathrm{~cm}^{-1}$ e $A_{1 g}=404 \mathrm{~cm}^{-1}$ para o $M_{2}$, com larguras $\Delta \omega=5,0 \mathrm{~cm}^{-1} \mathrm{e}$ $\Delta \omega=8,3 \mathrm{~cm}^{-1}$, respectivamente. Já para o $\mathrm{WS}_{2}$, encontramos $E_{2 g}^{1}=356 \mathrm{~cm}^{-1}$ e $A_{1 g}=418 \mathrm{~cm}^{-1}$, com larguras $\Delta \omega=6,2 \mathrm{~cm}^{-1}$ e $\Delta \omega=4,5 \mathrm{~cm}^{-1}$. Já nos espectros $\mathrm{PL}$ vemos picos em energias de $\Delta E=1,84 \pm 0,04 \mathrm{eV}$ e $\Delta E=$ $1,95 \pm 0,03 \mathrm{eV}$ para $\mathrm{MoS}_{2}$ e $\mathrm{WS}_{2}$, respectivamente. 

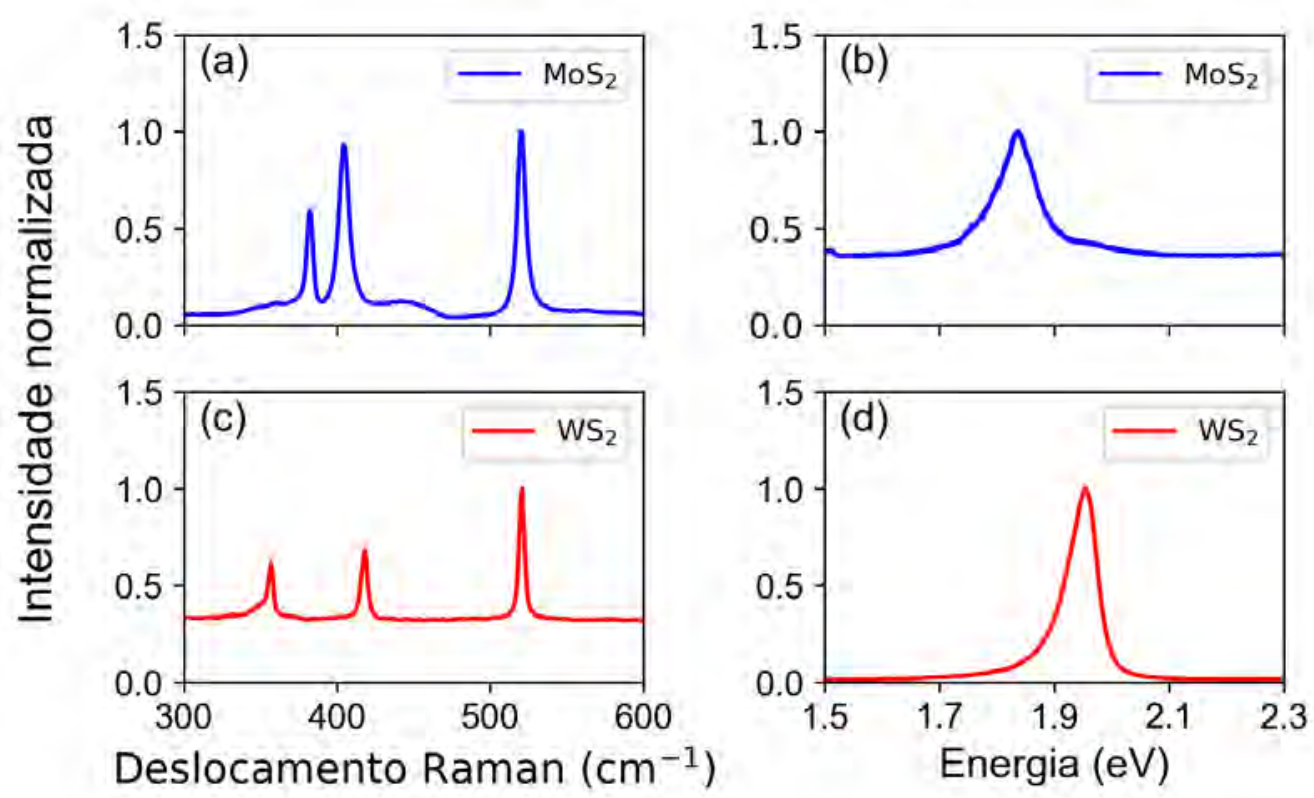

Figura 4.10: (a) Espectro Raman para $\mathrm{MoS}_{2}$; (b) Espectro PL para $\mathrm{MoS}_{2}$; (c) Espectro Raman para $\mathrm{WS}_{2}$; (d) Espectro PL para $\mathrm{WS}_{2}$.

Uma ampliação numa interface entre o substrato de $\mathrm{SiO}_{2}$ e uma monocamada de $\mathrm{MoS}_{2}$ é mostrada na Figura 4.11a. A linha de perfil é exibida na Figura 4.11b. A altura entre o substrato e uma monocamada de $\mathrm{MoS}_{2}$, assim com a altura da barreira, é estimada pela Figura 4.11b. Temos que o cristal está a uma altura de $\Delta h \sim 1,1 \mathrm{~nm}$, e a barreira possui uma altura de $\Delta h \sim 2,3 \mathrm{~nm}$.
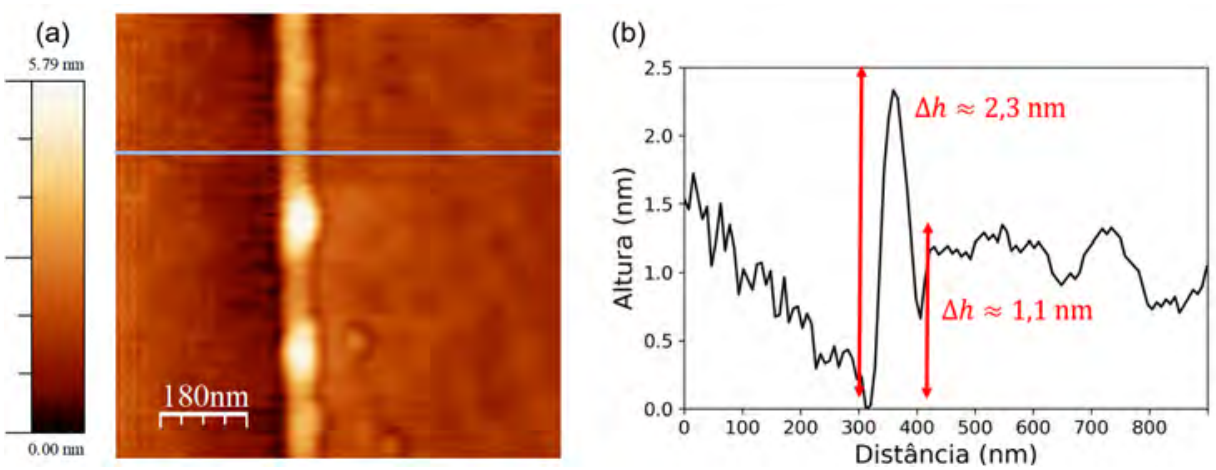

Figura 4.11: (a) Topografia da interface entre $\mathrm{SiO}_{2}$ e cristal de $\mathrm{MoS}_{2}$; (b) Linha de perfil demarcada na imagem topográfica, medindo alturas entre cristal e substrato e da barreira entre eles.

Comparação entre topografia e mapas de fricção é mostrada na Figura... As Figuras 4.12a e 4.12b mostram respectivamente topografia e mapa de fricção de um cristal triangular de $\mathrm{MoS}_{2}$, enquanto as Figuras 4.12c e 4.12d mostram o mesmo para um cristal de $\mathrm{WS}_{2}$. Em ambos casos percebe-se que os resíduos 
possuem um contraste mais claro que o monocamada do cristal, indicando um maior coeficiente de atrito.
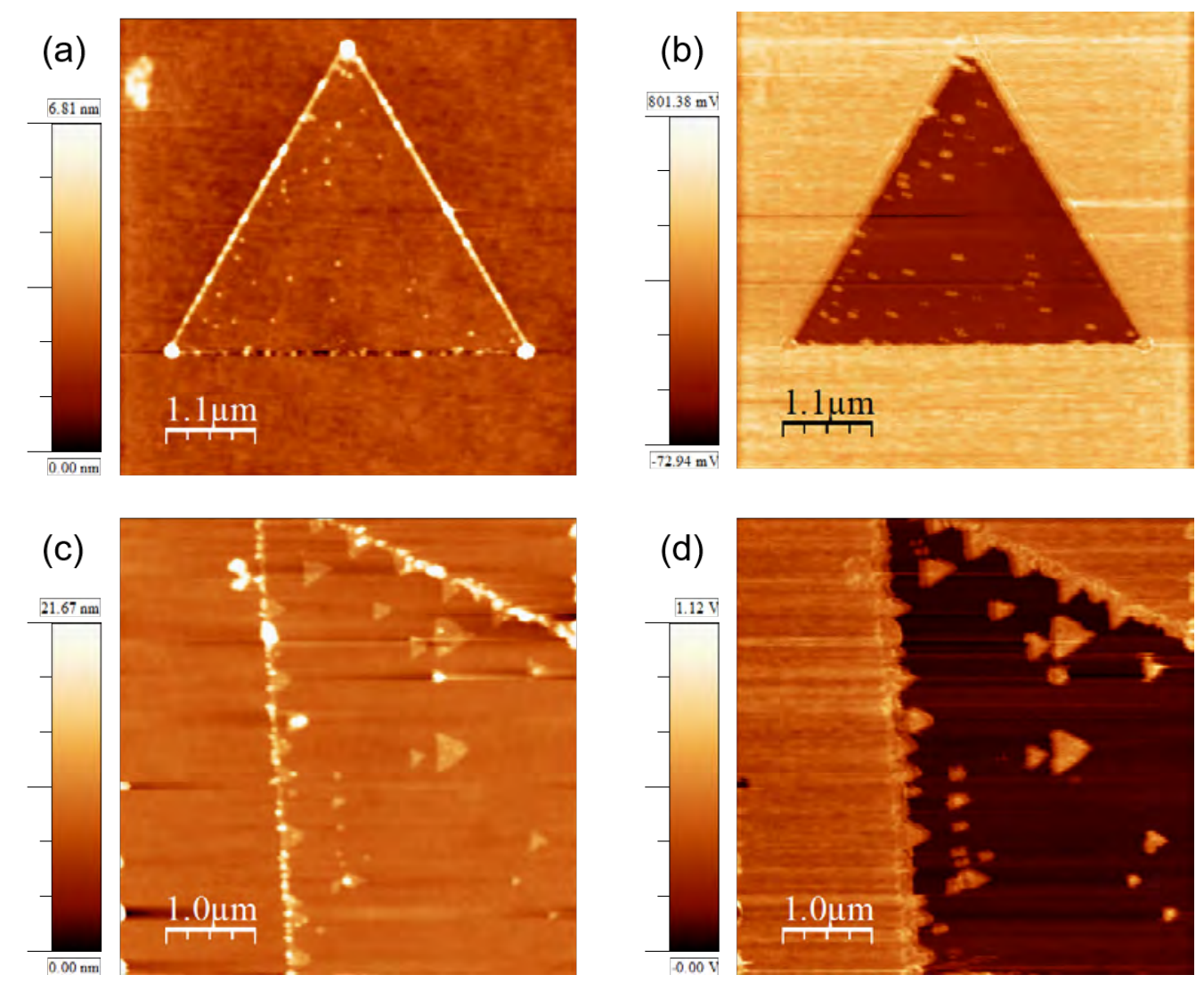

Figura 4.12: (a) e (c) Topografia para cristais de $\mathrm{MoS}_{2}$ e $\mathrm{WS}_{2}$, respectivamente; (b) e (d) Mapas de fricção para os mesmos.

Imagens de fricção em resolução de rede para ambos materiais são mostrados nas Figuras 4.13, para $\mathrm{MoS}_{2}$ (Fig. 4.13a) e $\mathrm{WS}_{2}$ (Fig. 4.13c). Perfis stick-slip de ambos são mostrados nas Figuras 4.13b e 4.13d. Ao contrário do grafeno, não vemos inclinação notável no perfil de força lateral por deslocamento. Ademais, o perfil para o $\mathrm{WS}_{2}$ exibe uma área maior entre curvas de ida e volta, indicando maior dissipação de energia. 

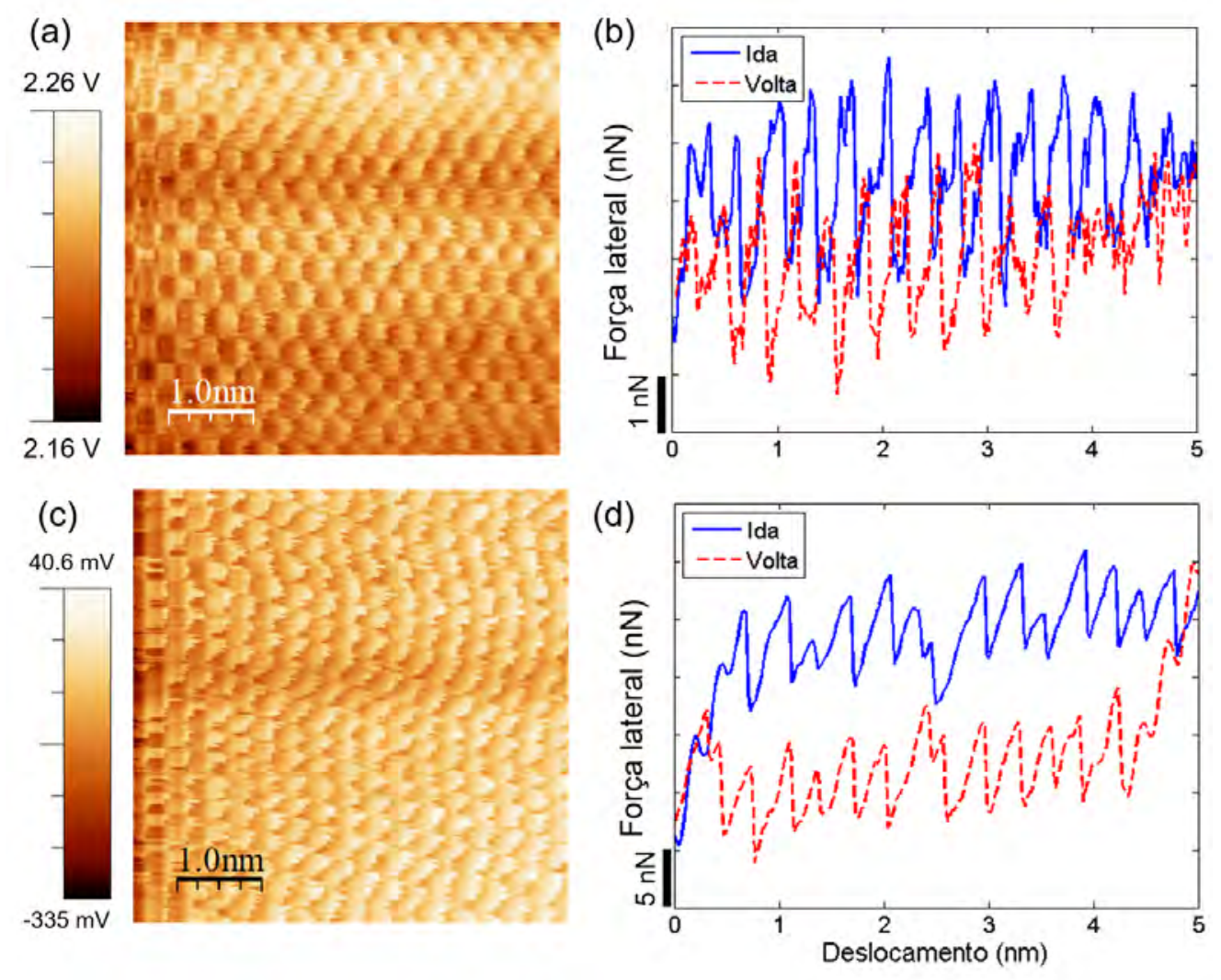

Figura 4.13: (a) e (c) Imagens de resolução de rede para $\mathrm{MoS}_{2}$ e $\mathrm{WS}_{2}$, respectivamente. (b) e (d) Perfis stick-slip de força lateral em função do deslocamento da ponta para ambos. Força normal de $120 \mathrm{nN}$ utilizada em ambas as medidas.

\subsection{3 \\ Mica}

\subsubsection{1}

\section{Muitas camadas}

A Figura 4.14 mostra imagens topográfica de folhas de mica em multicamadas, assim como medidas de altura entre substrato e a superfície de interesse. Vemos que as folhas apresentam bolhas em suas superfícies. A formação de bolhas parece ocorrer mesmo em multicamadas de mica, com alturas superiores à $30 \mathrm{~nm}$ (algo em torno de 30 camadas). 

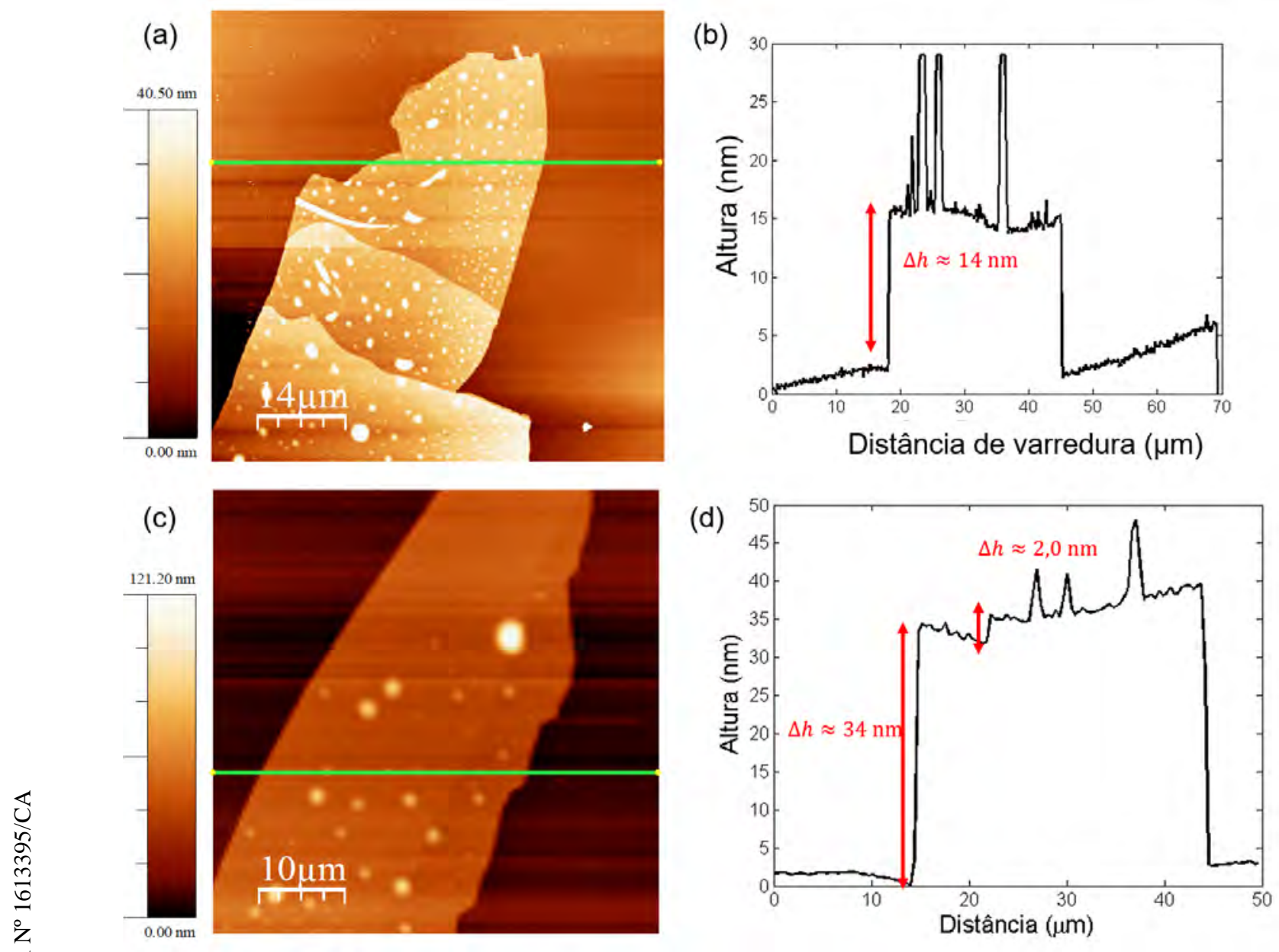

Figura 4.14: (a) Folha multicamadas de mica; (b) Linha de perfil mostrada em (a); (c) Outro exemplo de folhas multicamadas apresentando bolhas na superfície; (d) Linha de perfil mostrada na imagem (c).

Na Figura 4.15a, vemos a mesma topografia da da Figura 4.14c, com o quadrado destacado amplificado na Figura 4.15b, mostrando duas bolhas maiores. A Figura 4.15c mostra bolhas menores ao redor da região mapeada na Figura 4.15b. 

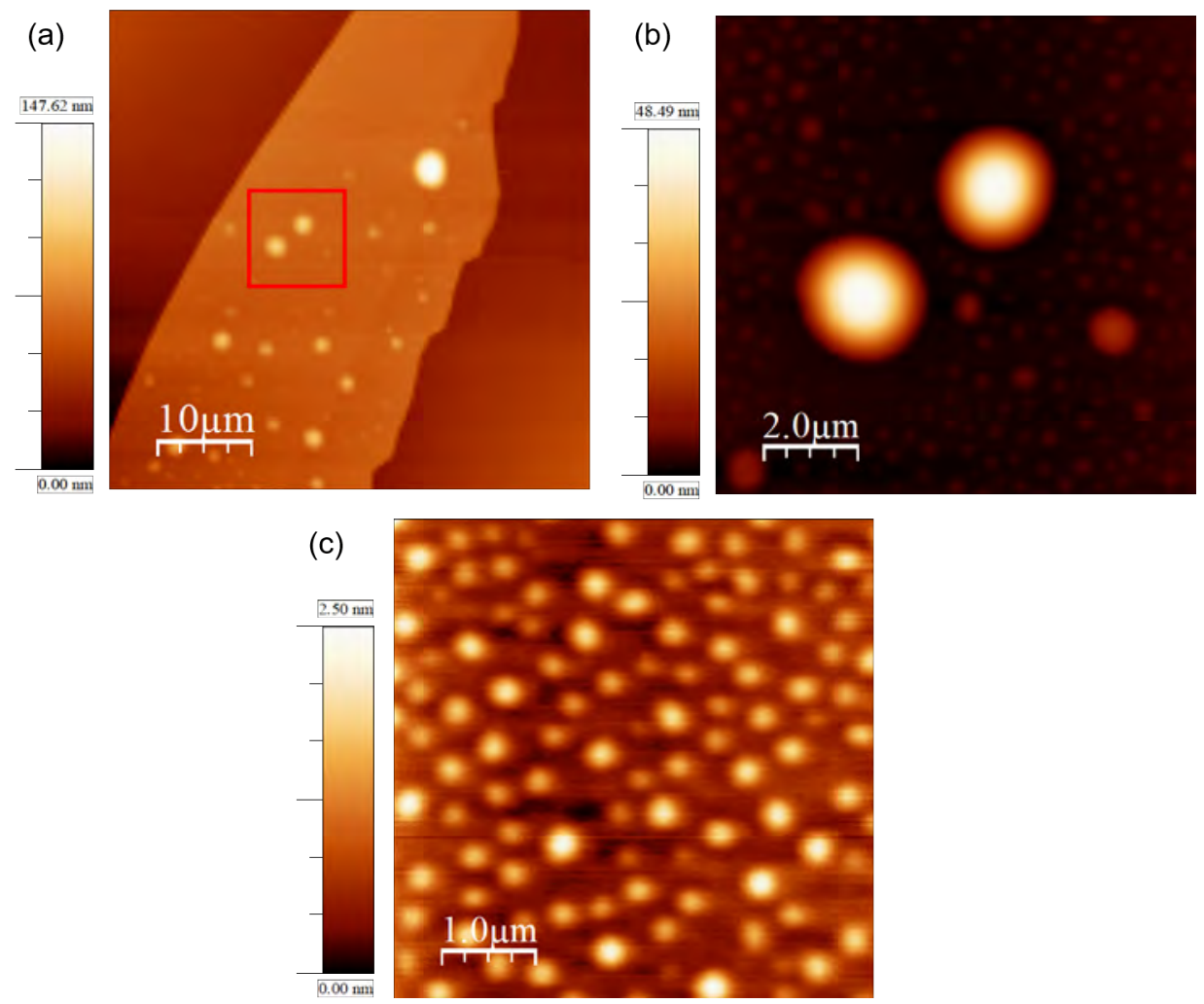

Figura 4.15: (a) Folha de mica exibindo bolhas na superfície; (b) Área destacada em (a); Bolhas menores na superfície em região ao redor das bolhas em (b).

Uma análise dessas bolhas foi feita com o uso do software FIJI [56], com o uso de segmentação pelo histograma de valores de cinza da imagem. A imagem topográfica em escala de cinza é mostrada na Figura 4.16a, e o resultado da segmentação é exibido na Figura 4.16b.

(a)

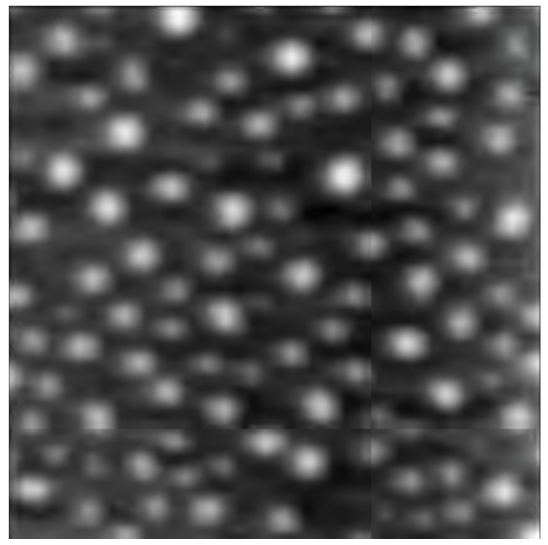

(b)

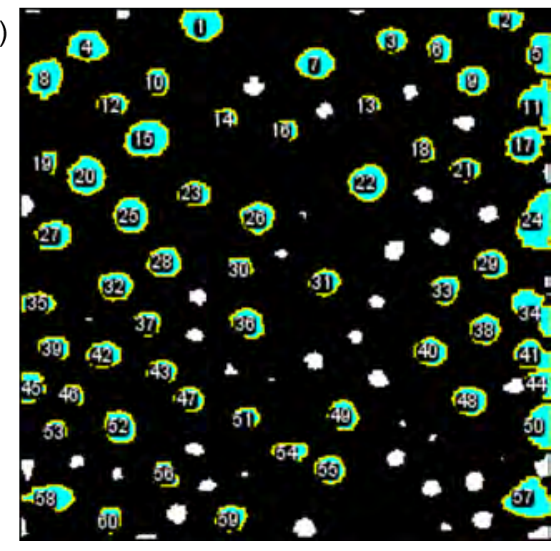

Figura 4.16: (a) Exemplo de topografia em escala de cinza; (b) Resultado de segmentação pelo método de Otsu.

A Figura 4.17 mostra histogramas de distribuições de área, períme- 
tro e altura das partículas. A análise foi feita para várias forças normais diferentes. A altura média foi de $h=1,88 \pm 0,25 \mathrm{~nm}$, a área média foi $S=(5,5 \pm 0,2) \times 10^{-2} \mu^{2}$, e um perímetro de $0,88 \pm 0,18 \mu \mathrm{m}$.
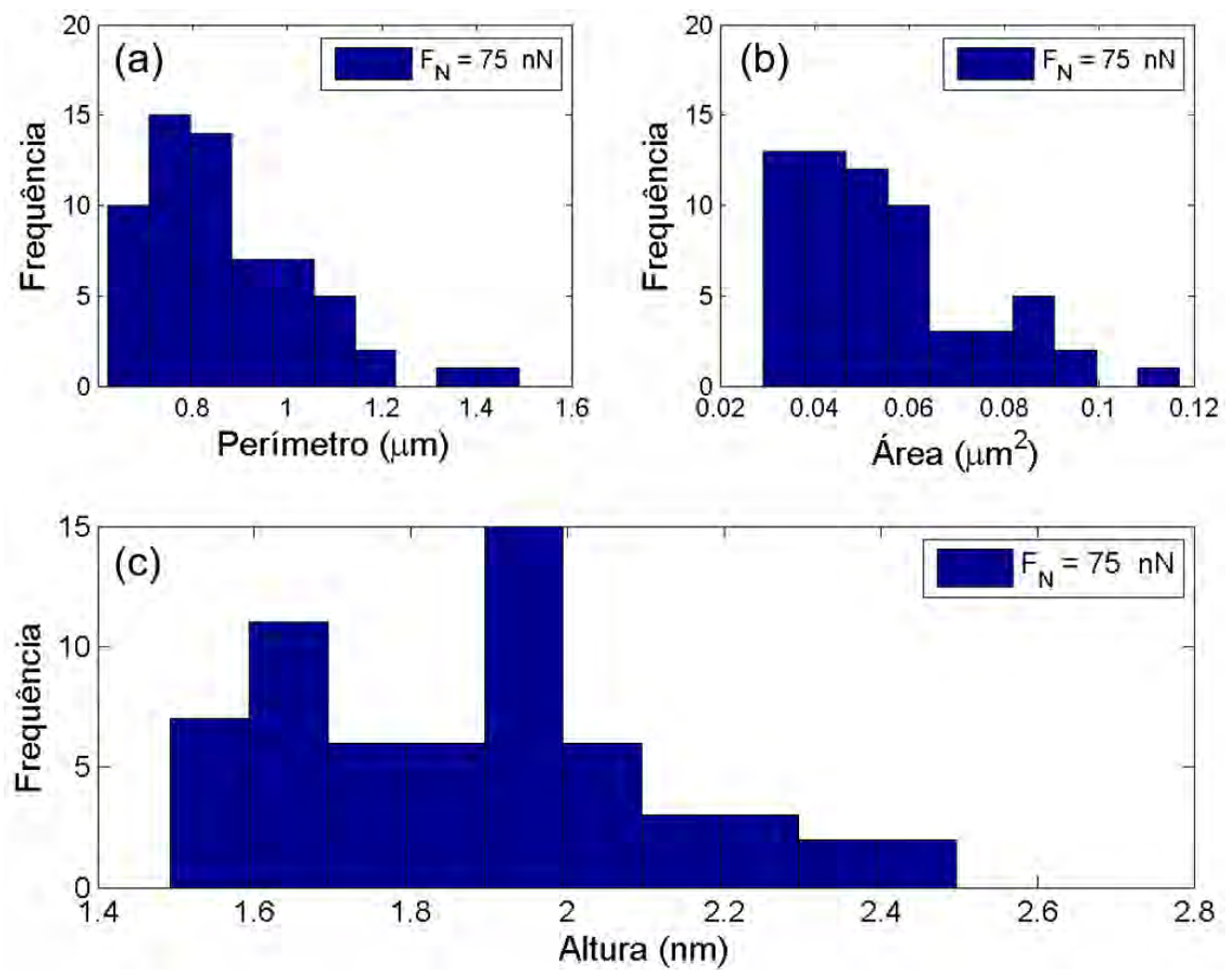

Figura 4.17: Distribuição de perímetros (a), área (b) e altura(c) das partículas para uma dada força normal.

A Figura 4.18 mostra um gráfico da altura medidas para cada partícula em função da área das mesmas. Percebe-se uma correlação em que quanto maior a área, maior a altura de cada. A linha vermelha mostra uma função linear ajustada aos dados. Os ajustes para cada força normal tem um coeficiente de determinação médio de $\bar{R}^{2}=0,69 \pm 0,01$. 


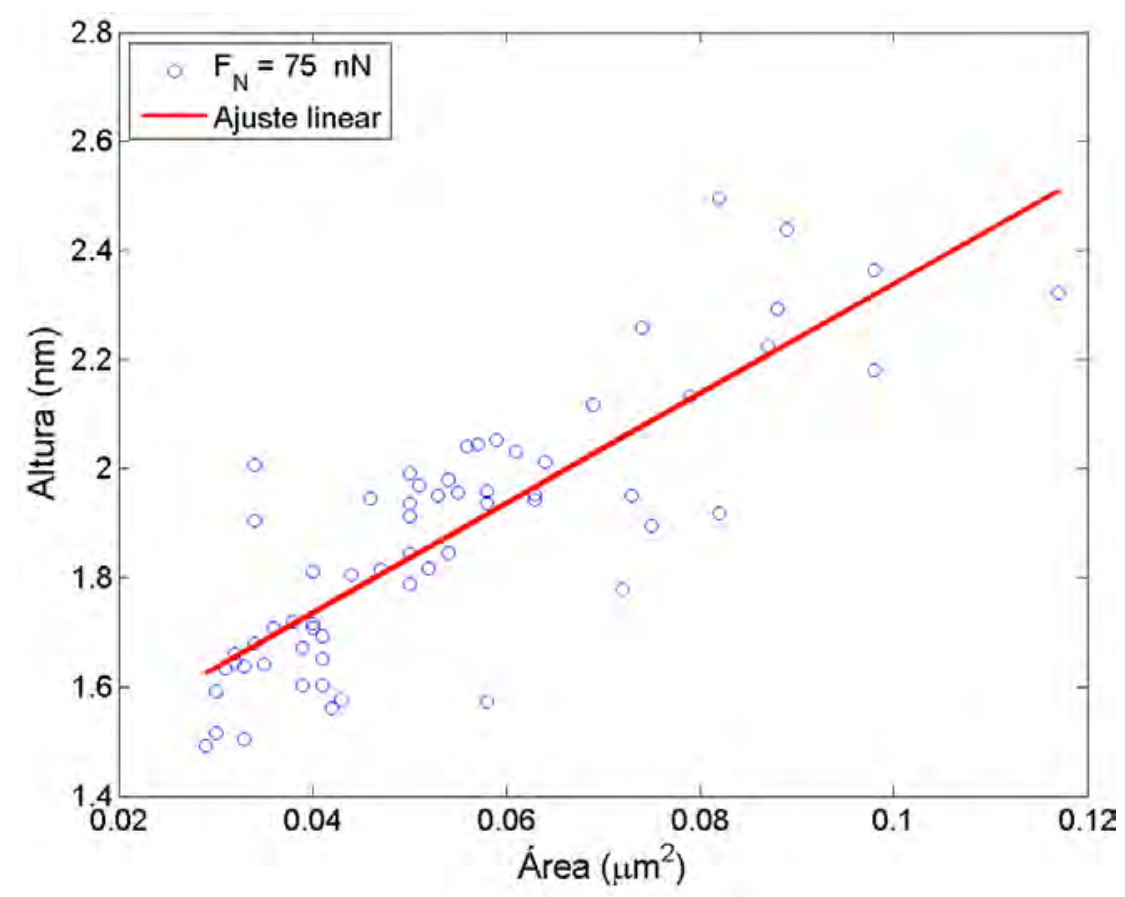

Figura 4.18: Correlação entre altura e área das partículas segmentadas. Linha vermelha é um ajuste linear. $\bar{R}^{2}=0,69$

Um mapa de fricção segmentado é exibido na Figura 4.19a. Quanto mais alto o contraste, maior a fricção medida. Percebe-se que as bolhas exibem um coeficiente de fricção menor do que a superfície de mica. O histograma do mapa é mostrado na Figura 4.19b, contendo claramente dois modos.

(a)

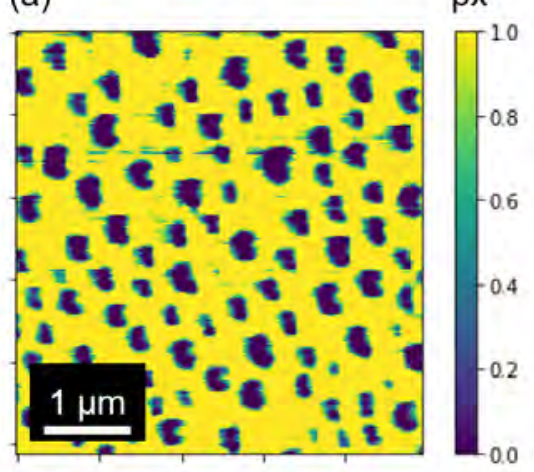

(b)

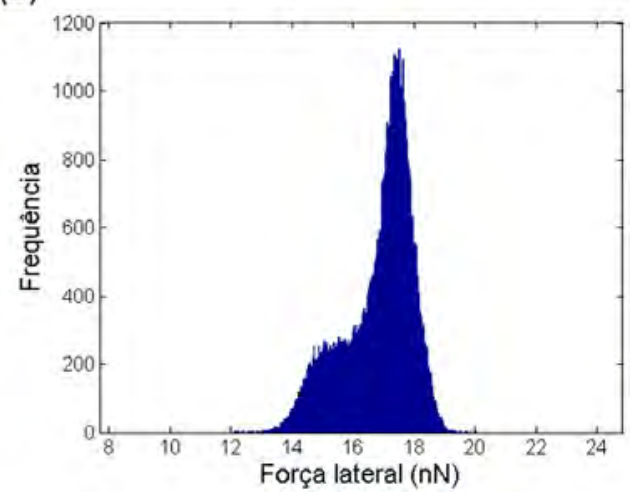

Figura 4.19: (a) Mapa de friç̧ão de mica e bolhas na superfície; (b) Histograma do mapa mostrando dois modos.

Um gráfico de fricção em função da força normal é exibido na Figura 4.20. É possível ver que as bolhas seguem o mesmo comportamento da superfície de mica. Como é visto na Figura 4.19a as bolhas tem um contraste menor, atribuímos o modo de menor média no histograma exemplificado na Figura 4.19b às bolhas, e o modo de maior média à superfície de mica. 


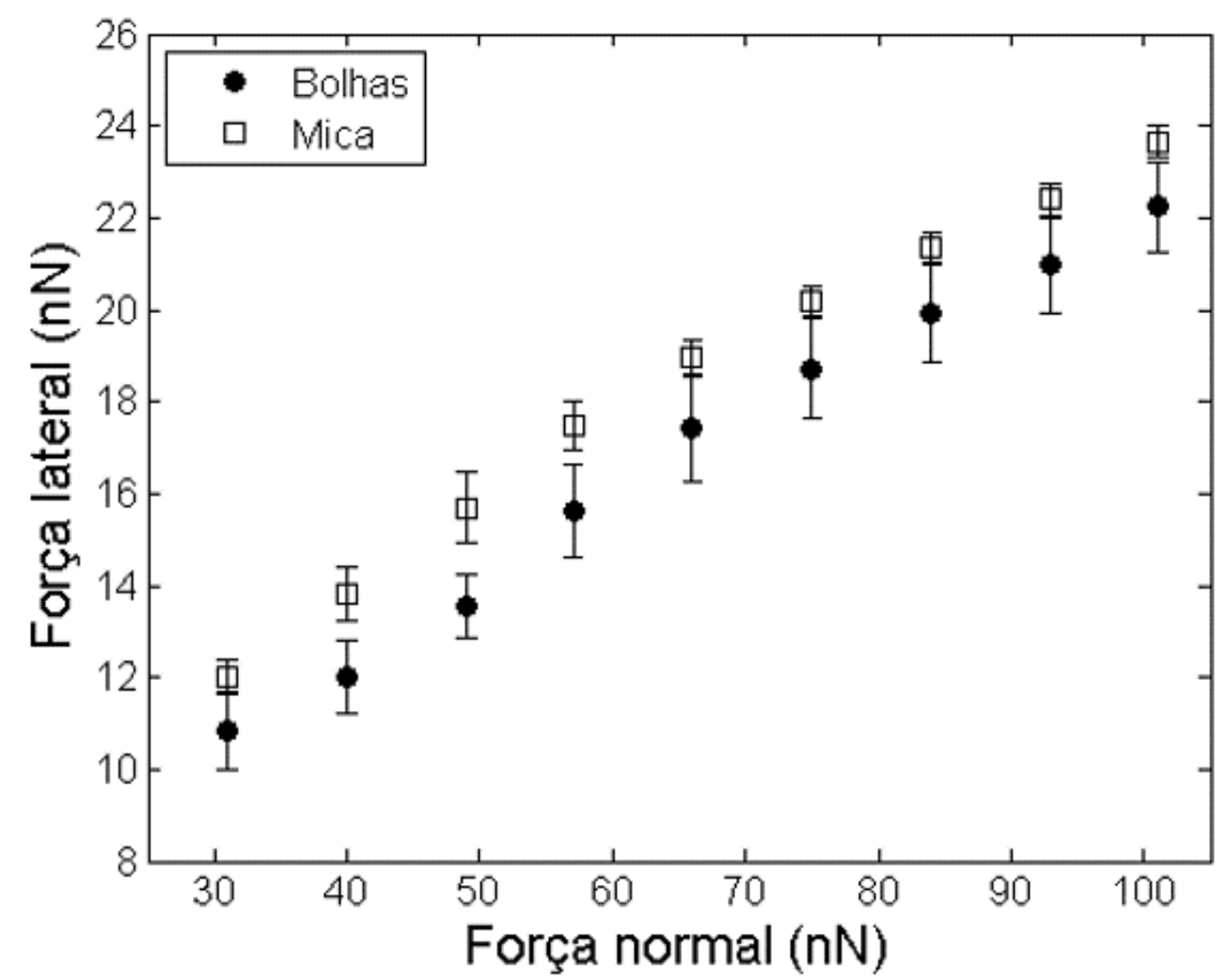

Figura 4.20: Gráfico de fricção em função da força normal para bolhas e superfície de mica.

\subsubsection{2}

\section{Poucas camadas}

Bolhas também aparecem nas camadas mais finas da mica. Na Figura 4.21a vemos uma imagem de topografia com uma possível monocamada apresentando bolhas. Nota-se que as bolhas são mais dispersas do que as vistas em multicamadas, além de parecerem mais alongadas. A Figura 4.21 apresenta a linha de perfil mostrada na imagem de topografia. A altura entre as camadas foi medida na ordem de $\Delta h \sim 2,5 \mathrm{~nm}$. 

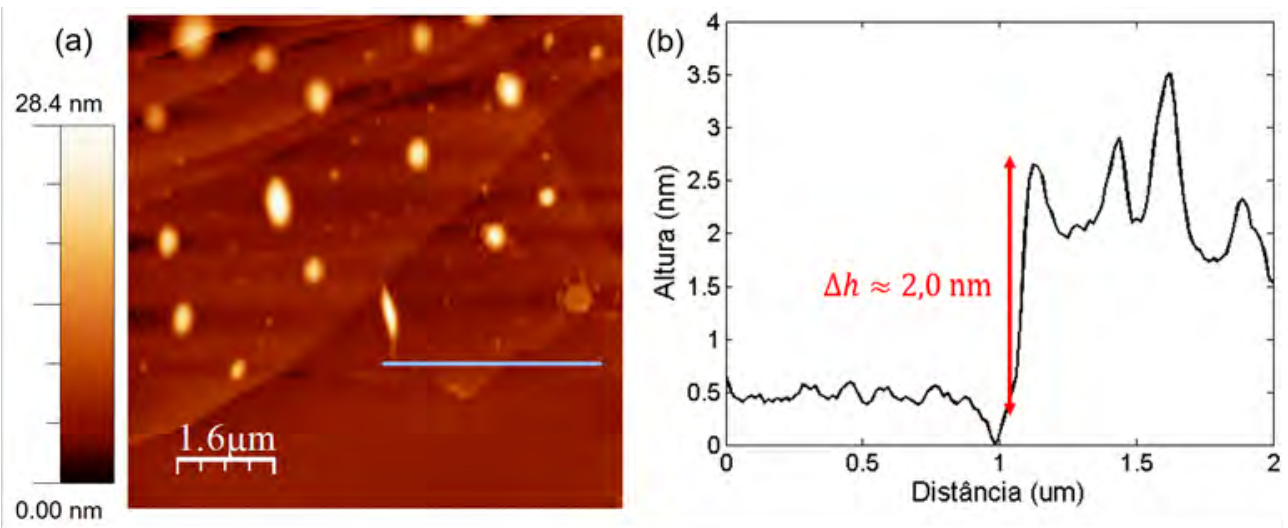

Figura 4.21: (a) Topografia para uma monocamada e poucas camadas adjacentes; (b) Linha de perfil destacada na imagem de topografia.

Uma análise similar a das bolhas em multicamadas foi feita. A altura média dessas bolhas é dada por $h=21,6 \pm 4,2 \mathrm{~nm}$, a área $S=0,11 \pm 0,06 \mathrm{um}^{2}$ e o perímetro $1,24 \pm 0,42 \mu \mathrm{m}$. A Figura 4.22 mostra a altura das bolhas em função da área delas. Nota-se uma menor correlação nesse caso. A linha vermelha é um ajuste linear aos dados. O coeficiente de determinação é dado por $\bar{R}^{2}=0,59$, menor do que o caso das bolhas em multicamada.

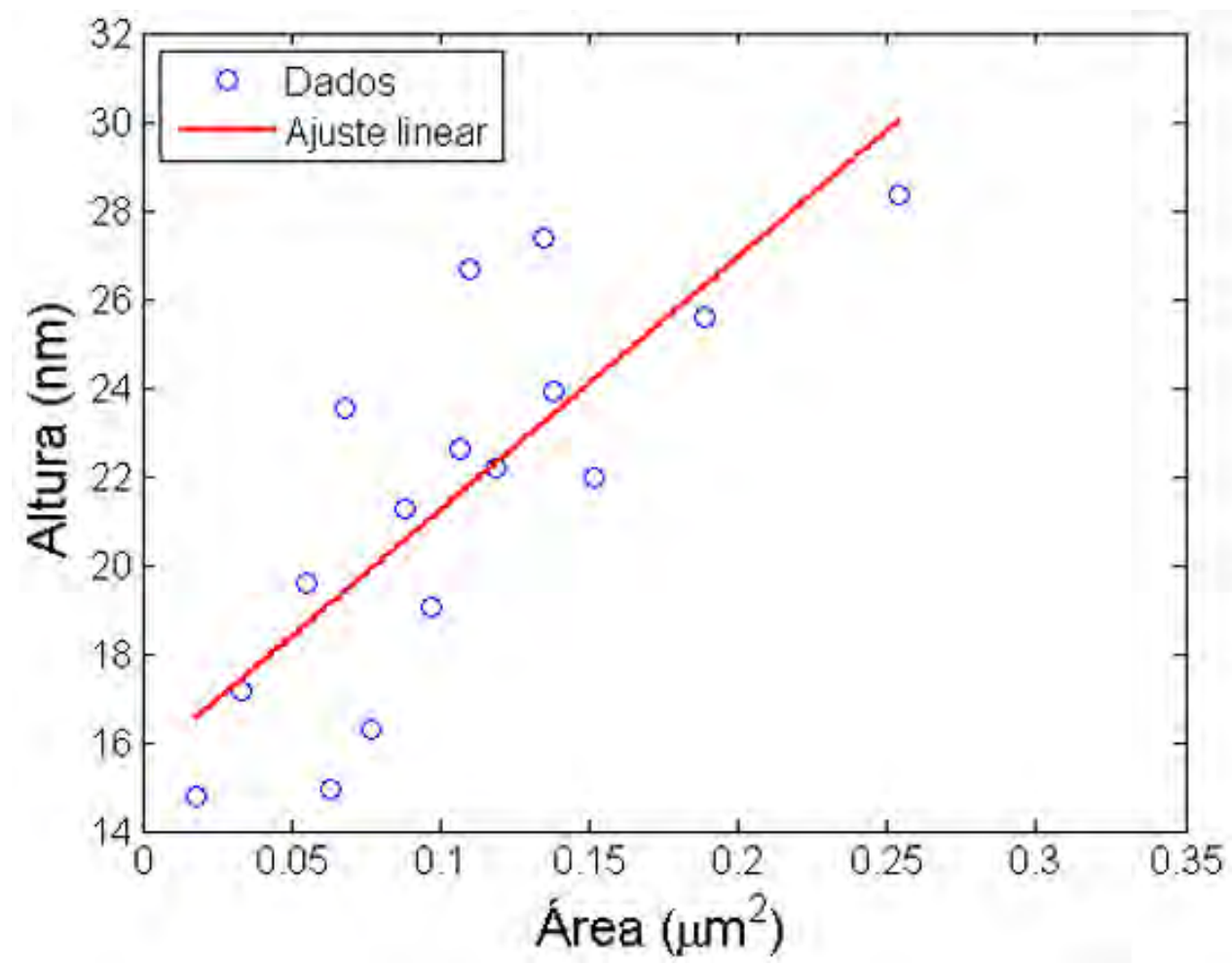

Figura 4.22: Altura das bolhas em poucas camadas em função da área de cada uma. Linha vermelha é um ajuste linear aos dados. $\bar{R}^{2}=0,59$

O mapa de fricção é mostrado na Figura 4.23a. Percebe-se que as bolhas 
em camadas mais finas exibem contraste mais claro, indicando maior atrito. Esse contraste vai se desfazendo à medida em que o número de camadas vai aumentando. Medidas de altura entre camadas indicam que o contraste das bolhas é indistinguível das bolhas a partir da quinta camada. A Figura 4.23b mostra a segmentação das bolhas a partir do mapa de fricção.

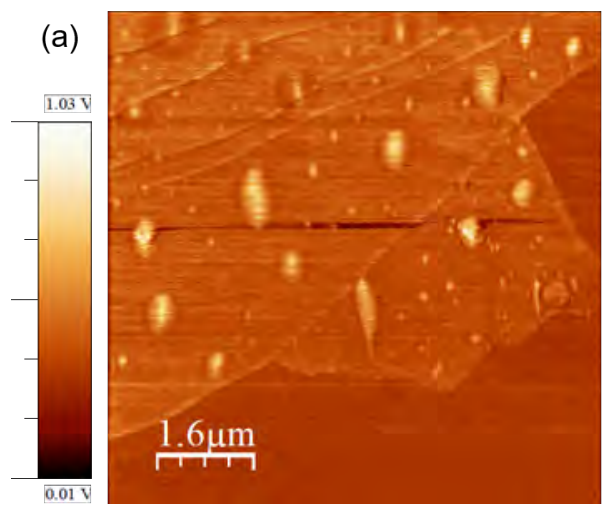

(b)

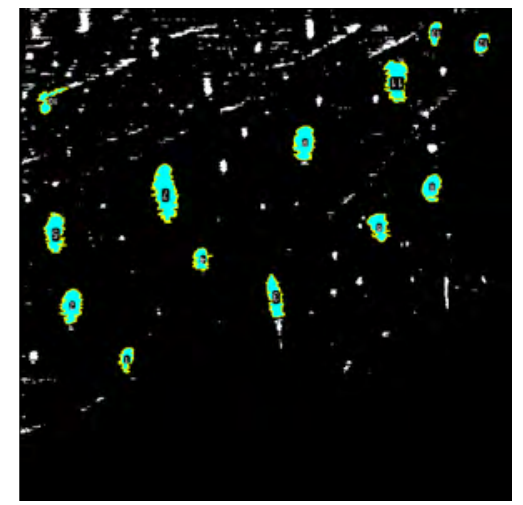

Figura 4.23: (a) Mapa de fricção de poucas camadas de mica; (b) Resultado da segmentação em função da intensidade dos pixels.

Como confirmação de que as bolhas possuem um maior coeficiente de atrito, a Figura 4.24a mostra um histograma de uma área da superfície de mica, sem bolhas, enquanto a Figura 4.24b mostra um histograma da distribuição da força lateral média para cada partícula segmentada, ambos dados em V. A média da área sem bolhas é $f_{L}=0,39 \pm 0,03 \mathrm{~V}$, enquanto cada valor mostrado no histograma das bolhas já supera esse resultado obtido para área contendo apenas mica.
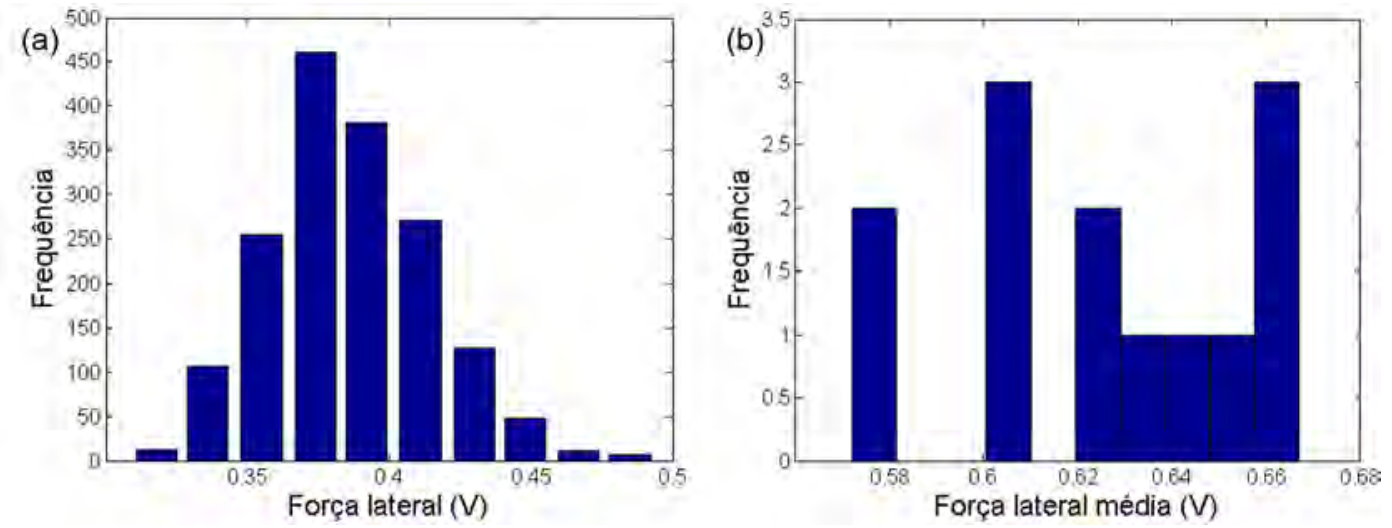

Figura 4.24: (a) Histograma de força lateral para uma área na monocamada de mica sem bolhas; (b) Força lateral média para cada partícula segmentada.

Tentamos estabelecer uma correlação entre força lateral e área das partículas, como visto no gráfico da Figura 4.25, com a força lateral média de 


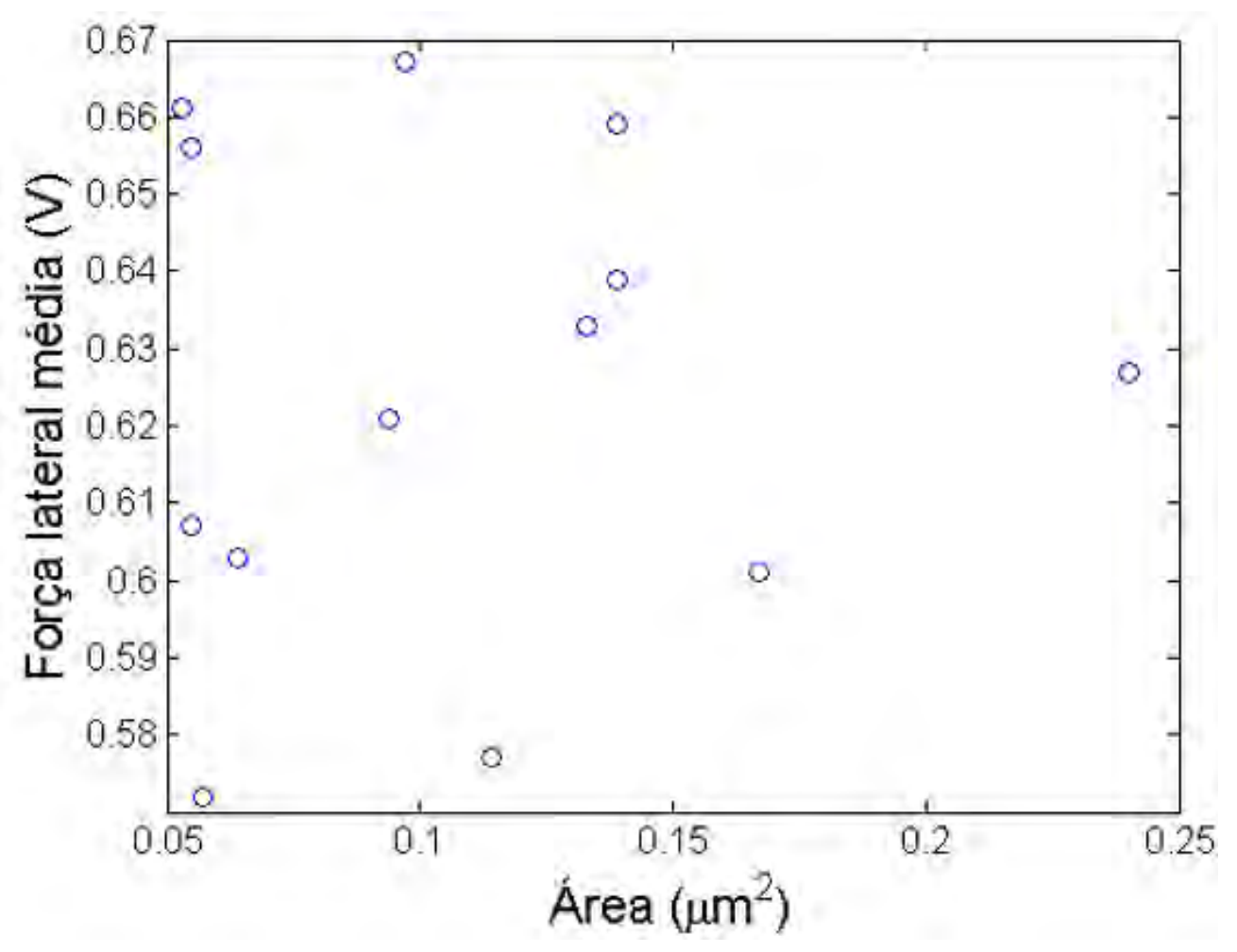

Figura 4.25: Força lateral média em função da área das bolhas.

cada partícula segmentada em função da área estimada de cada uma. Porém, os dados mostram-se dispersos, sem nenhuma correlação aparente.

\section{3}

Discussão

\subsection{1}

\section{Grafeno}

A Figura 4.1 mostra uma micrografia ótica e sua colocalização por AFM. O grafeno é notoriamente um material transparente, com uma transmitância de luz de cerca de $98 \%$, diminuindo com o número de camadas [6]. As camadas de grafeno são identificadas com o uso de microscopia ótica. Para ajudar na identificação, espectros Raman são feitos, como mostrado na Figura 4.2. O espectro mostra uma amostra com poucos defeitos, típico de uma amostra esfoliada, exibindo as bandas $G$ e $2 D$. O pico $2 D\left(\Delta \omega \sim 2700 \mathrm{~cm}^{-1}\right)$ é usado para identificação de camadas. Na monocamada, o pico é mais intenso e com menor largura. Com o aumento do número de camadas, o pico perde intensidade, além de ficar mais largo. Já numa bicamada de grafeno, o pico $2 D$ é composto por quatro outros picos sobrepostos [59].

A altura entre as camadas é medida e exibida na Figura 4.3. Nota-se que a altura entre camadas de grafite é atingida por volta da quarta camada 
de grafeno. Essa irregularidade na altura pode estar associada à presença de camadas de água entre o substrato e a folha de grafeno, assim como entre as camadas de grafeno [60]. Por isso faz-se necessário a combinação de instrumentos como AFM, Raman e microscopia ótica para a determinação do número de camadas.

A Figura 4.4 mostra a tendência da diminuição do atrito com o aumento do número de camadas de grafeno, resultado este bem reportado na literatura [16, 17, 22]. Entretanto, há diferentes explicações para tal fenômeno. T. Filleter e colaboradores compararam amostras de grafeno epitaxial de uma e duas camadas, atribuindo a diferença entre elas pelo acoplamento elétron-fônon, no qual durante o deslizamento da ponta pela superfície, há transferência de energia através de vibrações para a rede do grafeno. A movimentação da rede seria então amortecida pela criação de estados eletrônicos pelo acoplamento $e-f$, o qual é muito maior para uma monocamada [16]. O resultado mais aceito na literatura, porém, é do trabalho de Ch. Lee e colaboradores, o qual atribui à diferença entre as camadas devido às deformações fora do plano sofridas pela rede do grafeno ao deslizar a ponta do microscópio, efeito conhecido como puckering. Este efeito está ligado à interação da superfície de grafeno com o substrato, e ligações mais fracas, como caso de uma monocamada com o substrato, tendem a ter maior deformação [17]. Um modo de se medir tal efeito de puckering é com o uso de mapas de fricção em resolução de rede, verificando os perfil stick-slip. Quando a deformação ocorre, os perfis de força lateral costumam apresentar uma inclinação, e quanto maior a inclinação, maior a deformação. Isto é verificado na Figura 4.7, com uma maior inclinação no perfil de força lateral para a monocamada do que para três camadas. Vale ressaltar também que a presença de água entre camadas mencionadas anteriormente pode contribuir de alguma forma para a dissipação de energia no grafeno.

Contrário ao resultado de Z. Ye e colaboradores, o resultado da Figura 4.5 mostra uma não correlação entre rugosidade e atrito medido em função do número de camadas. No estudo citado, a rugosidade das camadas diminui com o aumento do número de camadas, resultando em menor corrugações topográficas, resultando numa menor área de contato diminuindo o atrito. Porém, para substratos suficientemente lisos $(\sim 0,1 \mathrm{~nm}$, as simulações mostram que há um aumento do número de átomos em contato quanto menor for a camada, aumentando o atrito, tendo as trës camadas rugosidade comparável. Note-se que nosso resultado para o substrato de $\mathrm{SiO}_{2}$ dá uma rugosidade de $\sim 0,14 \mathrm{~nm}$, de ordem comparável ao estudo [22]. Ademais, em estudo comparando grafeno esfoliado com $\mathrm{MoS}_{2}$ esfoliado, M. Vasirisereshk e colaboradores não encontram relação entre a rugosidade das amostras e a diferença no comportamento da 
força de atrito medida, uma vez que a rugosidade de ambas são praticamente iguais, porém com o grafeno apresentando menor atrito [61].

A Figura 4.6 mostra uma comparação entre a força de adesão atrito medido para diferentes camadas de grafeno. O resultado para as forças de adesão é contraintuitivo, uma vez que é esperado que uma monocamada tenha maior adesão com a ponta pela interação com a camada debaixo, no caso o substrato, ser menor do que a mesma interação para as demais camadas. A diferença no resultado pode ser devido à desgaste da ponta durante as varreduras, causando um maior raio e aumentando a área de contato. Entretanto, a não correlação do atrito com a adesão tem embasamento com a literatura. Z. Chen e colaboradores não estabelecem correlação entre os dois ao estudá-los em bordas de interface entre camadas de grafeno [62]. Igualmente, em estudo supracitado de M. Vasirisereshk, mostra tendencias opostas da adesão e fricção em grafeno, $\mathrm{MoS}_{2}$ e $\mathrm{MoS}_{2}$ depoistado em grafeno [61].

A rigidez do contato $k_{\text {eff }}$, calculado por perfis de força lateral em sitckslip, como na Figura 4.8 é indistinguível entre as camadas de grafeno. Como este parâmetro está associado às propriedades elásticas dos materiais, nossos resultados sugerem que a elasticidade dentro-do-plano é razoavelmente a mesma para as diferentes camadas de grafeno. Tal resultado está de acordo com estudos prévios na literatura, os quais mediram propriedades elásticas em grafeno com uma, duas e três camadas. O resultado de Lee e colaboradores [63] mostra que, embora uma bicamada de grafeno precise de forças maiores para ter a mesma deformação que uma monocamada, o módulo elástico das três camadas é o mesmo dentro da faixa de erro do experimento.

\subsection{2} TMDs

Cristais de TMD crescidos por CVD costumam apresentar uma forma triangular. Na Figura 4.9a, vemos um cristal em forma de estrela com seis pontas, o que pode ocorrer pela fusão de dois núcleos de crescimento, formando estruturas de diferentes tipos, formando fronteira de grãos [64, 65]. As Figuras $4.9 \mathrm{~b}$ e d mostram uma amplificação dos cristais, exibindo pequenas estruturas na superfície, podendo ser ou pequenas camadas de $\mathrm{MoS}_{2}$ e $\mathrm{WS}_{2}$, ou resíduoes de $\mathrm{MoO}_{3}$ e $\mathrm{WO}_{3}$. Os espectros Raman mostrados em 4.10a e c estão de acordo com valores típicos de monocamadas para $\mathrm{MoS}_{2}$ e $\mathrm{WS}_{2}$ encontrados na literatura, assim como os espectros $\mathrm{PL}[50,66]$. A altura medida na Figura 4.11 em $\Delta h \sim 1,0 \mathrm{~nm}$ é um pouco maior do que o comumente reportado na literatura, em torno de $\Delta h \sim 0,7 \mathrm{~nm}$ [50]. Acreditamos que essa diferença se dê pela dificuldade de tratamento das imagens. Devido ao 
material acumulado na borda dos cristais, não foi possível fazer o método do histograma mencionado na seção 4.1, pois os picos nas distribuições de alturas ficavam indistinguíveis. Foi feito então um tratamento de planificação geral da imagem, subtraindo cada pixel por um polinômio de segunda ordem. A hipótese de que os cristais são de fato monocamadas é corroborada pelos espectros Raman e PL. O material acumulado nas bordas dos cristais, como vistos nas imagens de topografia se devem à oxidação e adsorção de moléculas orgânicas contaminantes pela exposição ao ar [67]. A exposição prolongada ao ar provoca uma diminuição na quantidade de enxofre na rede dos cristais [67], sendo substituídos por átomos de oxigênio [68]. J. C. Kotsakidis e colaboradores mostra que esse processo de oxidação é intensificado pela incidência de luz nos materiais [69].

Na Figura 4.12 vemos uma comparação das topografias dos TMDs com os mapas de fricção. Os objetos espalhados nas superfícies dos cristais apresentam um contraste mais claro nos mapas de fricção, indicando maior atrito. Considerando que a fricção em TMDs pode ter a mesma dependência com camadas que o grafeno, isto é, diminuindo com o aumento de camadas [17], este resultado indica que tais objetos são, na verdade, resíduos dos óxidos usados no crescimento. Entretanto, a forma triangular vista na Figura 4.12d sugere se tratar de outras camadas de TMDs.

Dos perfis stick-slip de força lateral exibidos em 4.13b e d não mostra uma inclinação clara de $f_{L}$ com o deslocamento, sugerindo que há pouca deformação nos materiais. Percebe-se que o loop de fricção para o $\mathrm{WS}_{2}$ é consideravelmente maior que para o $\mathrm{MoS}_{2}$, resultando em maior dissipação de energia e maior coeficiente de atrito. A diferença nos loops de fricção talvez possa ser explicada pela orientação das amostras. Dienwiebel e colabores, assim como C. M. Almeida e colabores mostram uma dependência do atrito em grafite e grafeno, respectivamente, com a orientação relativa entre ponta e superfície, particularmente com maior dissipação de energia ao longo da direção armchair $[24,70]$. Em nosso caso, ambas medidas foram feitas em diferentes orientações, o que compromete o resultado e, infelizmente, por problemas operacionais, não foi possível variar a orientação das amostras ${ }^{1}$.

\footnotetext{
${ }^{1}$ Para medir o atrito em função da orientação da amostra, temos de mudar a posição da amostra na cerâmica piezoelétrica do microscópio. Os loops de fricção em stick-slip são obtidos apenas com o modelo MultiMode (Bruker). Devido à calibração antiga feita no $\mathrm{AFM}$, os parafusos nunca voltaram à sua posição original, de modo que a área de varredura é limitada, não percorrendo toda área da cerâmica piezoelétrica e, ao mudar a amostra de orientação, o local dos triângulos não eram mais alcançáveis pela ponta.
} 


\subsection{3 \\ Mica}

Fica claro pelas Figuras 4.15 e 4.21 que há presença de bolhas na superfície da mica esfoliada. A formação destas é discutida por D. Hull, atribuindo-a à defeitos mecânicos microscópicos causados pela clivagem da superfície. Segundo o autor, as bolhas se formam por defeitos não restaurados, o que causaria um preenchimento de ar na área deformada, gerando bolhas sob a superfície de mica [71]. Em estudo recente, D. A. Sanchez e colaboradores investigam a formação de bolhas em materiais atomicamente finos como grafeno e $\mathrm{MoS}_{2}$ transferidos para diferentes substratos, tanto em processo de esfoliação como em sínteses por CVD. Tal estudo observa o comportamento de bolhas na superfície dos materiais ao longo de três meses, notando uma deflação de $20 \%$ à $30 \%$ em tamanho e área com o passar do tempo, sugerindo que o conteúdo destas é líquido, provavelmente camadas de água [72]. Corroborando com a hipótese da presença de líquido dentro das bolhas, P. Cao e colaboradores notam uma diminuição na densidade de formação de bolhas em grafeno esfoliado em ambientes com menor umidade relativa do ar [73]; e F. Pizzochero e colaboradores mostram superfícies de heteroestruturas 2D sem bolhas com transferências feitas em temperaturas superiores à $T>110^{\circ} \mathrm{C}$ [74].

Por nossas medidas, é fácil perceber uma mudança de comportamento das bolhas de acordo com a espessura, ou a quantidade de camadas, na superfície de mica. Em poucas camadas, as bolhas mostram-se maiores e mais alongadas, chegando à formas elípticas, como altura máxima em dezenas de nanometros, enquanto em muitas camadas, as bolhas são pequenas, com poucos nanometros de altura, na ordem de $h \sim 2,0 \mathrm{~nm}$. A diferença é também confirmada pela circularidade, sendo 0,83 $\pm 0,12$ para poucas camadas, e 0,87 $\pm 0,01$ em muitas camadas. Neste parâmetro, quanto mais próximo de 1,0, mais circular é a partícula. O erro uma ordem de magnitude maior para poucas camadas é explicado pela alteração da forma à medida em que a espessura da amostra aumenta, de modo que as bolhas tornam-se menos elípticas. Há uma correlação levemente superior entre altura das bolhas e a área de cada uma para o caso de muitas camadas, porém, em ambos os casos, a tendência é maior altura quanto maior a área.

O comportamento tribológico, entretanto, mostra-se bastante distinto nos dois casos. vale ressaltar que não há na literatura, ao menos não em nosso conhecimento, qualquer relato sobre medições de atrito nessas estruturas formadas, independentemente do tipo de material atomicamente fino. Enquanto em poucas camadas as medidas mostram uma fricção maior nas bolhas do que na superfície de mica, para muitas camadas esta tendência se inverte, com 
as bolhas tendo menor coeficiente de fricção do que a superfície de mica. De fato, já na Figura 4.23a é possível ver que as bolhas passam a ter o mesmo contraste da mica por volta da quinta camada, indicando um coeficiente de atrito praticamente indistinguível. Note, por exemplo, que as bolhas da parte superior da imagem sequer são segmentadas (Fig. 4.23b), pois este processo se dá pela intensidade dos pixeis. Nossa hipótese é que, de fato, as bolhas contém líquido, provavelmente camadas de água numa estrutura tipo gelo, e há uma dinâmica dessas camadas d'água entre as camadas de mica. A água e, consequentemente, as bolhas, podem terem sido incorporadas na mica pela longa exposição da superfície num ambiente de alta umidade como é o nosso laboratório, com a umidade relativa do ar em cerca de 60\%. Esse contraste é confirmado na Figura 4.24, em que o atrito numa região da superfície de mica se mediu $f_{L} \sim 0,4 \mathrm{~V}$, enquanto o resultado da segmentação mostram forças laterais médias superiores, com $f_{L}>0,6 \mathrm{~V}$. O que vemos na Figura 4.23a provavelmente são bolhas entre camadas de mica cobertas pela camada superior. A estrutura de água tipo gelo em camadas de mica em umidades relativas superiores à $20 \%$ foi mostrada por Miranda e colaboradores, com o uso de microscopia de força atômica por polarização e microscopia por geração de soma de frequências [75]. Já S. de Beer e colaboradores mostram que água confinada entre duas camadas de mica podem ser distribuídas em gotas pela superfície caso haja compressão das camadas de forma abrupta, como pode ocorrer no processo de esfoliação e transferência para o substrato [76]. Já em muitas camadas, as bolhas apresentam fricção menor que a superfície de mica. O gráfico de força lateral por força normal na Figura 4.20 mostra que ambos seguem a mesma tendência, o que indica que as bolhas não são deformadas durante a varredura da ponta.

\section{4}

\section{Conclusões}

Neste capítulos exibimos uma breve caracterização das superfícies analisadas. Vimos que uma monocamada de grafeno tem uma altura relativa ao substrato de $\Delta h \sim 1,0 \mathrm{~nm}$, o que indica uma provavelmente adosrção de água entre as folha e o substrato. Medindo as alturas relativas entre camadas, concluímos que as camadas atingem a distância interplanar do grafite em cerca de cinco camadas. O espectro Raman mostra uma superfície limpa com poucos defeitos. O atrito no grafeno varia de acordo com o número de camadas, diminuindo com o aumento do número de camadas, o que se deve à deformação fora do plano da superfície de grafeno, aumentando a área de contato e consequentemente o atrito. Essa deformação é maior numa monocamada de- 
vido à fraca interação com o substrato. Não obtivemos correlação entre atrito e rugosidade das superfícies, tampouco entre atrito e adesão ponta-superfície para diferentes camadas.

Os cristais de TMDs apresentam formas triangulares, e, no caso do $\mathrm{MoS}_{2}$, foi observada também a formação de estruturas policristalinas oriundas da fusão de dois núcleos de crescimento, resultando em diferentes formas, como uma estrela de seis pontas. A superfície é oxidada, o que provoca um acúmulo de material nas bordas dos cristais. Outras estruturas são espalhadas ao longo da superfície dos cristais, podendo ser resíduos do óxido utilizado no crescimento ou pequenas camadas adicionais. Na medição de atrito, o $\mathrm{WS}_{2}$ mostra uma maior dissipação de energia, conclamando em maior coeficiente de atrito.

Já a mica apresenta bolhas em sua superfície, tanto para folhas com muitas camadas como em folhas de poucas camadas. Essas bolhas provavelmente são formadas por estruturas de água tipo gelo, confinada entre camadas da mica. O comportamento tribológico muda de acordo com a espessura da amostra, sendo as bolhas em poucas camadas apresentando maior atrito que a superfície de mica. Esta relação é invertida à medida em que o número de camadas aumentam, não havendo distinção no atrito medido entre bolhas e mica em cerca de cinco camadas. Em regiões com muitas camadas $(N>10$, onde $N$ é o número de camadas), as bolhas apresentam menor atrito que a mica. A curva de friç̧ão por força normal em muitas camadas mostra um mesmo comportamento tanto para bolha quanto para a mica. 


\section{5}

\section{Mecânica de contato em materiais atomicamente finos}

Neste capítulo será abordada a mecânica de contato em materiais atomicamente finos. O estudo é feito medindo o atrito em função da força normal aplicada à superfície. Veremos como dois modelos diferentes são aplicados, a mecânica de Johnson-Roberts-Kendall para o grafeno e o $\mathrm{MoS}_{2}$, e a mecânica de Derjaguin-Muller-Toporov para o $\mathrm{WS}_{2}$ e a mica. Uma hipótese é estipulada para tentar entender por quê dois materiais tão similares como os dois TMDs analisados apresentam uma mecânica diferente.

\section{1}

\section{Metodologia}

Neste capítulo, são analisadas amostras de grafeno em substratos de $\mathrm{SiO}_{2}$, obtidas por esfoliação mecânica; TMDs crescidos diretamente em substratos de $\mathrm{SiO}_{2}$ por CVD; e folhas de mica mecanicamente esfoliadas em substratos de $\mathrm{SiO}_{2}$. As regiões de interesse são identificadas por microscopia ótica e então levadas ao AFM para realização dos experimentos.

Imagens de fricção e topografia são simultaneamente adquiridas num AFM MultiMode (Bruker), em varreduras de $300 \mathrm{~nm} \times 300 \mathrm{~nm}$, com velocidade de $v=1,0 \mathrm{\mu m} \mathrm{s}^{-1}$. Pontas triangulares de $\mathrm{Si}_{3} \mathrm{~N}_{4}$, modelo DNP-10(Bruker), cantiléver A, com $k_{n}=0,4 \pm 0,1 \mathrm{~N} \mathrm{~m}^{-1}$ e $k_{\varphi}=86 \pm 4 \mathrm{~N} \mathrm{~m}^{-1}$, raio nominal $R=20 \mathrm{~nm}$ foram utilizadas. As constantes foram calculadas de acordo com parâmetros geométricos dos cantilévers. A direção de varredura foi mantida perpendicular ao eixo principal do cantiléver.

A variação de força aplicada se dá pela variação do setpoint no microscópio. Todas as medidas foram feitas em temperatura ambiente, $T \sim 25^{\circ} \mathrm{C}$, e umidade relativa de $R H \sim 60 \%$. Os dados experimentais foram ajustados de acordo com as equações (2-12) e (2-11), em dois métodos diferentes: primeiro usando apenas o coeficiente de atrito não linear $\tilde{\mu}$ como parâmetro livre, fixando a força de adesão $F_{\text {ad }}$ de acordo com o resultado experimental. O segundo ajuste é feito com ambos $\tilde{\mu}$ e $F_{\text {ad }}$ como parâmetros livres. Os ajustes foram feitos usando o software comercial Matlab [77], usando a função nlinfit [78]. 


\section{2 \\ Resultados}

A Figura 5.1a mostra a curva de fricção por força normal aplicada para os quatro diferentes materiais em análise, grafeno (círculos pretos), $\mathrm{MoS}_{2}$ (losangos azuis), $\mathrm{WS}_{2}$ (quadrados vermelhos) e mica (triângulos verdes). Notase claramente que a mica possui um coeficiente de atrito muito maior que os demais materiais. Para melhor análise, separamos as curvas $f_{L} \times F_{k}$ sem a mica, mostrado na Figura 5.1b. É possível notar que o $\mathrm{WS}_{2}$, além de apresentar maior fricção que o grafeno e o $\mathrm{MoS}_{2}$, tem um aumento mais íngreme com o aumento da força normal, o que faz com que seus dados sejam melhores ajustados por modelos diferentes. As linhas sólidas na Figura representam o ajuste pelo modelo JKR, via eq. (2-12), e as linhas pontilhadas o ajuste pelo modelo DMT, por meio da eq. (2-11). Em ambos casos, foram usados o coeficiente não linear de atrito $\tilde{\mu}$ e a força de adesão $F_{\text {ad }}$ como parâmetros livres.
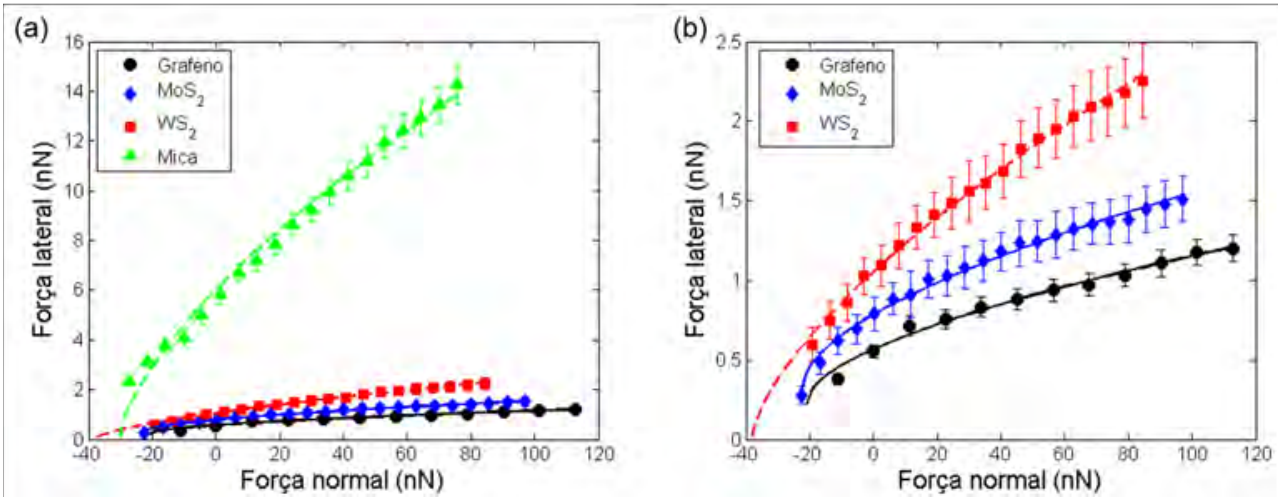

Figura 5.1: Curvas das medidas de força lateral em função da força normal aplicada pela ponta $F_{k}$. (a) Curva para os quatro materiais; (b) Curvas sem a mica para evidenciar os demais. Linhas sólidas mostram o ajuste pelo modelo JKR, e as linhas pontilhadas pelo modelo DMT.

O resultado dos ajustes, junto de outros parâmetro, como força de adesão medida experimentalmente $F_{\text {ad }}^{\exp }$, energia da adesão $\Delta \gamma$, o módulo elástico $E$ e a resistência ao cisalhamento $\tau$ é mostrado na Tabela 5.1. Os parâmetros $\Delta \gamma$ e $\tau$ foram calculados a partir das eqs. (2-6) e (2-8), e (2-13), respectivamente. Para o cálculo de $\Delta \gamma$, foi usado o raio $R$ nominal da ponta, de $R=20 \mathrm{~nm}$. Para o cálculo de $\tau$, foram usados os módulos elásticos $E^{\text {grafeno }}=1025 \pm 35 \mathrm{GPa}$ para o grafeno, $E^{\mathrm{MoS}_{2}}=264 \pm 13 \mathrm{GPa}$ para o $\mathrm{MoS}_{2}, E^{\mathrm{WS}_{2}}=272 \pm 18 \mathrm{GPa}$ para o $\mathrm{WS}_{2}$ [79], e $E^{\text {mica }}=202 \pm 22 \mathrm{GPa}$ para a mica [80].

Na Tabela 5.2 temos uma comparação as forças de adesão medidas experimentalmente, por curvas força-distância, com os resultados dos ajustes para 


\begin{tabular}{|ccccc|}
\hline \hline Material & $F_{\text {ad }}(\mathrm{nN})$ & $\tilde{\mu}\left(\times 10^{-3} \mathrm{nN}^{1 / 3}\right)$ & $\Delta \gamma\left(\mathrm{mJ} / \mathrm{m}^{2}\right)$ & $\tau(\mathrm{MPa})$ \\
\hline \hline Grafeno & $20,8 \pm 3,9$ & $2,9 \pm 2,0$ & $221 \pm 41$ & $73,1 \pm 4,9$ \\
$\mathrm{MoS}_{2}$ & $22,4 \pm 0,5$ & $3,9 \pm 0,5$ & $237 \pm 5$ & $96,2 \pm 1,2$ \\
$\mathrm{WS}_{2}$ & $38,2 \pm 2,2$ & $9,3 \pm 1,8$ & $304 \pm 18$ & $228 \pm 4$ \\
Mica & $30,2 \pm 2,4$ & $62 \pm 17$ & $241 \pm 19$ & $1522 \pm 42$ \\
\hline \hline
\end{tabular}

Tabela 5.1: Parâmetros obtidos através dos ajustes dos modelos JKR (grafeno e $\mathrm{MoS}_{2}$ ) e DMT (WSS 2 e mica). $F_{\text {ad }}$ e $\tilde{\mu}$ foram usados como parâmetros livres no ajuste. Energia livre de superfície $\Delta \gamma$ calculada pela relação com a força de adesão. Tensão de cisalhamento calculada com o coeficiente de atrito não linear.

\begin{tabular}{|cccc|}
\hline \hline Material & $F_{\text {ad }}^{\text {exp }}(\mathrm{nN})$ & $F_{\text {ad }}^{\text {JKR }}(\mathrm{nN})$ & $F_{\text {ad }}^{\text {DMT }}(\mathrm{nN})$ \\
\hline \hline Grafeno & $15,0 \pm 1,5$ & $20,8 \pm 3,9$ & $55,4 \pm 12,3$ \\
$\mathrm{MoS}_{2}$ & $26,4 \pm 0,6$ & $22,4 \pm 0,5$ & $50,7 \pm 17,3$ \\
$\mathrm{WS}_{2}$ & $42,0 \pm 1,5$ & $19,5 \pm 0,8$ & $38,2 \pm 2,2$ \\
Mica & $37,6 \pm 0,3$ & $16,2 \pm 2,8$ & $30,2 \pm 2,4$ \\
\hline \hline
\end{tabular}

Tabela 5.2: Comparação da força de adesão medida experimentalmente por curvas força-distância com os resultados dos ajustes.

os dois modelos. A força de adesão mais próxima da medida experimentalmente foi usada como critério para a utilização de um determinado modelo.

Para efeito de comparação, a Figura 5.2 mostra histogramas de distribuição de forças laterais para uma dada força normal para as amostras de $\mathrm{MoS}_{2}$ e $\mathrm{WS}_{2}$. Percebe-se de fato uma maior média para o $\mathrm{WS}_{2}$, com um pico mais largo.

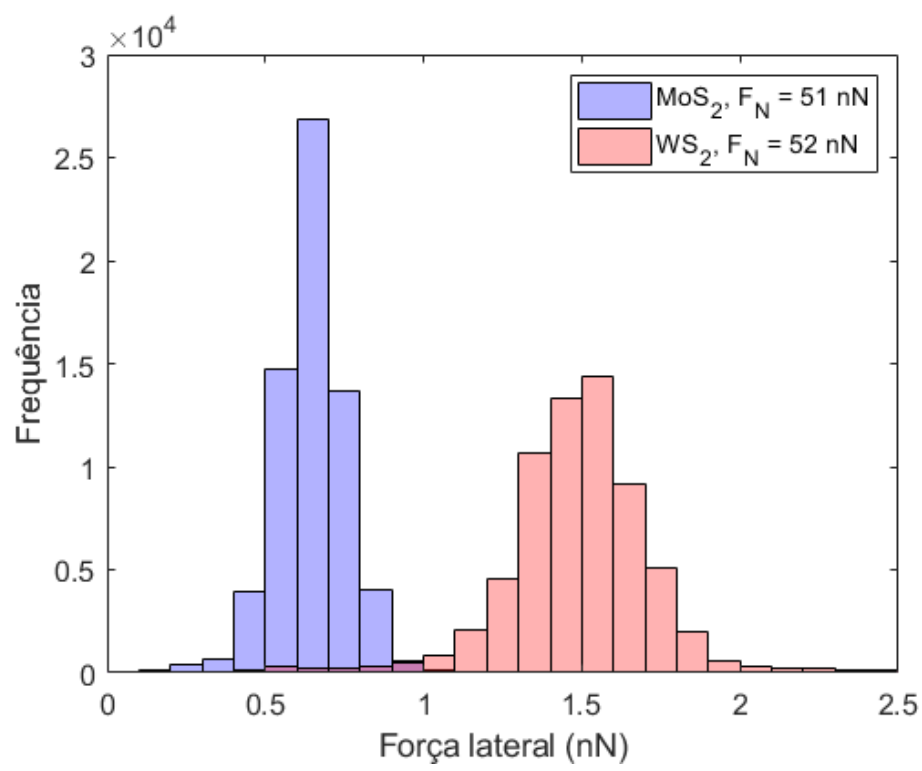

Figura 5.2: Histograma de forças laterais para $\mathrm{MoS}_{2}$ e $\mathrm{WS}_{2}$ em forças normais similares. 
Uma vez que a fricção pode ser influênciada pela rugosidade, esta foi então medida para os quatro diferentes materiais. A Figura 5.3a mostra uma imagem topográfica em 3D do grafeno, enquanto a Figura 5.3 mostra um histograma de distribuição de alturas da mesma área. As rugosidades quantificadas, com seus respectivos erros são mostradas na Figura 5.3c. Percebe-se que o grafeno apresenta menor rugosidade e menor variação, enquanto a rugosidade dos outros três materiais são similares e indistinguíveis dentro do erro.

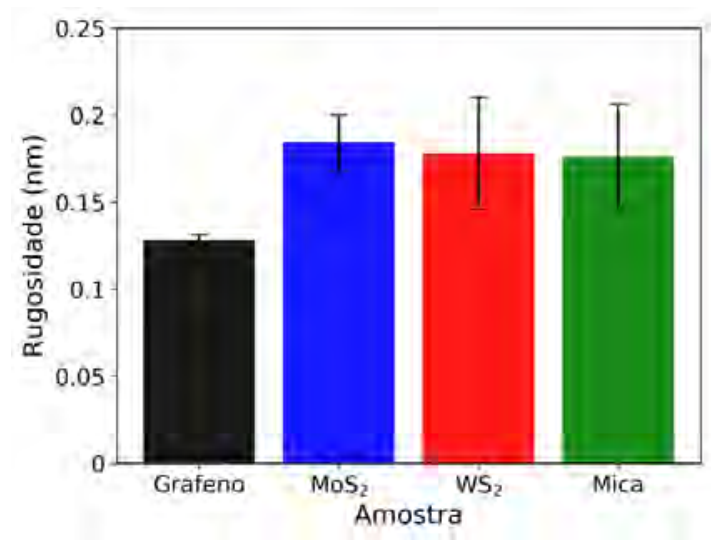

Figura 5.3: Rugosidade RMS média para os materiais estudados.

\section{3 \\ Discussão}

\subsection{1}

\section{Grafeno}

No caso do grafeno, a literatura sobre o comportamento da fricção com a força normal é um tanto quanto controversa. Um ponto em comum, porém, se trata da adesão com o substrato e a deformação sofrida pela folha de grafeno durante o deslizamento da ponta. Em ensaios microscópicos, com forças da ordem de $\mathrm{mN}$, K.-S. Kim e colaboradores compararam três tipos de amostras diferentes de grafeno crescidas por CVD diferentes: usando cobre como catalisador e então transferindo para um substrato de $\mathrm{SiO}_{2}$; usando níquel como catalisador e transferindo para $\mathrm{SiO}_{2}$; e grafeno em substrato de níquel, sem transferência. O menor coeficiente de atrito foi medida na amostra de grafeno em níquel, e o maior na amostra crescida em cobre. A diferença entre elas foi atribuída à uma maior adesão do grafeno aos substratos pelo grafeno crescido em níquel [81].

Igualmente, em estudo publicado por S. Kwon e colaboradores, amostras de grafeno limpo são comparadas como grafeno fluorinado, tendo este último o atrito aumentado em até seis vezes em comparação ao primeiro. A diferença 
é atribuída à um aumento na energia de dobramento provocada pela incorporação de flúor na rede do grafeno [82].

Apesar de vasta quantidade de trabalhos publicados, poucos trabalhos discutem sobre o regime de contato. De fato, há controvérsias nos resultados relatados na literatura. Alguns apresentam uma relação linear do atrito com a força normal, como em Filleter e colaboradores [16], os quais mediram para grafeno epitaxial crescido em carbeto de silício, com forças de ordem até $200 \mathrm{nN}$; e Smolyanitsky e colabores [43], em simulação computacional por dinâmica browniana, em faixas de forças menores, em da ordem de $\sim 20 \mathrm{nN}$.

Nosso resultado com o ajuste JKR obtendo melhor resultado é corroborado com o trabalho $\mathrm{Z}$. Deng e colaboradores, os quais também mediram grafeno mecanicamente esfoliado em substrato de $\mathrm{SiO}_{2}$ [83]. O trabalho da adesão obtido é razoavelmente similar ao nosso, com $\Delta \gamma^{\text {Deng }}=340,00 \pm 0,60 \mathrm{~mJ} \mathrm{~m}^{-2}$. A resistência ao cisalhamento é cerca de três vezes menor do que a calculada nesta tese, com $\tau^{\text {Deng }}=23,6 \pm 2,3 \mathrm{MPa}$. Supondo um raio da ponta parecido, a diferença principal pode estar nos valores usados para o módulo elástico do grafeno, onde Deng e colaboradores utilizaram o mesmo módulo do substrato de $\mathrm{SiO}_{2}, E^{\mathrm{SiO}_{2}}=70 \mathrm{GPa}$.

Em contrapartida, B.-C. Tran-Khac e colaboradores obtiveram um comportamento seguindo o modelo DMT, com uma resistência ao cisalhamento de $\tau^{\mathrm{TK}}=50,5 \pm 1,0 \mathrm{MPa}$, cerca de 1,4 vezes menor que nosso resultado [41]. As diferenças entre os resultados se devem, novamente, à diferentes módulos elásticos utilizados, além de condições experimentais diferentes. O experimento no trabalho citado foi realizado com pontas de diamante, de forma que o contato ponta-superfície pode ser diferente do observado em nossos experimentos.

Ademais, os valores obtidos para a força de adesão pelo ajuste DMT aos dados do grafeno mostram que o modelo JKR se ajusta melhor ao nosso caso. Com o ajuste pelo modelo DMT, obtemos $F_{\text {ad }} \approx 55 \mathrm{nN}$, um valor muito acima do medido experimentalmente (Tabela 5.2). Vale ressaltar que o modelo JKR é associado à maiores deformações da superfície, tal qual vista no loop de fricção apresentado na Figura 4.7, no Capítulo 4. De fato, o modelo JKR é utilizado, por exemplo, em experimentos de nanoindentação em materiais mais macios, com menor módulo elástico, como polímeros e materiais biológicos [84, 85].

\subsection{2}

\section{Comparação entre os TMDs}

A Figura 5.1b mostra um diferente comportamento para os dois TMDs, e uma comparação no histograma de forças laterais é mostrada na Figura 5.2. A amostra de $\mathrm{WS}_{2}$ mostra um crescimento mais abrupto com a força normal 


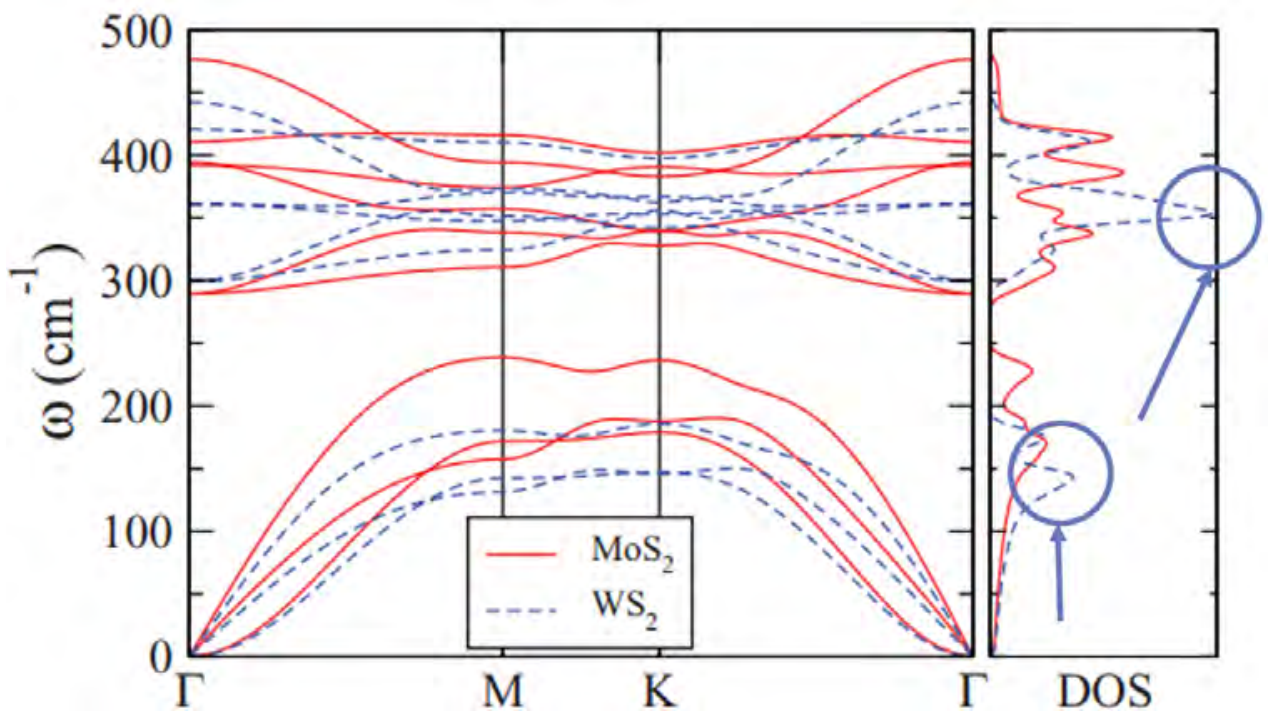

Figura 5.4: Espectro de fônons para monocamadas de $\mathrm{MoS}_{2}$ (linhas sólidas em vermelho) e $\mathrm{WS}_{2}$ (linhas pontilhadas em azul). Os picos para o $\mathrm{WS}_{2}$ na densidade de estados são identificados pelas setas azuis. Figura adaptada da Referência [86].

e, enquanto o $\mathrm{MoS}_{2}$ se adequa mais ao modelo JKR, com uma resistência ao cisalhamento de $\tau=96,2 \pm 1,2 \mathrm{MPa}$, o $\mathrm{WS}_{2}$ se ajusta ao modelo DMT, com $\tau=228 \pm 4 \mathrm{MPa}$, até 2,4 vezes maior que o valor obtido para o $\mathrm{MoS}_{2}$. O valor de $\tau$ para o $\mathrm{MoS}_{2}$ é razoavelmente similar ao obtido B.-C. Tran-Khac e colaboradores [41]. Tal resultado é intrigante, uma vez que os dois materiais são similares. O espectro de fônons dos dois, por exemplo, são muito parecidos, com ambos tendo os mesmos modos de vibração. Diferenças nesses modos ocorrem principalmente pela maior massa dos átomos de $\mathrm{W}$, diminuindo a frequência de vibração das moléculas. Entretanto, o $\mathrm{WS}_{2}$ apresenta em sua curva de densidade de estados picos acentuados em $\omega \approx 150 \mathrm{~cm}^{-1}$ e $\omega \approx 350 \mathrm{~cm}^{-1}$, os quais não aparecem no espectro de $\mathrm{MoS}_{2}$, como visto na Figura 5.4 [86]. Uma hipótese a ser estudada, portanto, é se durante a varredura da ponta, este modo pode estar sendo excitado, gerando maior dissipação de energia, contribuindo para um maior atrito.

A adesão ao substrato e a rugosidade também podem ser importantes, assim como o nível de tensão na superfície. A Figura 5.3 mostra que a rugosidade dos dois materiais é similar, praticamente indistinguível dentro do erro estatístico, de modo que este não é o fator contribuinte para a diferença entre os dois. Resultados na literatura mostram que amostras de TMDs crescidas por CVD em $\mathrm{SiO}_{2}$ ficam tensionadas. Ao serem transferidas para outros substratos, a tensão é relaxada provocando mudanças tanto no gap de energia como nas ressonâncias no espectro Raman [87, 88]. Seguindo esses passos, a deformação estimada para o $\mathrm{MoS}_{2}$ é de 1,3\% [87], e de 0,25\% para o 
$\mathrm{WS}_{2}[88]$.

Outra hipótese relevante a ser considerada envolve o efeito piezoelétrico. As estruturas bidimensionais de TMDs podem apresentar piezoeletricidade intrínseca devido à quebra de simetria de inversão [89]. Ademais, estudos recentes tentam correlacionar a fricção com propriedades elétricas desses materiais atomicamente finos. F. Lavini e colaboradores mostra que para filmes policristalinos de $\mathrm{MoS}_{2}$, o atrito é maior para números ímpares de camadas, enquanto para números pares o efeito piezoelétrico não ocorre [90]. Já J. Peng e colaboradores conseguem uma modulação no coeficiente de atrito por aplicação de campo elétrico em cristais de $\mathrm{MoSe}_{2}$ [91]; e F. He e colaboradores obtém uma redução de $\sim 30 \%$ no coeficiente de atrito pela aplicação de um potencial ao longo do plano para diferentes materiais 2D, como $\mathrm{MoS}_{2}$ e h-BN [92]. As constantes piezoelétricas seguem uma tendência com a tabela periódica, sendo maior para compostos com átomos de Mo em relação à W, e também maior a medida em que se desce a coluna dos calcogenetos na tabela [93]. Sendo assim, as contantes piezoelétricas $d_{11}$ e $e_{11}$ são maiores para o $\mathrm{MoS}_{2}$ do que para o $\mathrm{WS}_{2}[93,94]$, o que efetivamente significa que é preciso uma maior quantidade de carga elétrica para deslocar os átomos no $\mathrm{MoS}_{2}$ de uma mesma quantidade. Nossa hipótese é que a tnsão aplicada pela ponta provoca uma perturbação na rede dos materiais, desformando a superfície, gerando uma polarização, a qual contribui para o potencial e para o mecanismo de fricção.

Ademais, hipóteses como a direção de varredura, o efeito puckering ou mesmo a degradação das amostras por oxidação. É sabido que a orientação cristalográfica influência na medição do atrito em materiais $2 \mathrm{D}$, com a direção armchair (AC) provocando maior dissipação de energia que a direção zigzag (ZZ) [24]. Como discutido anteriormente, infelizmente não foi possível variar a orientação cristalográfica das amostras analisadas. Porém, pelas imagens de resolução de rede obtidas para os TMDs, como na Figura 4.13, vemos que o $\mathrm{MoS}_{2}$ está mais próximo da direção $\mathrm{ZZ}$, enquanto o $\mathrm{WS}_{2}$ está próximo à direção AC. Sendo assim, também é possível que o efeito de puckering, isto é, a deformação do material durante o movimento da ponta, formando uma onda, seja maior para o $\mathrm{WS}_{2}$ devido à orientação com a qual foi feita. De fato, na Figura 4.13d é possível ver uma leve inclinação no loop de fricção no perfil stick-slip do $\mathrm{WS}_{2}$, e a ausência do mesmo na Figura 4.13b para o $\mathrm{MoS}_{2}$.

Quanto à degradação, esta ocorre pela oxidação das amostras. Uma comparação quanto à propriedades físicas e morfológicas para ambos estes materiais foi feita por J. Gao e colaboradores, onde notou-se que o $\mathrm{WS}_{2}$ sofre uma deterioração maior em relação à oxidação por exposição ao ambiente de laboratório, tendo uma maior atenuação nos picos característicos de fotoluminescên- 
cia e uma superfície mais defeituosa [67]. Essa maior degradação do $\mathrm{WS}_{2}$ em relação ao $\mathrm{MoS}_{2}$ também pode ser uma razão da diferença no comportamento tribológico entre os dois materiais.

\subsection{3}

Mica

A Figura 5.1a mostra como a mica se ddiferencia dos outros materiais, mostrando forças de atrito até $\sim 7$ vezes maior que os outros. Apesar de muito usada em ensaios tribológicos, resultados na literatura sobre a mica em geral descrevem-na em sua forma volumétrica. J. Hu e colaboradores mostram dados de fricção em mica volumétrica seguindo uma dependência com a força normal de $f_{L} \propto F_{k}^{1 / 2}$, o que é condizente com o modelo DMT para pontas cônicas [95].

A Figura 5.3 mostra a mica com rugosidade similar à dos outros materiais, logo, descartando tal parâmetro como influente na comparação entre os materiais. A. Castellanos-Gomez e colaboradores mostra que poucas camadas mica suspensas são suscetíveis à deformações pela força aplicada pela ponta de um AFM. Foi calculado um módulo elástico $E=202 \pm 22 \mathrm{GPa}$, compatível com outros materiais atomicamente finos, como $\mathrm{MoS}_{2}$ e $\mathrm{WS}_{2}$. Uma constante efetiva do contato $k_{\text {eff }}<2,0 \mathrm{~N} \mathrm{~m}^{-1}$ para uma bicamada mostra que o material é facilmente deformável, o que pode então contribuir para o alto atrito medido [80].

Estabelecendo uma relação entre $\tilde{\mu}, E$ e $\tau$, vemos que o fator preponderante para a resistência ao cisalhamento está no coeficiente de atrito não linear, uma vez que a mica apresenta o menor módulo elástico entre os materiais analisados, porém a maior resistência e coeficiente de atrito.

\section{4}

\section{Conclusões}

Neste capítulo vimos como a fricção se comporta em função da força normal aplicada pela ponta do microscópio. Vemos que grafeno e $\mathrm{MoS}_{2}$ tiveram os dados melhores ajustados pelo modelo JKR, enquanto $\mathrm{WS}_{2}$ e mica pelo modelo DMT. No caso do grafeno, há corroboração com a literatura mostrando o mesmo tipo de comportamento, associado à uma maior deformação da folha durante o deslizamento da ponta na superfície. Para os TMDs, é intrigante notar essa diferença, uma vez que são materiais similares. Dentre as hipóteses, podemos ter modos de vibração fonônicos diferentes e contribuição para o potencial deinteração devido ao efeito piezoelétrico. A mica, por sua vez, apresenta o maior atrito entre os materiais, mesmo tendo o menor módulo elástico. Comparações com a literatura mostram um ajuste também pelo 
modelo DMT, porém para contatos com pontas cônicas, além de resultados mostrarem uma fácil deformação de uma folha atomicamente fina de mica. 


\section{6 \\ Influência da velocidade nas medidas de fricção}

Uma vez caracterizada as superfícies, estudamos a relação entre fricção e velocidade, validando o modelo PTT, em especial para o caso do grafeno. Veremos como a velocidade influência as medidas para o caso de números de camadas do grafeno, saturando numa dada força crítica $F_{c}$ em diferentes pontos para cada camada. Outros parâmetros para o modelo também são estimados, como a barreira de potencial entre ponta e superfície, e a frequência de pulos de um mínimo de potencial para outro.

As medidas e análises referentes ao grafeno aqui descritas nos rendeu uma publicação no periódico Scientific Reports [96].

\section{1}

Grafeno

\subsection{1 \\ Metodologia}

Amostras de grafeno foram preparadas por esfoliação mecânica. Para auxiliar na identificação das folhas de grafeno, as amostras foram levadas à um microscópio ótico. Quanto ao número de camadas, espectroscopia Raman foi realizada. Os principais picos para identificação de camadas de grafeno são as chamadas bandas $G$ e $2 D$, as quais ocorrem em comprimentos de onda típicos de $\lambda \sim 1580 \mathrm{~cm}^{-1}$ e $\lambda \sim 2700 \mathrm{~cm}^{-1}$ [59].

Imagens de friç̧ão e topografia foram adquiridas simultaneamente num AFM NanoWizard (JPK Instruments), varrendo uma área de 1,0 $\mathrm{\mu m} \times 1,0 \mu \mathrm{m}$. Após estas medidas, imagens em resolução de rede, numa área de $5,0 \mathrm{~nm} \times$ $5,0 \mathrm{~nm}$ foram feitas num AFM MultiMode (Bruker) para obter a orientação da amostra e a constante de mola efetiva $k_{\text {eff }}$ do contato. As pontas usadas foram do tipo triangular, de $\mathrm{Si}_{3} \mathrm{~N}_{4}$, modelos DNP-10 (Bruker), cantiléver A, com constantes de mola normal e lateral de $k_{n}=0,4 \pm 0,1 \mathrm{~N} / \mathrm{m}$ e $k_{\varphi}=86 \pm 4 \mathrm{~N} / \mathrm{m}$, respectivamente. As constantes foram calculadas de acordo com parâmetros geométricos dos cantilévers. A força normal total utilizada no experimento foi de $F_{N} \approx 110 \mathrm{nN}$. A direção de varredura foi mantida perpendicular ao eixo principal do cantiléver. 
A variação da velocidade foi realizada num limite de $0,4 \mu \mathrm{m} / \mathrm{s}$ à $50 \mu \mathrm{m} / \mathrm{s}$. Todas as medidas foram feitas em temperatura ambiente, $T \sim 25^{\circ} \mathrm{C}$, com uma umidade relativa de $R H \sim 60 \%$. Os dados foram ajustados ao modelo PTT pela eq. (2-36) com o software Matlab [77], usando a função nlinfit, a qual usa um algoritmo do tipo Levemberg-Marquardt [78], tendo como parâmetros livres $\Delta V_{0} / k T, F_{c}$ e $\ln v_{0}$.

Após as medidas em função da velocidade, foram feitas medidas de ressonância de contato, seguindo o método desenvolvido por Killgore e DelRio [97]. As ressonâncias normais e laterais do sistema cantiléver-grafeno foram adquiridas simultaneamente com o uso de uma cerâmica piezoelétrica, um gerador de funções AFG301 (Tektronix, Inc.) e um amplificador lock-in SR844 (Stanford Research Systems). A amostra é colocada em cima da cerâmica, a qual é posta para vibrar com um sinal enviado pelo gerador de funções. A amplitude de excitação da cerâmica é mantida constante, enquanto a frequência é variada entre $25 \mathrm{kHz}$ e $5,0 \mathrm{MHz}$. Durante a varredura, o amplificador lock-in mede os sinais de deflexão normal e lateral do cantiléver.

\subsection{2}

\section{Resultados}

Como visto no capítulo anterior, a fricção no grafeno depende do número de camadas. Não apenas isso, a velocidade também apresenta influência na medida. A Figura 6.1 mostra o atrito medido para quatro camadas de grafeno em diferentes velocidades, indicadas pelas setas. Há uma clara tendência de diminuição do atrito com o aumento do número de camadas, e, ao aumentar a velocidade de varredura da ponta, também há um aumento na fricção medida. Nota-se também que este aumento na fricção com a velocidade é mais evidente numa monocamada de grafeno do que nas camadas seguintes. 


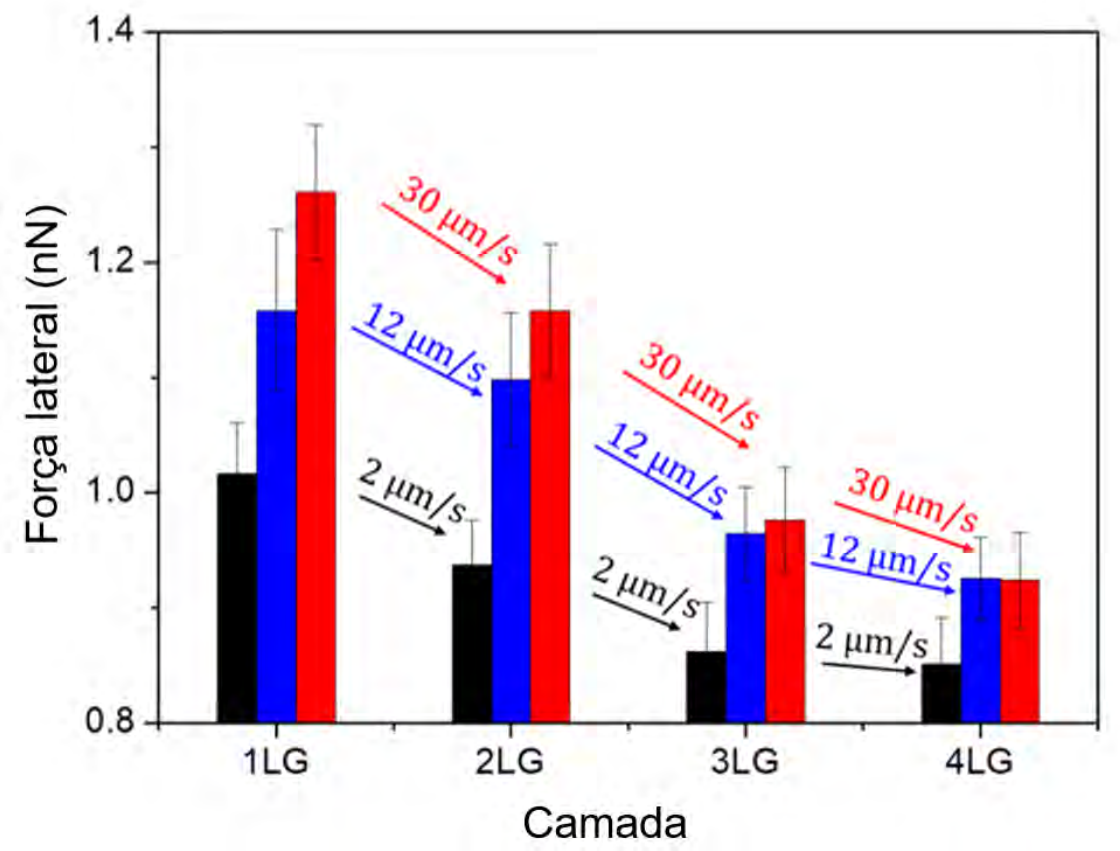

Figura 6.1: Fricção medida para diferentes camadas à diferentes velocidades.

A Figura 6.2 mostra o atrito medido em função do logaritmo da velocidade. As curvas ajustadas pela eq. (2-36) são mostradas como linhas sólidas, e os parâmetros obtidos são mostrados na Tabela 6.1 Observa-se um comportamento linear com o logaritmo da velocidade até uma certa parte em que a fricção atinge um ponto de saturação. Este ponto é caracterizado por uma força crítica $F_{c}$. A velocidade mostra-se relevante principalmente nas duas primeiras camadas do grafeno, uma vez que a inclinação da parte linear da curva é mais acentuada que em três e quatro camadas, além de ser necessário atingir maiores velocidades $(v \sim 30 \mu \mathrm{m} / \mathrm{s})$ para se atingir $F_{c}$. A inclinação da curva para três e quatro camadas de grafeno é mais suave, e a velocidade para se atingir $F_{c}$ está em $v \sim 10 \mu \mathrm{m} \mathrm{s}^{-1}$. 


\begin{tabular}{|ccccc|}
\hline \hline Camada & $\Delta V / k T$ & $F_{c}(\mathrm{nN})$ & $\ln v_{0}(\mu \mathrm{m} / \mathrm{s})$ & $f_{0}(\mathrm{MHz})$ \\
\hline \hline 1LG & $18 \pm 3$ & $1,33 \pm 0,08$ & $2,0 \pm 1,0$ & $1,8 \pm 0,8$ \\
2LG & $16 \pm 2$ & $1,22 \pm 0,03$ & $1,9 \pm 0,4$ & $1,6 \pm 0,6$ \\
3LG & $28 \pm 6$ & $1,01 \pm 0,01$ & $1,5 \pm 0,5$ & $2,1 \pm 0,9$ \\
4LG & $30 \pm 10$ & $0,96 \pm 0,01$ & $1,0 \pm 0,6$ & $1,6 \pm 0,8$ \\
\hline \hline
\end{tabular}

Tabela 6.1: Resultados do ajuste pela eq. (2-36), e frequência de pulos estimada.

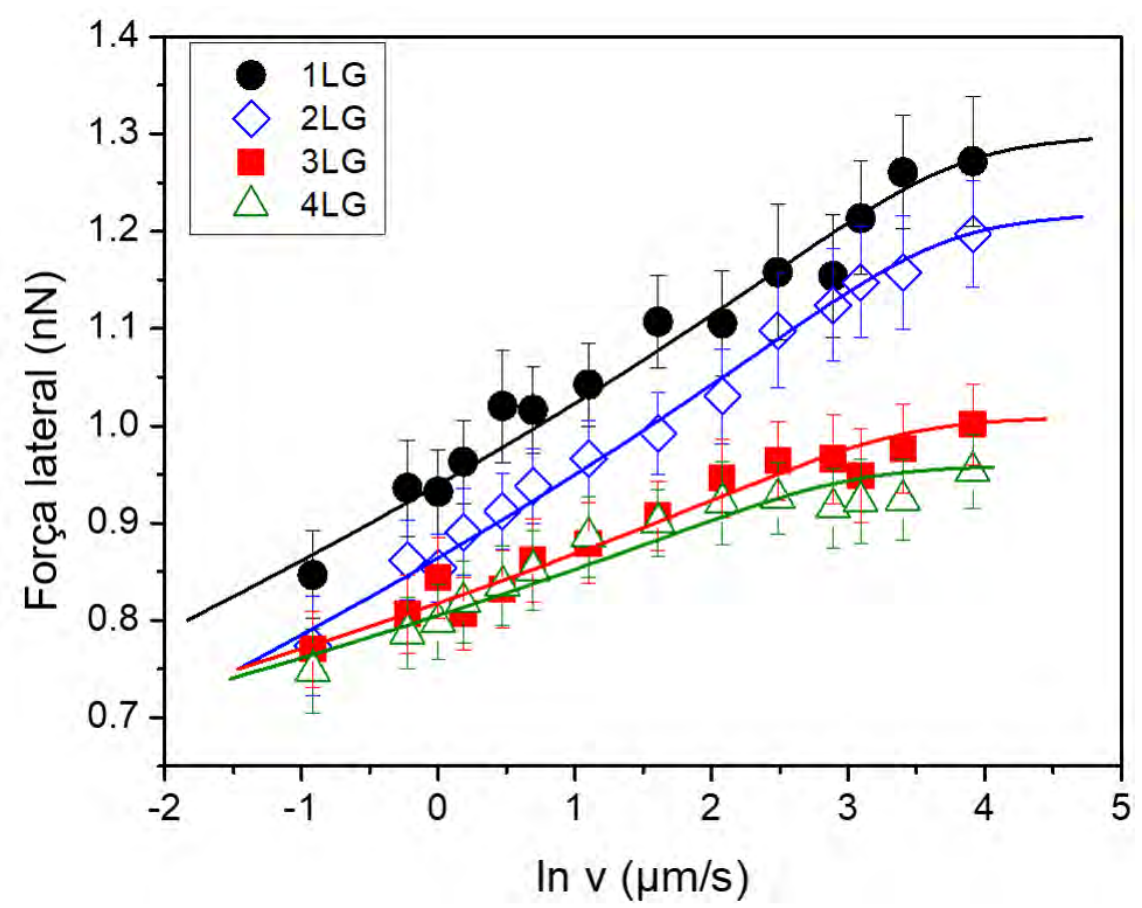

Figura 6.2: Medição de força lateral em função do logaritmo da velocidade de varredura para diferentes camadas de grafeno. Linhas sólidas representam as funções do modelo PTT ajustada aos dados.

Com a curva de fricção por velocidade, também é possível calcular a energia dissipada durante o movimento da ponta usando o método de Colchero e colaboradores [98]. A energia dissipada é calculada pelo loop de fricção e é diretamente proporcional à fricção média medida, ocasionando, portanto, também uma saturação na energia. Energias de até $\sim 2,0 \mathrm{eV}$ para uma monocamada, e $\sim 1,5 \mathrm{eV}$ para $4 \mathrm{LG}$. O resultado é visto na Figura 6.3. 


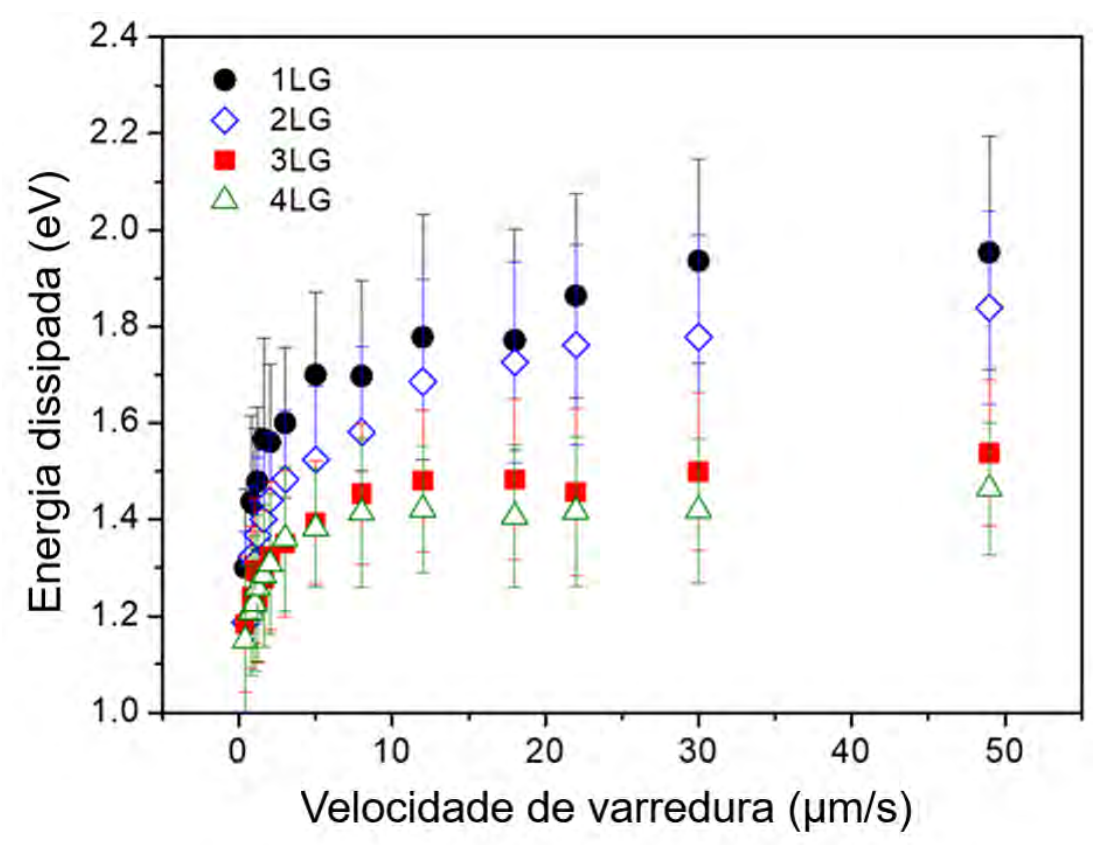

Figura 6.3: Energia dissipada calculada em função da velocidade de varredura.

Na Figura 6.4 a probabilidade cumulativa das forças de fricção em diferentes velocidades é mostrada para diferentes camadas. Essas curvas mostram a probabilidade de ocorrer um pulo entre mínimos de potencial numa dada força de fricção. Em baixas velocidades de deslizamento, $v \leqslant 5,0 \mu \mathrm{m} / \mathrm{s}$, o início dos pulos ocorrem com aproximadamente a mesma força de fricção tanto para a monocamada quanto para as multicamadas de grafeno, em $f_{L} \sim 0,9 \mathrm{nN}$, e a probabilidade máxima de um pulo acontece em forças maiores para a monocamada $\left(f_{L} \sim 1,4 \mathrm{nN}\right)$ do que para as outras camadas $\left(f_{L} \sim 1,0 \mathrm{nN}\right)$. 


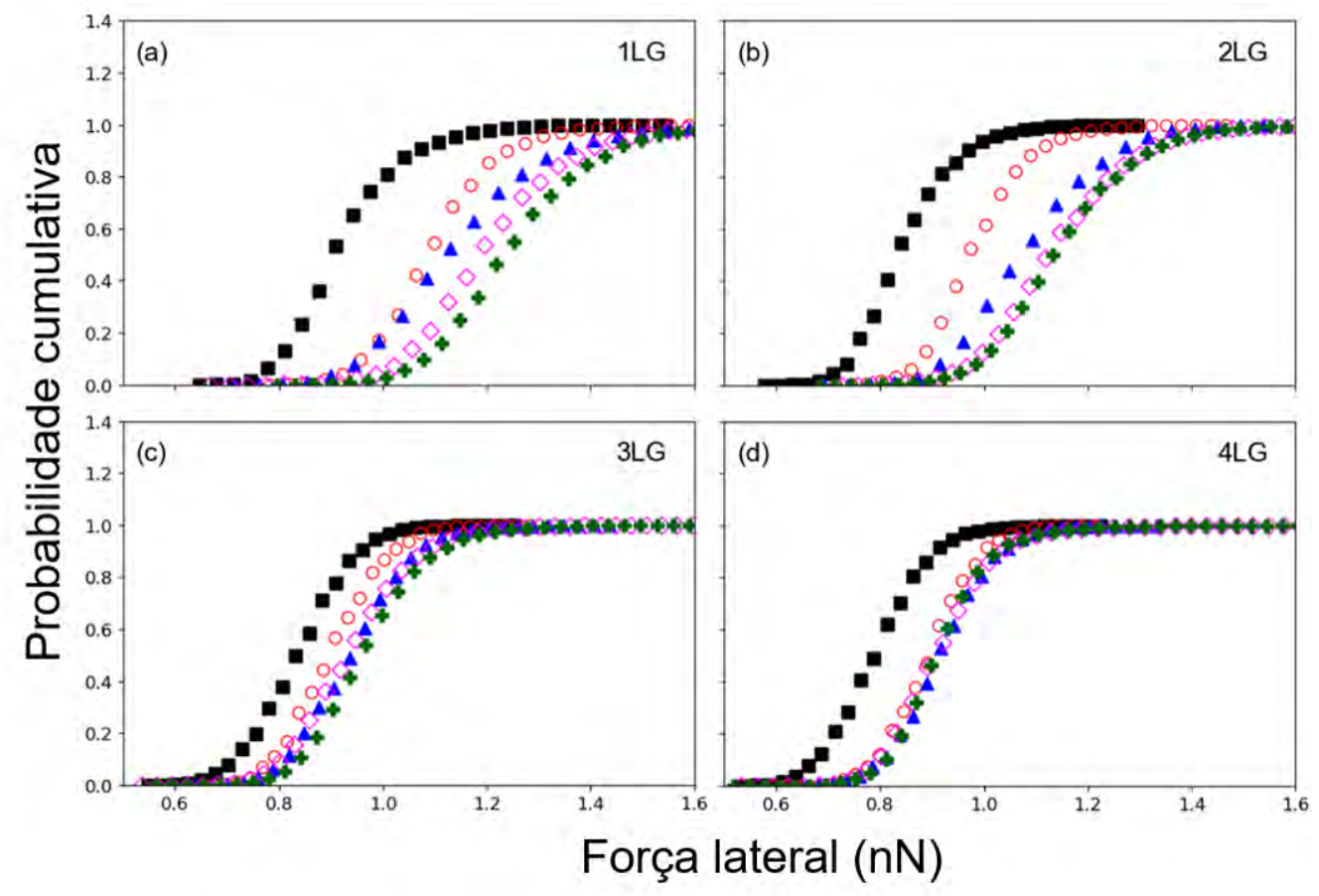

Figura 6.4: Probabilidade cumulativa de forças de friç̧ão para (a) 1LG; (b) 2LG; (c) 3LG; e (d) 4LG em diferentes velocidades de varredura. As velocidades são dadas por: $1,0 \mathrm{\mu m} \mathrm{s}^{-1}$ (quadrados pretos), $5,0 \mu \mathrm{m} \mathrm{s}^{-1}$ (círculos vermelhos), $12 \mu \mathrm{m} \mathrm{s}^{-1}$ (triângulos azuis), $22 \mu \mathrm{m} \mathrm{s}^{-1}$ (losangos magenta) e $30 \mu \mathrm{m} \mathrm{s}^{-1}$ (cruzes verdes)

Com o aumento da velocidade, as curvas para a monocamada tornam-se bem distintas, ao contrário das multicamadas, as quais tendem à se unir numa única curva. Em velocidades mais altas, como $v \geqslant 22 \mu \mathrm{m} / \mathrm{s}$, o início dos pulos já se mostra diferente para mono e bicamadas, com $f_{L} \sim 1,0 \mathrm{nN}$ e $f_{L} \sim 0,9 \mathrm{nN}$, respectivamente, do que para três e quatro camadas, com $\sim 0,7 \mathrm{nN}$. A força de fricção com a probabilidade máxima de um pulo $P_{\text {pulo }}\left(f_{L}\right)$ para esta faixa de velocidade decresce com o número de camadas, como visto na Tabela 6.2.

\begin{tabular}{|c|c|}
\hline \hline Camada & $f_{L} \mid P_{\text {pulo }}\left(f_{L}\right)=1$ \\
\hline \hline $1 \mathrm{LG}$ & $1,6 \mathrm{nN}$ \\
$2 \mathrm{LG}$ & $1,4 \mathrm{nN}$ \\
$3 \mathrm{LG}$ & $1,2 \mathrm{nN}$ \\
$4 \mathrm{LG}$ & $1,1 \mathrm{nN}$ \\
\hline
\end{tabular}

Tabela 6.2: Força de friç̧ão com maior probabilidade de pulo entre mínimos de potencial.

Na Figura 6.5 uma estimativa para a barreira de potencial é mostrada, fazendo a aproximação $\Delta V_{0} \approx \Delta V$ [46], assim como a estimativa da amplitude pela aproximação do potencial periódico, $V_{0}$,calculada pela eq. (2-17). Os 
parâmetros apresentam comportamento opostos. A amplitude $V_{0}$ decresce com o número de camadas, diminuindo de $V_{0} \sim 0,7 \mathrm{eV}$ para $V_{0} \sim 0,5 \mathrm{eV}$. Já a barreira $\Delta V$ cresce com o número de camadas, aumentando de $\Delta V_{0} \sim 0,5 \mathrm{eV}$ para $\Delta V_{0} \sim 0,8 \mathrm{eV}$.

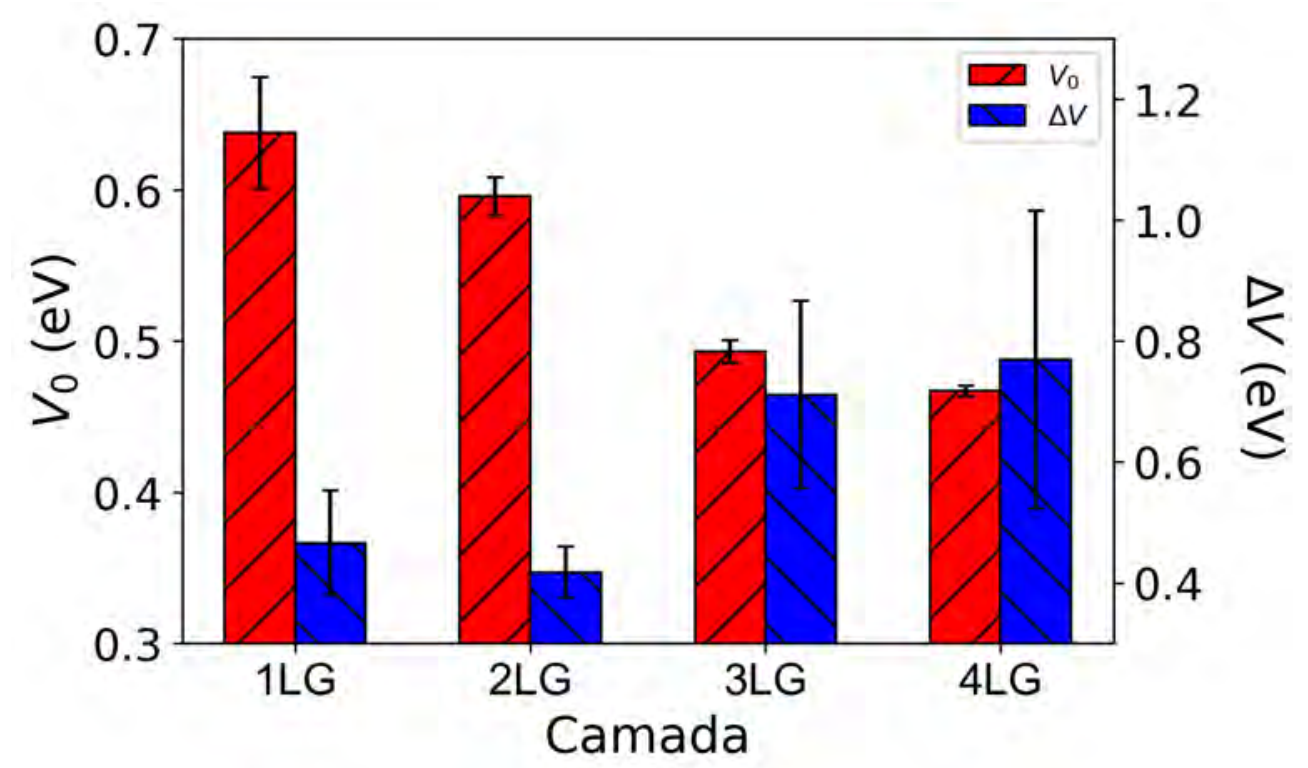

Figura 6.5: Estimativa da amplitude do potencial periódico $V_{0}$ (barras vermelhas) e barreira de potencial $\Delta V$ (barras azuis) para quatro diferentes camadas de grafeno.

Com os resultados do ajuste pelo modelo PTT, tentamos estimar a frequência com que os pulos ocorrem para cada camada. Para tanto, é necessário medir a constante elástica efetiva $k_{\text {eff }}$ do contato ponta-amostra. Esta é medida como a inclinação das curvas de fricção no padrão stick-slip, e é mostrada no Capítulo 4, Figura 4.8. O resultado calculado foi $k_{\text {eff }}=12 \pm 5 \mathrm{~N} \mathrm{~m}^{-1}$. A frequência $f_{0}$ dos pulos é estimada pela eq. (2-34) Ela permanece razoavelmente a mesma para as quatro camadas analisadas, em $f_{0} \sim 1,8 \mathrm{MHz}$, como visto na Tabela 6.1.

Com $f_{0}$ obtido, verificamos se esta está associada à alguma frequência de ressonância do cantiléver em contato com a amostra. Foram medidas, então, o espectro de ressonância normal e lateral do sistema ponta-amostra. Na Figura 6.6 temos parte do espectro entre $1,5 \mathrm{MHz} \leqslant f \leqslant 2,2 \mathrm{MHz}$. A curva em azul representa a amplitude lateral do cantiléver, enquanto a curva em vermelho representa a amplitude vertical. Um espectro mais abrangente, com a frequência variando de $1,0 \mathrm{kHz}$ à $4,0 \mathrm{MHz}$ é mostrado na Figura 6.7. No limite da Figura 6.6, um pico lateral pode ser observado em $f_{R} \sim 1,7 \mathrm{MHz}$, com uma largura de banda de $\Delta f \sim 40 \mathrm{kHz}$, e um pico para a amplitude 
vertical é observado em $f_{R} \sim 2,1 \mathrm{MHz}$, com uma largura de $\Delta f \sim 30 \mathrm{kHz}$. As ressonâncias encontradas no espectro completo são exibidas na Tabela 6.3.

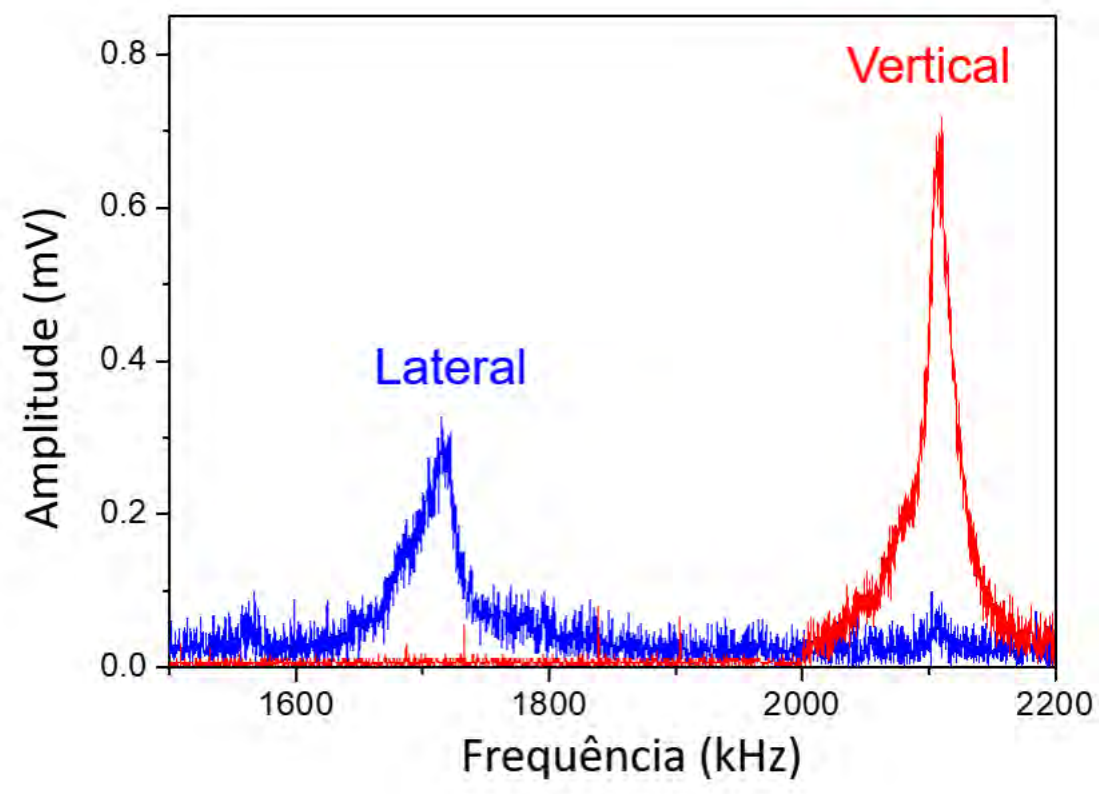

Figura 6.6: Espectros de ressonância lateral (linha azul) e vertical (linha vermelha) do cantiléver em contato com a superfície de grafeno. Pico de ressonância lateral em $f_{0}=1,7 \mathrm{MHz}$, e ressonância vertical em $f_{0}=2,1 \mathrm{MHz}$ ).
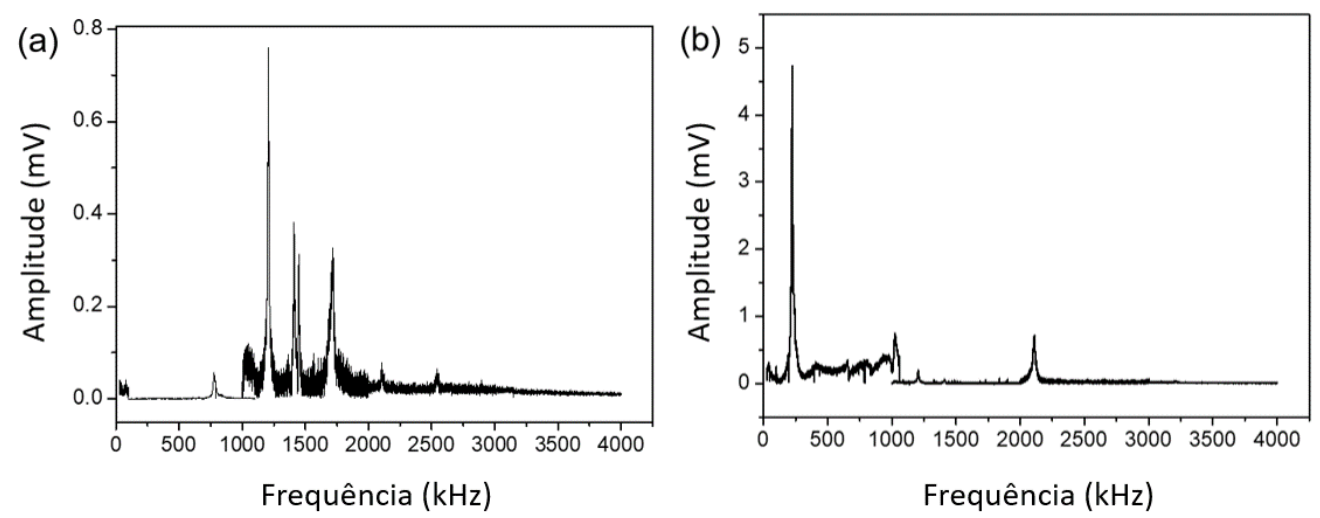

Figura 6.7: Espectro de ressonância do sistema cantiléver-grafeno. (a) Deflexão lateral; (b) deflexão vertical.

\subsection{3}

\section{Discussão}

A dependência do atrito com o número de camadas é bem reportado na literatura e parte já foi discutida no capítulo anterior. Vale ressaltar que o experimento da dependência do atrito com o número de camadas em função 


\begin{tabular}{|c|c|}
\hline \hline$f_{R}^{\text {vertical }}(\mathrm{MHz})$ & $f_{R}^{\text {lateral }}(\mathrm{MHz})$ \\
\hline \hline 0,04 & 0,8 \\
0,2 & 1,2 \\
1,2 & 1,4 \\
1,4 & 1,7 \\
2,1 & 2,1 \\
3,2 & 2,5 \\
\hline \hline
\end{tabular}

Tabela 6.3: Frequências de ressonância normal e lateral do sistema cantilévergrafeno.

da velocidade não exclui os fenômenos citados no Capítulo 4, como a interação e-f [16], a deformação da folha de grafeno [17] ou a corrugação do grafeno [22]. Nosso experimento, entretanto, indica que a velocidade tem contribuição importante na energia dissipada. Os resultados também sugerem que até mesmo a corrugação da folha de grafeno seja influenciada pela velocidade de deslizamento.

A relação entre friç̧ão e velocidade é influenciada pela velocidade relativa entre os dois corpos em contato, e pela ressonância do contato, como visto no Capítulo 2, seção 2.3. Tal influência afeta a probabilidade dos átomos em contato pular de um mínimo do potencial de interação para outro, ultrapassando uma barreira de energia. Os resultados apresentados nas Figuras 6.1 e 6.2 mostram que pode haver interesse nesse estudo, principalmente para o grafeno mono e bicamada, uma vez que a influência da velocidade é mais pronunciada nestas do que em camadas maiores de grafeno.

Os primeiros resultados para a influência da velocidade no atrito em nanoescala mostraram uma relação linear da força de fricção com o logaritmo da velocidade relativa entre os objetos [36]. Pouco depois, dois estudos mostraram que esta relação linear é válida até um certo ponto em que a fricção se torna constante, ao menos dentro de uma flutuação estatística, atingindo uma saturação [38, 39]. Nossos resultados revelam um aumento linear com o logaritmo da velocidade bem pronunciado para as duas primeiras camadas de grafeno, e a saturação é atingida em velocidades maiores que $\sim 30 \mathrm{\mu m} \mathrm{s}^{-1}$, enquanto para três e quatro camadas, a inclinação da curva é mais suave e a saturação ocorre em velocidades mais baixas. A saturação das forças de friç̧ão ocorre quando a energia térmica $k T$ já não ajuda no processo de superação da barreira de potencial entre dois mínimos. Com nossos resultados mostrando saturação em altas velocidades, verifica-se que este efeito da temperatura ainda é relevante para uma e duas camadas de grafeno. As inclinações da curva na parte linear indicam que o potencial de interação para as duas primeiras camadas tem uma maior corrugação do que para três e quatro camadas de grafeno [39]. 
Deve-se notar, porém, que o estudo aqui realizado se difere dos principais resultados da literatura em dois pontos principais:

1. No nosso caso, estamos lidando com materiais atomicamente finos, enquanto os resultados na literatura apresentam materiais volumétricos, como cristais de $\mathrm{NaCl}$ [Gnecco 2000], mica [Riedo 2003] e grafite [Hölscher, PRL 2010];

2. Nossos experimentos foram realizados em condições de temperatura ambiente, com alta umidade relativa do ar $(R H \sim 60 \%)$, enquanto os resultados da literatura foram realizados em condições de ultra alto vácuo (UHV).

A condição 1 é importante pois materiais atomicamente finos se deformam mais facilmente do que seus equivalentes volumétricos. Com a deformação da folha de grafeno, a área de contato aumenta à medida em que a ponta varre a superfície, consequentemente aumentando a fricção medida e o trabalho realizado pela ponta para superar a barreira de potencial e pular para um mínimo adjacente. Para o grafeno em três e quatro camadas, essa deformação já é significativamente menor do que o caso das duas primeiras camadas, portanto um trabalho menor é necessário para que essa superação da barreira aconteça. Como consequência, a influência da velocidade é maior quanto menor o número de camadas. Ademais, a energia dissipada no processo pode induzir maiores corrugações locais nas folhas de uma e duas camadas de grafeno. Resultados recentes na literatura mostram que, de fato, a temperatura pode ter impacto significativo na tribologia do grafeno, com uma correlação direta entre aumento da temperatura e aumento da rugosidade e deformação das folhas [28]. Quanto à condição 2 , uma possível consequência seria uma correlação entre adesão e o atrito medido, porém, como visto no Capítulo 4, tal correlação parece não ocorrer.

Além dos resultados experimentais, a literatura apresenta resultados de simulações feitas em computadores. Tais resultados diferem bastante dos aqui apresentados. Smolyanitsky e colaboradores [43] observaram um comportamento não linear para a fricção com o logaritmo da velocidade, diferente do comportamento previsto pela eq. (2-36). Em outro resultado apresentado por Li e colaboradores [33] não se observa influência da velocidade nos perfis sitckslip da força de atrito. Um ponto a se destacar é a diferença das condições em que as simulações são realizadas, as quais são feitas com velocidades na ordem de $\mathrm{ms}^{-1}$. Esse limite está longe do que pode ser alcançado experimental por um AFM, o qual atinge velocidades na ordem de $\mu \mathrm{m} \mathrm{s}^{-1}$. 
A Figura 6.3 mostra que a energia dissipada no processo de friç̧ão é diretamente proporcional ao atrito medido, como previsto pelo modelo de Colchero e colaboradores [98]. A dissipação de energia é relacionada com as elasticidades do contato. De acordo com a eq. (2-18), calculamos $k_{\text {contato }} \approx$ $14 \mathrm{~N} \mathrm{~m}^{-1}$, onde negligenciamos $k_{\text {ponta }}$ e usando $k_{\text {eff }}=12 \mathrm{Nm}^{-1}$. Como a constante elástica torsional $k_{\varphi}$ do cantiléver usado é maior que $k_{\text {contato }}$, estipulase que a energia é dissipada pela deformação do contato, com os átomos se arranjando numa nova posição de equilíbrio. A energia é então liberada tanto no cantiléver como também é irradiada em forma de ondas elásticas na rede cristalina do grafeno, excitando os átomos de carbono, provocando um aumento de temperatura local na folha durante a varredura [98]. Vale ressaltar também que a condutividade térmica do grafeno é muito maior que do nitreto de silício, material com o qual o cantiléver é feito, indicando que a maior parte da energia seja dissipada no grafeno.

As probabilidades cumulativas exibidas na Figura 6.4 evidenciam a diferença de comportamento com o número de camadas do grafeno com a velocidade de varredura. Em baixas velocidades, as forças laterais necessárias para iniciar um processo de pulo entre minimos de potencial são aproximadamente iguais e parecem não depender do número de camadas. Essa dependência do número de camadas é significativamente aumentada com maiores velocidades atingidas, o que também pode ser visto na fricção média mostrada na Figura 6.1, com a diferença no atrito entre as camadas menor para as velocidades baixas comparadas à faixa de velocidades maiores. Pode-se atribuir essa pouca diferença em baixas velocidades entre mono e multicamadas de grafeno à deformação fora-do-plano da folha, no processo de puckering [17]. Com o aumento da velocidade, além da deformação, uma maior distinção entre as camadas de grafneo pode também ser atribuída à influência da dissipação da energia durante o deslizamento da ponta, o qual pode ocasionar um maior enrugamento da folha [28].

Com os modelos PT e PTT, estimamos tanto a amplitude do potencial periódico da eq. como a barreira de potencial para diferentes camadas de grafeno, como visto na Figura 6.5. A amplitude do potencial periódico é diretamente proporcional à força crítica, logo também decresce com o acréscimo do número de camadas. Entretanto, a barreira depende da força lateral exercida pelo cantiléver enquanto é deformado ao deslizar a ponta pela superfície. Como as forças de fricção são maiores para mono e bicamada de grafeno, aumentando a torsão sofrida pela haste, assim como a energia elástica armazenada na mesma, provocando uma diminuição da barreira. Resultados relatados na literatura mostram barreiras calculadas por diferentes métodos, como uma 
análise estatística dos perfis stick-slip no grafite [99] e ativação dos pulos por variação de temperatura [100]. Em ambos os casos, os valores ficam em torno de $\Delta V=0,1 \mathrm{eV}$ e $\Delta V=0,2 \mathrm{eV}$, menores do que os aqui encontrados. Uma diferença significativa em nosso experimento está na força normal aplicada, sendo a barreira de potencial sensível à mudanças neste parâmetros [39]. A força aplicada $F_{N} \approx 110 \mathrm{nN}$ está uma à duas ordens de grandeza maior do que nos estudos citados. Ademais, comparando com Schirmeisen e colaboradores, parâmetros como frequência de ressonância e constante elástica do contato também se diferem em uma ou mais ordens de grandeza, assim como a velocidade de deslizamento.

Por fim, com os parâmetros obtidos pelo ajuste com o Modelo PTT, estimamos a frequência com que um pulo entre mínimos de potencial ocorre, o qual pode estar associado à frequência de ressonância lateral do cantiléver utilizado [39]. O espectro exibido na Figura 6.6 mostra um pico da frequência lateral da haste próximo ao valor estimado para uma monocamada, reforçando o argumento de associação do pulo com a frequência do cantiléver. Pela Tabela 6.3, nota-se que este pico de vibração lateral do cantiléver não é impulsionado pela vibração normal do mesmo, uma vez que ele não coincide com nenhum valor obtido para a ressonância vertical. Assim, a energia térmica pode contribuir com a relação entre fricção e velocidade ao provocar vibrações no cantiléver, antecipando um pulo e facilitando o movimento da ponta pela superfície. Portanto, um controle dos parâmetros que afetam a ressonância do cantiléver podem seria possível facilitar o processo de fricção e o deslizamento das superfícies.

\section{2}

\section{Outros materiais}

$\mathrm{Na}$ Figura 6.8 vemos a curva de fricção em função do logaritmo da velocidade de deslizamento para o $\mathrm{MoS}_{2}$ e $\mathrm{WS}_{2}$, respectivamente. Percebe-se que o erro experimental é muito grande, o que talvez seja pela irregularidade das amostras, e da dificuldade de se achar uma boa área para medição. Várias tentativas foram feitas, porém sem sucesso em obter boas curvas. O que se nota em ambos os casos é um aumento linear da friç̧ão em função do logaritmo, com a inclinação do $\mathrm{WS}_{2}$ uma ordem de grandeza maior que o caso para o $\mathrm{MoS}_{2}$. Devido ao erro experimental, não foi possível estabelecer se há uma força crítica de saturação. Diferenças no comportamento em comparação com o do grafeno pode ser devido à diferente interação com o substrato, uma vez que as amostras de TMDs foram sintetizadas. Há poucos resultados na literatura tratando da influência da velocidade para esse tipo de material. B. C. Tran-Khac mostra 
um comportamento similar ao do grafeno para amostras de $\mathrm{MoS}_{2}$ esfoliadas, com uma saturação ocorrendo em cerca de $v \sim 1,0 \mu \mathrm{ms}^{-1}$, em velocidades menores do que o grafeno [41]. O. Acikgoz e M. Z. Baykara também encontram comportamento similar ao grafeno em $\mathrm{MoS}_{2}$ esfoliado, com saturações em cerca de $v=1,1 \mu \mathrm{m} \mathrm{s}^{-1}$. Neste último, os autores não notam distinção entre uma monocamada de $\mathrm{MoS}_{2}$ com sua forma volumétrica. A frequência dos pulos $f_{0}$ para uma monocamada neste último se assemelha ao nosso resultado para o grafeno, com $f_{0}=13,0 \mathrm{kHz}$, e para o equivalente volumétrico é cerca de metade deste valor [42].

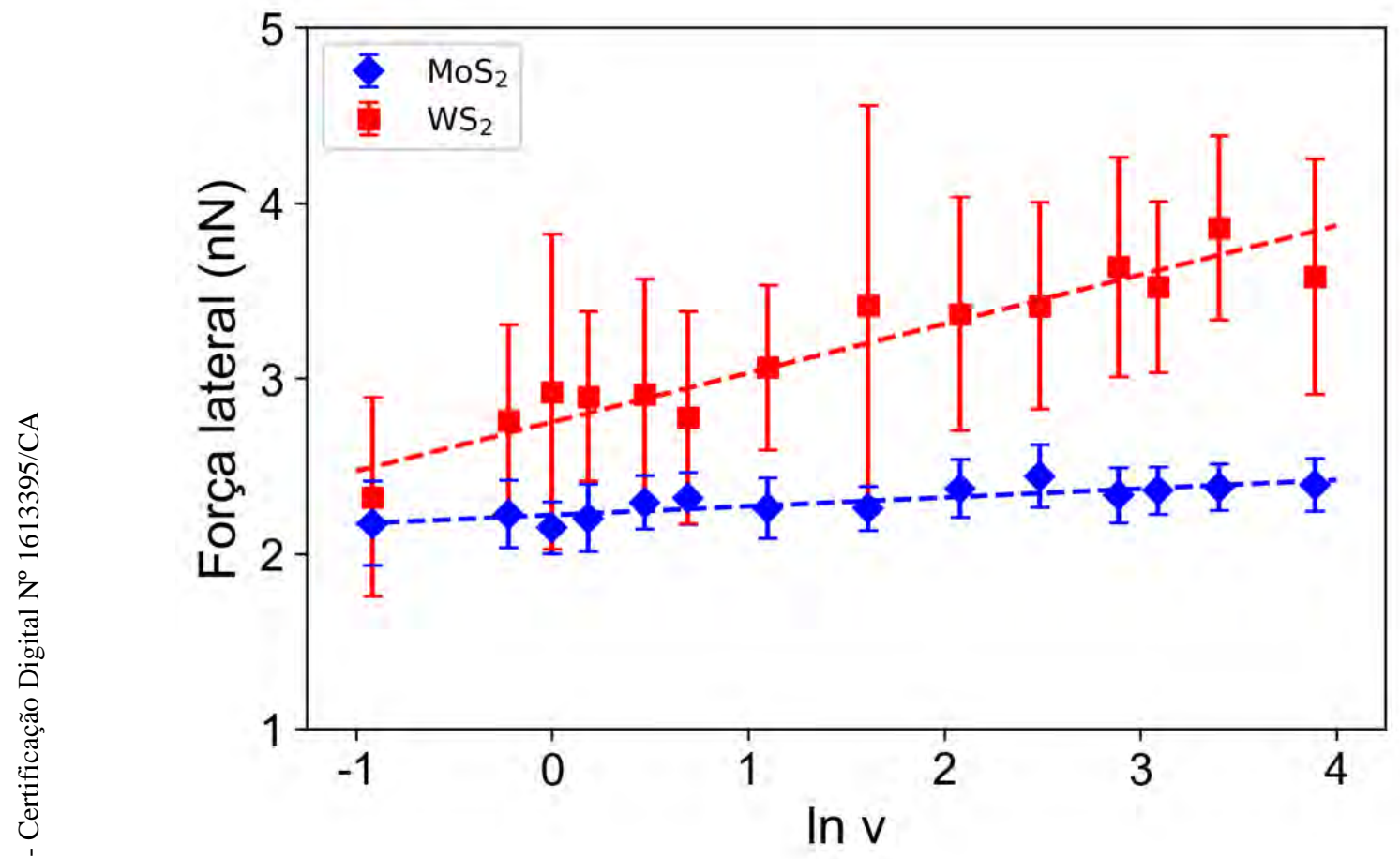

Figura 6.8: Fricção medida em função do logaritmo da velocidade de varredura para $\mathrm{MoS}_{2}$ (azul) e $\mathrm{WS}_{2}$ (vermelho). Linhas pontilhadas são ajustes lineares.

Na Figura 6.9 a curva de fricção por velocidade para uma monocamada de mica é exibida. Essas medições foram feitas com uma força normal de $F_{N}=55 \mathrm{nN}$. Percebe-se comportamento similar ao obtido com grafeno. Notase um atrito muito maior do que nos outros materiais, como já visto no Capítulo 5. A força crítica de saturação é uma ordem de grandeza superior à do grafeno, com $F_{c} \sim 13,0$ nN. Nota-se também que essa saturação ocorre já em baixas velocidades de varredura, com $v \sim 1,6 \mathrm{~mm} \mathrm{~s}^{-1}$. Apesar de muitas tentativas, não foi possível ajustar os dados ao modelo PTT. Porém, usando a eq. (2-17), calculamos $E_{0}=2,1 \mathrm{eV}$, um valor cerca de três vezes maior que o obtido para o grafeno, mesmo que a força normal usada seja metade da usada no experimento com o grafeno. E. Riedo e colaboradores mediram a friç̧ão em 


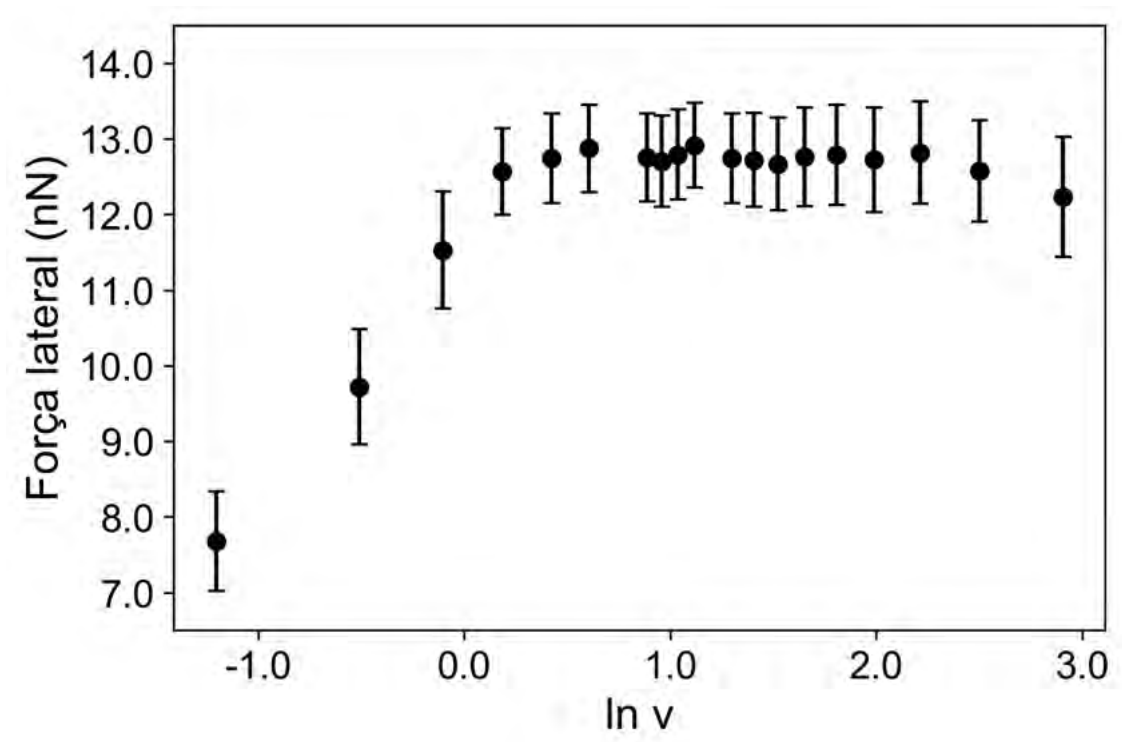

Figura 6.9: Fricção em função do logaritmo da velocidade de varredura para monocamada de mica.

função da velocidade num cristal volumétrico de mica, encontrando saturação valores superiores ao nosso, em $v \sim 7,4 \mu_{\mathrm{m} \mathrm{s}}{ }^{-1}$. Além do fator da espessura dos materiais, a força normal máxima usada no trabalho citado é de $F_{N}=12 \mathrm{nN}$ [39].

\section{3}

\section{Conclusões}

Neste capítulo mostramos a influência da velocidade nas medidas de fricção para o grafeno com diferentes camadas, e para os outros materiais, o $\mathrm{MoS}_{2}$, o $\mathrm{WS}_{2}$ e a mica. No caso do grafeno, há uma clara dependência com o número de camadas, a qual é amplificada com o aumento da velocidade de deslizamento da ponta sobre a superfície. A influência da velocidade numa monocamada de grafeno é muito mais pronunciada do que nas camadas superiores, em especial em três e quatro camadas. A força crítica de saturação é encontrada em velocidades maiores nas mono e bicamadas de grafeno, sugerindo que a temperatura ainda tem papel importante nos mecanismos de fricção destas camadas. Uma hipótese apresentada é que a dissipação de energia seja feita principalmente ao longo da rede cristalina do material, provocando corrugações fora-do-plano na folha, aumentando a área de contato e, consequentemente, o atrito medido. Já as camadas mais altas apresentam forças críticas de saturação da fricção em velocidades menores.

Nossos resultados no grafeno foram ajustados pelo modelo de PrandtlTomlinson termicamente ativado. Com isso, parâmetros como as forças críticas em que a saturação ocorre, as amplitudes de um potencial periódico, as bar- 
reiras de potencial, e a frequência com que os pulos ocorrem foram estimados. A amplitude do potencial decresce com o aumento do número de camadas, pois está diretamente associada à força crítica. Já a barreira tende a diminuir com o aumento de camadas, pois é influenciada pela energia elástica armazenada no cantiléver, a qual depende do atrito medido. A frequência dos pulos foi associada à ressonância lateral do cantiléver em contato com a superfície de grafeno. Deste modo, vibrações por flutuações térmicas do sistema podem facilitar o processo de fricção, diminuindo o atrito no deslizamento da ponta em contato com a superfície. 


\section{7 \\ Domínios de fricção por contaminação e exposição ao ar}

Neste capítulo descreveremos como a contaminação ambiente influencia nas medidas de fricção do grafeno. No Capítulo 4, vimos brevemente que o ambiente tem influência sobre as superfícies analisadas, seja por oxidação ou pela provável formação de uma camada de água entre camadas de grafeno e mica. Ademais, a exposição ao ar pode causar contaminação por adsorção de hidrocarbonetos na superfície, e o grafeno não está isento desse processo $[101,102]$.

De fato, para o caso do grafeno, a literatura diz que este pode ter propriedades alteradas pela adsorção de moléculas [103], como a molhabilidade [104, 105]. É possível até mesmo ter um controle do gap de energia pela adsorção de água [106] ou hidrocarbonetos [107]. A fricção no grafeno não é diferente, e resultados recentemente publicados mostram que contaminação ambiente podem acarretar em diferentes domínios de fricção numa mesma folha de grafeno [35] e um aumento do atrito medido comparado à uma amostra limpa [108].

Fica evidente, portanto, a importância do estudo da contaminação ambiente para a tribologia no grafeno. Neste capítulo fazemos uma observação dos estágios de contaminação, mostrando que esta começa em defeitos e bordas da monocamada, para então passar para as camadas superiores. A taxa de contaminação é estimada, com a monocamada sendo contaminada muito mais rapidamente que as demais. Além disso, é mostrado que a contaminação na folha altera a mecânica de contato entre os materiais.

\section{1}

\section{Métodos}

As amostras de grafeno foram obtidas a partir da esfoliação mecânica de grafite e então depositados num substrato de $\mathrm{SiO}_{2}$, como já descrito no Capítulo 3, seção 3.1.1. Amostras recém esfoliadas foram imediatamente levadas à um microscópio ótico e um espectrômetro Raman para identificação de camadas. Após medições em amostras recém esfoliadas, ditas grafeno limpo, novas medições são feitas com o passar do tempo, tendo tempo para a contaminação ambiente ser observada. Essas amostras passam então a ser 
chamadas de grafeno contaminado.

Medidas de friç̧ão foram feitas com o AFM NanoWizard (JPK), com pontas triangulares de $\mathrm{Si}_{3} \mathrm{~N}_{4}$, modelo DNP-10 (Bruker), cantiléver $\mathrm{A}$, de constante elástica normal $k_{n}=0,4 \pm 0,1 \mathrm{~N} \mathrm{~m}^{-1}$ e constante elástica lateral $k_{\varphi}=86 \pm 4 \mathrm{~N} \mathrm{~m}^{-1}$. As constantes foram calculadas de acordo com parâmetros geométricos dos cantilévers. Curvas FD foram feitas para calibração em ambos os tipos de amostras, limpas e contaminadas. Para estimar a área de regiões contaminadas, foi feito uma análise da distribuição de intensidades. Os píxeis acima de um determinado limiar são identificados, e a quantidade de píxeis foi multiplicada pela área de cada um. As medidas foram feitas em condições ambientes, com temperatura $T \sim 25^{\circ} \mathrm{C}$ e umidade relativa do ar $R H \sim 60 \%$.

Espectros infravermelho por Transformada de Fourier (FTIR) foram feitos com um espectrômetro JASCO FTIR 4100, variando o comprimento de onda de $\lambda=400 \mathrm{~cm}^{-1}$ à $\lambda=4000 \mathrm{~cm}^{-1}$, com uma resolução de $2,0 \mathrm{~cm}^{-1}$, localizado no Laboratório van der Graaff, na PUC-Rio.

\section{2}

\section{Resultados}

Amostras limpas, recém esfoliadas, foram observadas em cerca de uma hora após a esfoliadas. A Figura 7.1 mostra topografia e mapa de fricção de uma interface entre monocamada e uma área com muitas camadas de grafeno. É possível observar uma espécie de rachadura na monocamada. Uma área de maior atrito é visto ao redor dessa rachadura, porém a mesma não é vista na imagem de topografia. O perfil de força lateral mostrado na Figura 7.1c mostra que existe uma fronteira específica desta área de maior fricção. Supomos que esse aumento se dá pela adsorção de contaminantes na superfície ao redor da rachadura. 

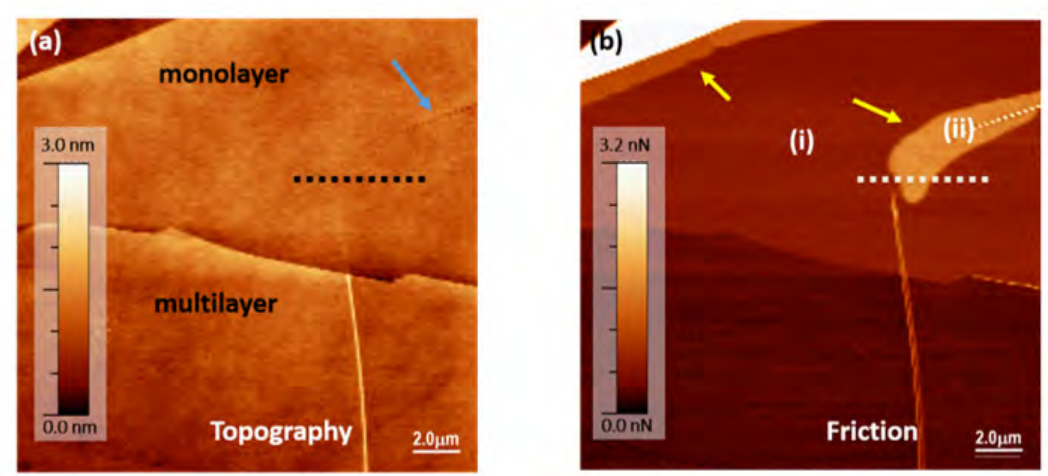

(c)

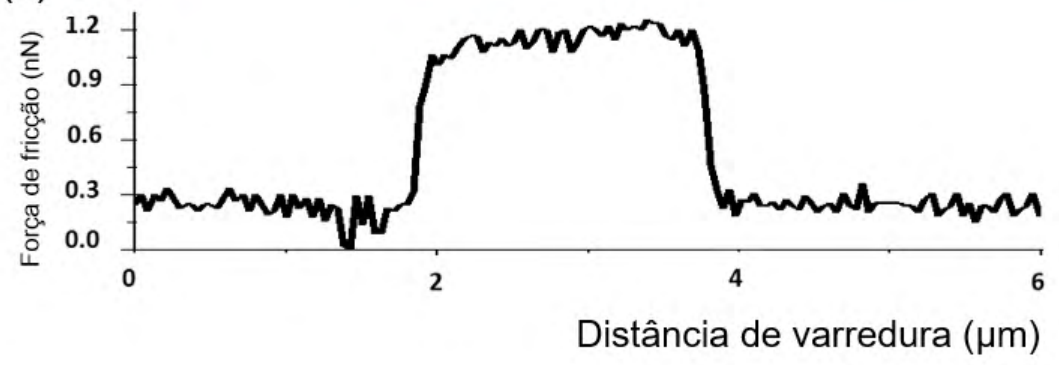

Figura 7.1: Região contendo mono e multicamada de grafeno em cerca de uma hora após a esfoliação. (a) Topografia obtida por AFM. A seta indica um defeito na folha; (b) Mapa de fricção da mesma região. As setas indicam regiões de maior fricção na monocamada; (c) Perfil de força lateral da linha tracejada em (a) e (b).

As Figuras 7.2a e b mostram mapas topográficos e de fricção, respectivamente, simultaneamente adquiridos. As linhas tracejadas indicam os perfis de topografia e força lateral mostrados nas Figuras 7.2c e d, respectivamente. No perfil de força lateral, nota-se claramente uma diferença na força lateral na região do grafeno com contraste mais claro, enquanto as variações topográficas parecem se dar apenas pela rugosidade da amostra. 

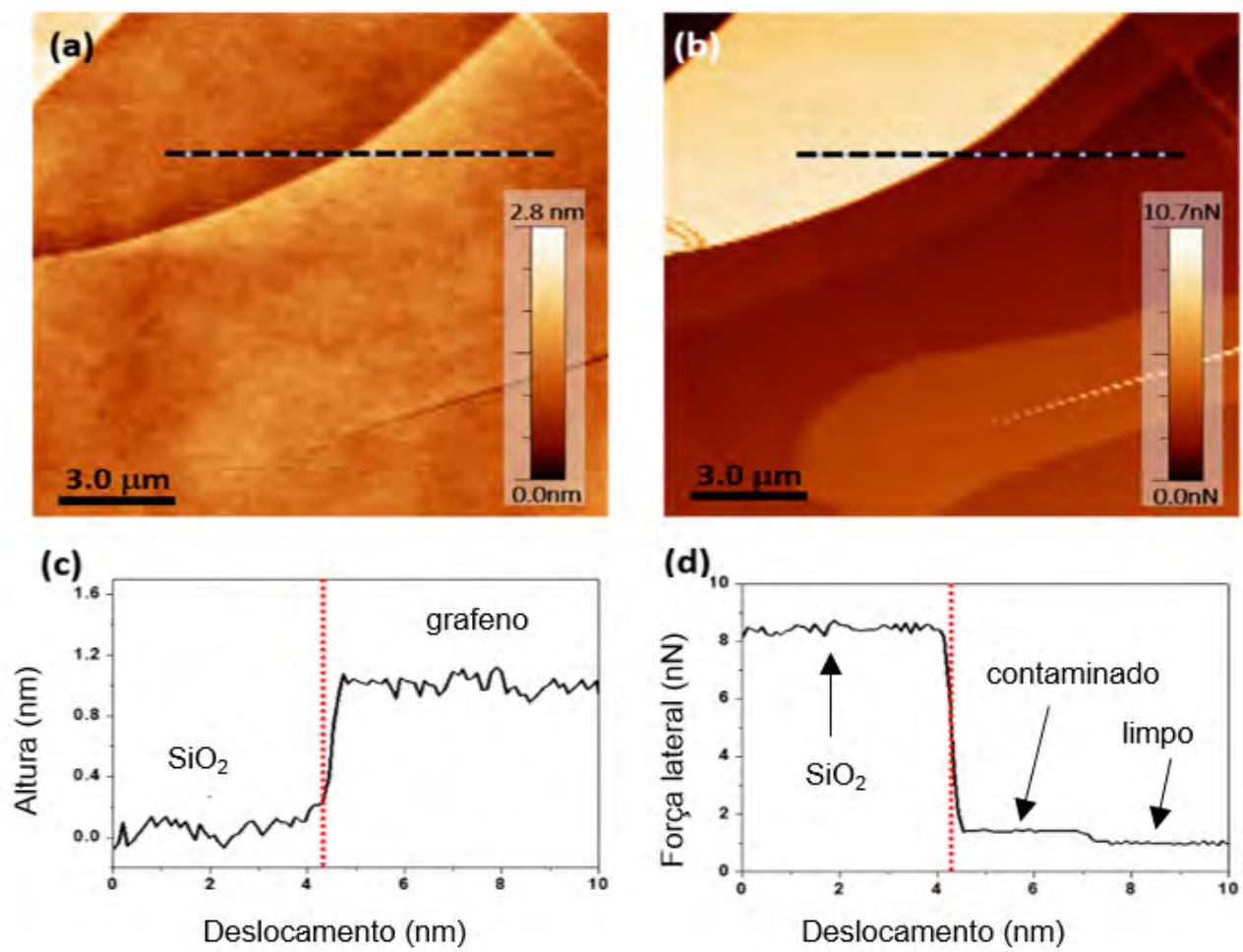

Figura 7.2: Topografia (a) e mapa de fricção (b) simultaneamente adquiridos pelo AFM. Perfil das linhas tracejadas de topografia (c) e força lateral (d).

Na Figura 7.3, exibimos um mapeamento de áreas contaminadas com o uso de mapas de fricção em função do tempo de exposição ao ar. A topografia mostra uma fronteira entre mono e bicamada de grafeno. Os primeiro mapa de fricção, mostrado na Figura 7.3b, mostra uma leve diferença no contraste da força lateral entre mono e bicamada, e não há sinais de contaminação. O atrito medido é maior na monocamada, sendo medido de $f_{L}=0,80 \pm 0,05 \mathrm{nN}$, enquanto medidas na bicamada dão $f_{L}=0,60 \pm 0,07 \mathrm{nN}$. No segundo mapa de fricção (Figura 7.3c), com cerca de 150 minutos de exposição, começam a aparecer sinais de contaminação com três diferentes domínios, um na parte central da monocamada, de menor intensidade; outro na parte superior e à direita da monocamada, com intensidade média; e um na borda esquerda da imagem, com maior intensidade. Na região de intensidade média foi meido $f_{L}=1,00 \pm 0,05 \mathrm{nN}$, e na região de maior atrito, temos $f_{L}=1,23 \pm 0,04 \mathrm{nN}$. Com o passar do tempo, observa-se pelos mapas de fricção que as duas áreas de maior fricção vão se difundindo pela monocamada, como mostrado nas Figuras 7.3d-f. A contaminação na bicamada ocorre a partir de 185 minutos após a esfoliação. $\mathrm{O}$ atrito medido na área contaminada em bicamada foi de $f_{L}=0,99 \pm 0,02 \mathrm{nN}$. 

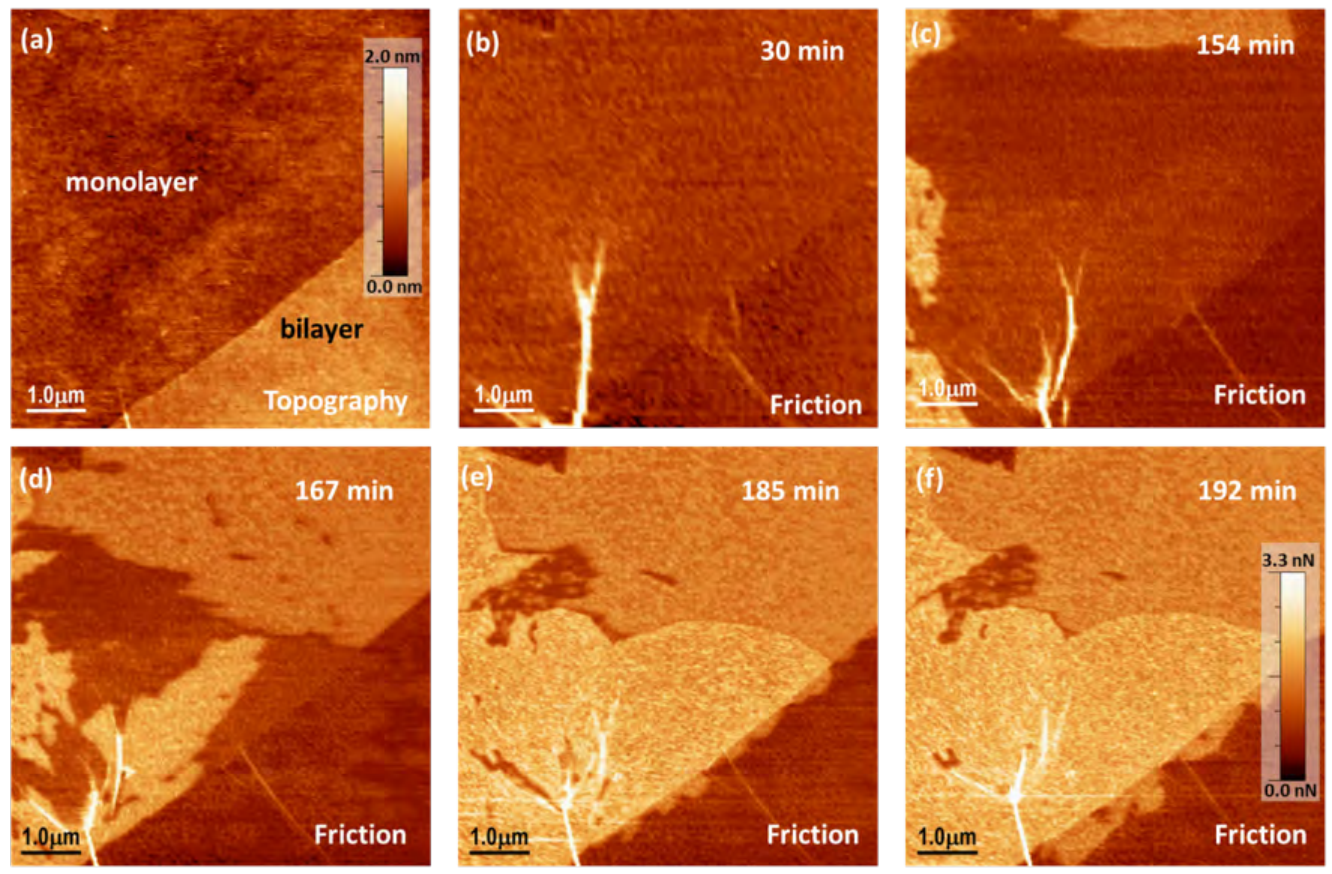

Figura 7.3: Evolução temporal dos domínios de fricção. (a) Topografia após cerca de 30 minutos da esfoliação; (b)-(f) mapas de fricção após cerca de 30 minutos (b), 150 minutos (c), 170 minutos (d), 185 minutos (e) e 190 minutos (f) da esfoliação.

Com a evolução temporal dos mapas de fricção, é possível estimar a área contaminada nas camadas de grafeno, e a taxa de contaminação por tempo. As áreas contaminadas são definidas pelo maior valor de fricção. Usando um histograma de distribuição de forças, foi possível ajustar um limiar para medir a área. Uma taxa de contaminação $\dot{C}=1,02 \pm 0,05 \mu \mathrm{m} \mathrm{min}{ }^{-1}$ foi medida na monocamada, enquanto na bicamada obtemos $\dot{C}=0,15 \pm 0,02 \mu \mathrm{m} \mathrm{min}{ }^{-1}$. Os valores são dados pelas inclinações dos gráficos mostrados na Figura 7.4. 

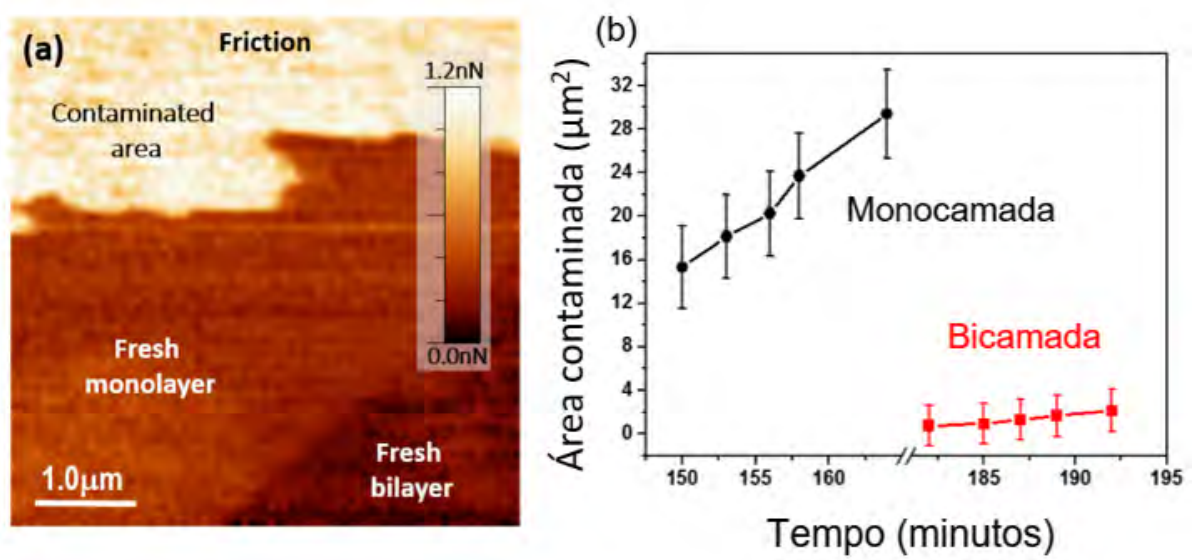

Figura 7.4: (a) Mapa de fricção mostrando área contaminada em mono e bicamada de grafeno; (b) Evolução temporal da área coberta pela contaminação.

Acreditamos que o processo se dá da seguinte forma: primeiramente, o grafeno é esfoliado e exposto ao ar. Com o passar do tempo, moléculas são adsorvidas nas bordas e defeitos da monocamada de grafeno, resultando em regiões distintas de maior atrito. Após um tempo maior de exposição, a contaminação é espalhada por toda a monocamada, e partir de então, moléculas passam a ser adsorvidas também na camada superior. Um esquema do processo proposto é mostrado na Figura 7.5. 

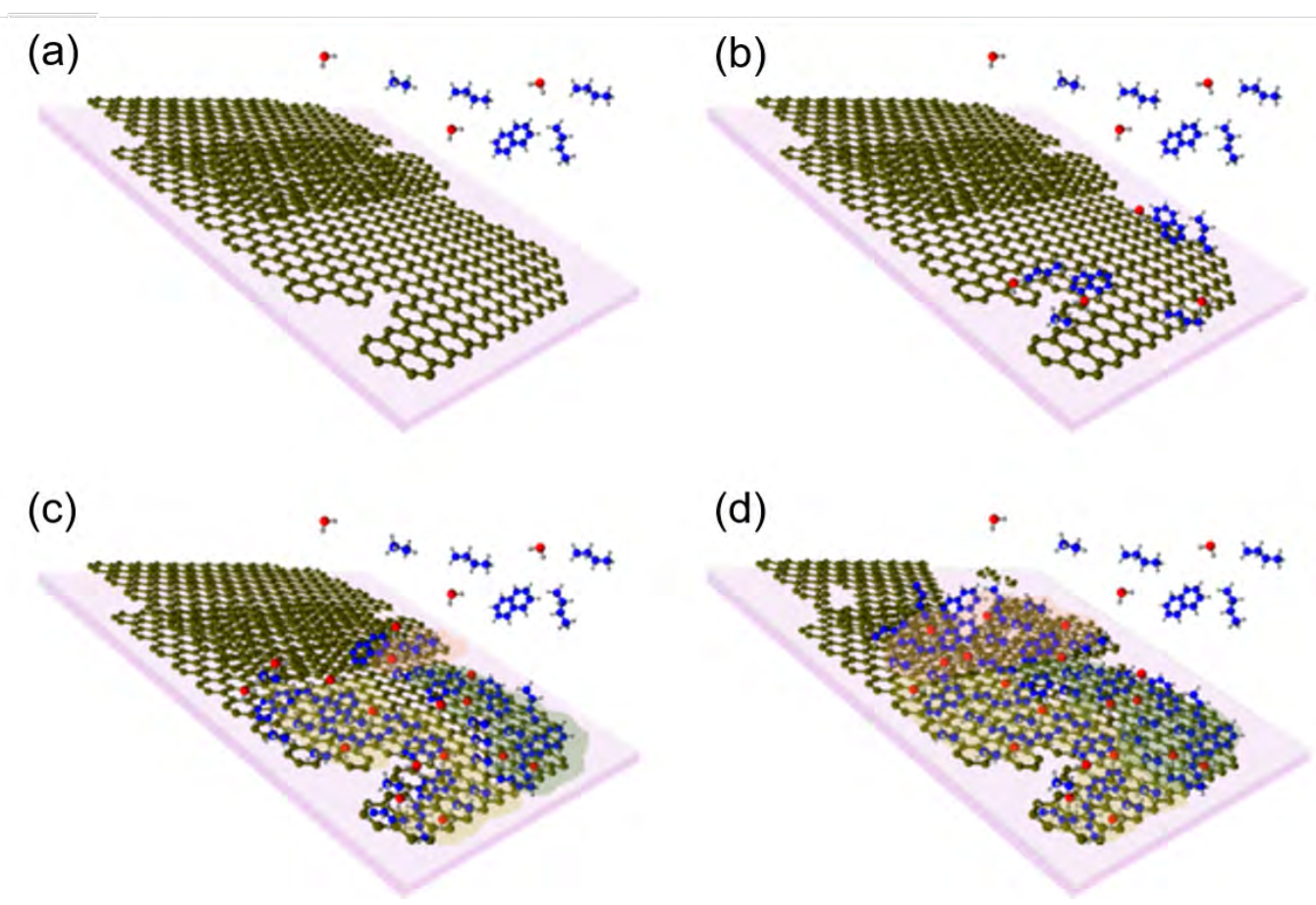

Figura 7.5: Esquema demonstrando a cinética de contaminação. (a) Superfície de grafeno e hidrocarbonetos no ar; (b) Moléculas de hidrocarbonetos adosrvidas nas bordas e defeitos da folha de grafneo; (c) Hidrocarbonetos cobrindo a monocamada de grafeno; (d) Após cobertura total da monocamada, a bicamada de grafeno passa também a adosrver moléculas de hidrocarbonetos.

A Figura 7.6 mostra medidas de atrito por força normal aplicada para amostras limpas e contaminadas. A medição na amostra limpa foi feita logo após a esfoliação, enquanto a amostra contaminada foi medida após 24 horas de exposição ao ar. É possível notar uma clara diferença de comportamento, com a fricção na área contaminada chegando a ser cerca de duas vezes maior que na área limpa. Os histogramas de adesão, medidos por curvas F-D, resultando em $F_{\text {ad }} \approx 15 \mathrm{nN}$ para a área limpa e $F_{\text {ad }} \approx 20 \mathrm{nN}$ para a área contaminada. As medidas foram variadas em carga e descarga de força aplicada pela ponta na superfície, e não foi observado histerese na friç̧ão em função da força normal em ambas áreas. 

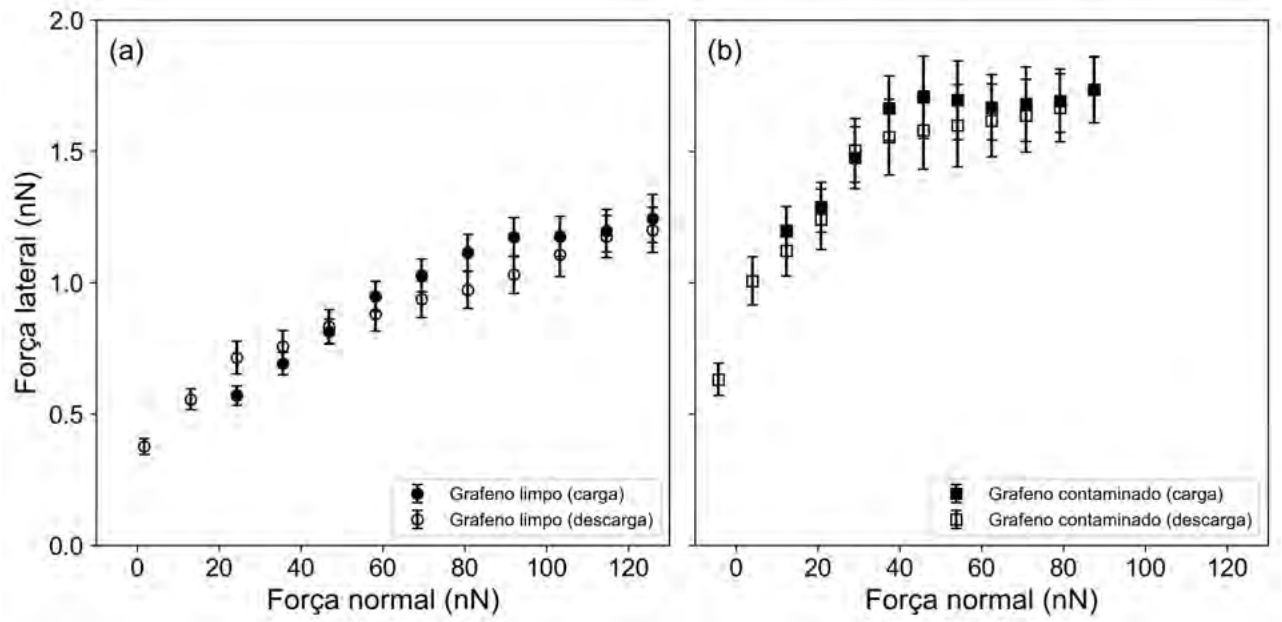

Figura 7.6: Curvas da força lateral medida em função da força normal para regiões limpas (a) e contaminadas (b) do grafeno. Símbolos (círculos e quadrados) preenchidos representam carga de força normal, e símbolos vazios descarga de força normal.

Como visto no Capítulo 4, o atrito no grafeno depende do número de camadas. Entretanto, com a contaminação na superfície, tal panorama pode mudar. O processo de adsorção segue com a exposição contínua da superfície ao ar, tomando conta de toda a monocamada e então passando para camadas adjacentes. A Figura 7.7 mostra mapas de topografia e fricção após 5 (Fig 7.7a e c) e 29 (Figs 7.7b e d) horas de exposição. Novamente não se nota nenhuma alteração na topografia por conta da contaminação. Entretanto, alterações nos contrastes de fricção são claros. Na Figura 7.7c, o atrito medido nessas áreas foi de $f_{L}=1,50 \pm 0,05 \mathrm{nN}$ e $f_{L}=2,00 \pm 0,05 \mathrm{nN}$ para mono e bicamada, respectivamente. Já a Figura 7.7 d mostra um contraste indistinguível entre as duas camadas devido ao espalhamento da contaminação, com $f_{L}=1,50 \pm 0,05 \mathrm{nN}$ medido em ambas camadas. 

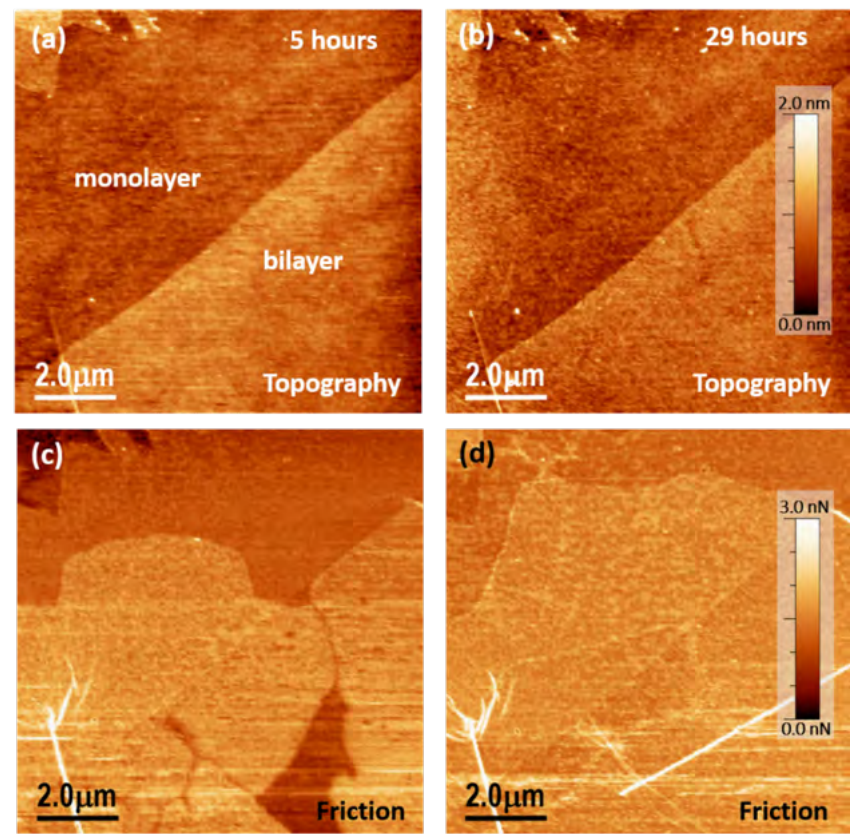

Figura 7.7: Topografia e mapas de fricção após contaminação por exposição ao ar. (a) e (c) Topografia e fricção após 5 horas de exposição; (b) e (d) Topografia e fricção após 29 horas de exposição.

Para tentar identificar o tipo de contaminação, medidas de espectroscopia FTIR foram feitas em substratos de silício limpos e após um longo tempo de exposição ao ambiente do laboratório. A Figura 7.8 mostra um espectro de um substrato de $\mathrm{SiO}_{2}$ após meses de exposição ao laboratório. O espectro apresenta apenas picos em ligações de silício com oxigênio em $\lambda \sim 1088 \mathrm{~cm}^{-1}$.

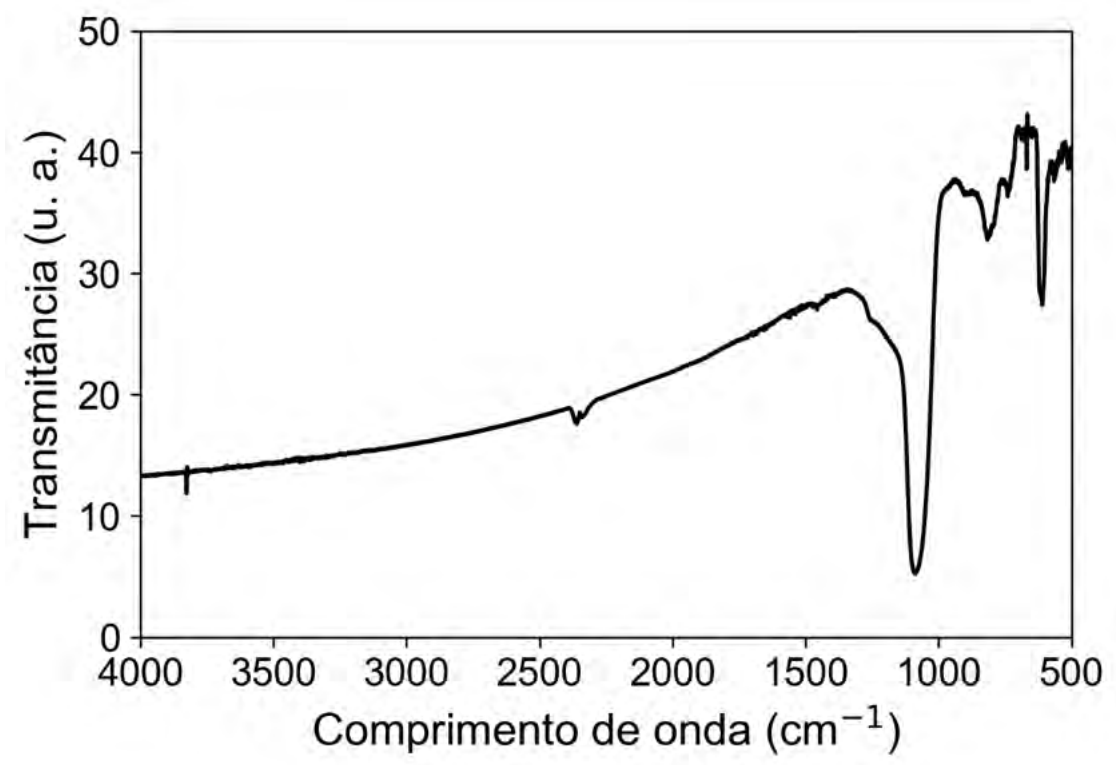

Figura 7.8: Espectro FTIR para um substrato de $\mathrm{SiO}_{2}$ após meses de exposição ao ar. 


\section{3 \\ Discussão}

Diferentes domínios no mapa de fricção tem sido reportados na literatura. Choi e colaboradores [34] atribuem o efeito à deformações na folha de grafeno provocadas pela interação da folha com o substrato de $\mathrm{SiO}_{2}$. Essas deformações seriam em formas onduladas, formando-se ao longo das direções $A C$ e $Z Z$, resultando numa periodicidade de $180^{\circ}$ na fricção medida. Os autores também verificaram que a razão entre o atrito nos diferentes domínios diminui com o aumento da carga aplicada pela ponta à superfície, chegando à valores iguais para uma força de $F_{N}=5,0 \mathrm{nN}$. Em trabalho posterior, Gallagher e colaboradores apontam para a aglomeração de hidrocarbonetos numa estrutura organizada em forma de listras, com um período entre 4,0 nm e 6,0 nm. Essa estrutura pode ser manipulada pela ponta do microscópio, dependendo da força normal aplicada, com $F_{N}=30 \mathrm{nN}$ já sendo o suficiente para a manipulação [35].

Nossos resultados não mostram variações topográficas no grafeno, como visto na Figura 7.2, entretanto, os mapas de fricção, adquiridos simultaneamente, revelam regiões com diferentes forças de atrito medidas, visto na Figura 7.1. Ao contrário de Gallagher e colaboradores [35], mesmo com cargas aplicadas entre $F_{N}=50 \mathrm{nN}$ e $F_{N}=100 \mathrm{nN}$ não foi possível observar nenhum tipo de manipulação nos domínios registrados, assim como nenhum tipo de listra. Os domínios observados neste trabalho parecem surgir em regiões de fronteira entre uma monocamada e o substrato de $\mathrm{SiO}_{2}$ e em defeitos na folha.

Como visto no Capítulo 4, a presença de água entre o substrato e a folha de grafeno parece ocorrer em amostras preparadas por esfoliação mecânica, causando enrugamentos e dobramentos das folhas de grafeno [109], podendo também contribuir para o atrito. Em amostras com água intercalada entre o substrato de $\mathrm{SiO}_{2}$ e a folha de grafeno, o movimento da ponta é facilitado pela presença da camada de água [110]. Já no caso do grafeno depositado em mica, a presença da água dificulta o moviento, aumentando o atrito [111]. No nosso caso, como visto na Figura 7.1c, mesmo com o grafeno sob $\mathrm{SiO}_{2}$, ocorre um aumento na força lateral medida. Ademais, a difusão das camadas de água entre grafeno e $\mathrm{SiO}_{2}$ pode depender da orientação cristalográfica, ocorrendo preferencialmente ao longo da direção $Z Z$ [110]. D. E. Lee e colaboradores estimaram uma evolução temporal para a área ocupada pela água entre grafeno e substrato na ordem de $\dot{C} \sim 1,0 \times 10^{-6} \mathrm{~m}^{2} \mathrm{~s}^{-1}$ [112]. Outro fator investigado foi a adesão entre ponta e superfície do grafeno depositado em mica, com água intercalada entre superfície e substrato, mostrando-se constante em relação à quantidade de água. Nestes pontos, nosso trabalho se 
difere consideravelmente da literatura, uma vez que os sinais da contaminação estão apresentes apenas nos mapas de fricção, e não no mapa topográfico; a adesão é maior em áreas contaminadas do que em áreas limpas; e a taxa de contaminação estimada é cerca de 3 ordens de grandeza maiores do que o reportado anteriormente. Estimamos, portanto, que a contaminação que observamos não se dá por camadas de água intercalada entre grafeno e substrato, assim como as moléculas adsorvidas encontram-se na superfície, e não entre superfície e substrato.

Outros estudos com grafeno exposto à contaminação ambiente em grafeno crescido por CVD mostram que a molhabilidade do material é alterada, tendo o ângulo de contato entre água e a superfície aumentado após a exposição. Tal fenômeno foi atribuído à adsorção de hidrocarbonetos por contaminação pelo ambiente [104, 105, 113]. Um aumento na fricção também foi observado em amostras expostas ao ar e em ambientes de alta umidade relativa [108], assim como histerese nas curvas de fricção por força normal devido à formação de meniscos d'água no contato ponta-amostra [108, 114]. Nossa curva de fricção por força normal também apresenta um aumento na fricção, assim como um aumento na força de adesão, porém, apesar de trabalharmos num ambiente de alta umidade, não é observada histerese em áreas limpas ou contaminadas, como visto na Figura 7.6. Este resultado pode estar associado à natureza das moléculas adsorvidas em nossas amostras. A presença de hidrocarbonetos altera a molhabilidade de tal modo que a superfície seja menos suscetível à formação de um menisco de água, e, portanto, não havendo histerese no processo de carga e descarga da ponta enquanto performa a varredura. Ademais, é perceptível uma mudança na mecânica de contato entre as áreas limpas e contaminadas. Enquanto a área limpa segue o modelo JKR, como discutido no Capítulo 5, a área contaminada exibe dois regimes diferentes, evidenciados por inclinações distintas na curva de fricção por força normal. Esse resultado indica que a adsorção de hidrocarbonetos aumenta a área de contato entre ponta e superfície, e passa a ser crítico após uma certa carga, passando para um regime mais linear. Fica claro também que esse aumento na área de contato provoca um aumento na força de adesão medida.

Como visto na Figura 7.3., os domínios de fricção evoluem com o tempo, eventualmente se espalhando por toda uma camada de grafeno. Apesar de relatos na literatura de domínios, não conhecemos nenhum estudo investigando sua evolução com o tempo. Essa sequência de imagens de mapas de fricção nos dá uma mostra de como a contaminação se difunde sob a superfície do grafeno, ocorrendo inicialmente nas bordas e defeitos da folha, devido à ligações não satisfeitas. Nossos resultados mostram que a monocamada é mais suscetível à 
contaminação do que o grafeno em multicamadas. Isto pode ocorrer pela existência prévia de impurezas no substrato a ser utilizado, uma vez que quanto mais longo o tempo de exposição do substrato, mais rápido se nota a presença de contaminantes na superfície de uma monocamada. A interação dessas impurezas com as moléculas do ar ambiente aumentam a probabilidade de ligação dos adsorventes na monocamada de grafeno. Tal interação é passível de ser blindada pela presença de de duas ou mais camadas de grafeno, consequentemente reduzindo a adsorção de moléculas em camadas adicionais de grafeno. Ademais, uma maior taxa de contaminação na monocamada, indicando maior adsorção por esta, concorda com resultados sobre função trabalho e densidade de portadores de carga no grafeno [115], assim como resultados sobre a reatividade por transferência de elétrons para mono e multicamada de grafeno [116]. Os diferentes domínios de fricção podem ser causados pela contínua adsorção, com moléculas em fase gasosa sendo adosrvidas em locais em que outras já foram previamente depositadas sobre a superfície.

Espectros infravermelhos tomados por FTIR foram feitos para tentar determinar a natureza dos contaminantes, mas nenhum sinal além da ligações entre silício e oxigênio do substrato de $\mathrm{SiO}_{2}$ foram detetados, como mostrado na Figura 7.8. A existência de diferentes domínios sugere que possa haver diferentes tipos de contaminantes, com diferentes composições em hidrocarbonetos ou moléculas de água, assim como diferentes orientações moleculares. Em trabalho realizado com o uso de microscopia de força eletrostática, MartínezMartín e colaboradores mostraram alterações no potencial da superfície de grafite devido à contaminação, e investigações adicionais por espectrometria de massa mostraram que os principais contaminantes são hidrocarbonetos policíclicos aromáticos [117]. Em estudo combinando métodos computacionais com experimentos em cromatografia inversa, Lazar e colaboradores mostraram que moléculas orgânicas como acetona e tolueno, entre outras, são facilmente adsorvidas pela superfície de grafeno [102]. Posteriormente, Kalathingal e colaboradores em estudo por DFT mostram adsorção de anéis de carbono na superfície de grafeno por interação não covalente [118]. Portanto, embora não tenhamos conseguido detectar diretamente a presença de hidrocarbonetos, é factível assumir, baseado nas diferenças entre nossos resultados e os da literatura, como nas Refs [104, 105, 113] que a contaminação vista em nossos resultados se dá por hidrocarbonetos presentes no ar ambiente do laboratório, e não pela difusão de água intercalada entre grafeno e substrato.

A difusividade de diferentes tipos de hidrocarbonetos presentes no ar ambiente numa superfície de carbono ativado foi estudada por D. D. Do e H. D. Do por vários métodos, tendo como resultado uma larga variação 
entre $1 \times 10^{-11} \mathrm{~m}^{2} \mathrm{~s}^{-1}$ e $1 \times 10^{-7} \mathrm{~m}^{2} \mathrm{~s}^{-1}$ [119]. Nossos resultados obtidos pela evolução das áreas contaminadas nos mapas de fricção mostram uma taxa entre $1 \times 10^{-14} \mathrm{~m}^{2} \mathrm{~s}^{-1}$ e $1 \times 10^{-13} \mathrm{~m}^{2} \mathrm{~s}^{-1}$, sugerindo que o processo analisado neste trabalho envolve um mecanismo de transferência de massa do ar para a superfície mais lento do que a difusão de moléculas adsorvidas.

Como já visto anteriormente, a fricção no grafeno é dependente do número de camadas. Na Figura 7.7, vemos que a adsorção de contaminantes faz com que essa diferença de fricção entre camadas praticamente se extingue, podendo inclusive ser revertida. Tais resultados sugerem que a adsorção de hidrocarbonetos inibe a deformação na direção fora do plano da folha de grafeno no deslizar da ponta sobre a superfície, dado como principal mecanismo para a diferença no atrito medido em diferentes camadas. Sendo assim, a adsorção de contaminantes mostra-se um importante mecanismo no comportamento tribológico do grafeno.

\section{4}

\section{Conclusões}

Neste capítulo, vimos que a exposição do grafeno ao ar ambiente altera as propriedades tribológicas do grafeno devido à adsorção de moléculas. Os contrastes nos mapas de fricção apresentados mostram a presença de diferentes áreas numa mesma camada com diferentes coeficientes de atrito medidos. O processo de contaminação começa por uma monocamada, em bordas e defeitos na folha. As moléculas são, então, adsorvidas ao longo de toda a superfície e depois o processo começa nas camadas seguintes. O espalhamento da contaminação na monocamada se dá mais rapidamente do que nas outras.

Também foi visto que a contaminação muda o da mecânica de contato no grafeno, o qual passa do modelo JKR para um comportamento diferente na curva de fricção por força normal, exibindo diferentes inclinações. Ademais, ao contrário da literatura, nenhuma histerese foi observada no processo de carga e descarga da ponta. A força de adesão também se mostra superior na área contaminada em relação a área limpa.

Embora não possamos provar definitivamente, nossos resultados sugerem que a contaminação é proveniente de moléculas de hidrocarbonetos adsorvidas na superfície do grafeno, e não pela presença e difusão de camadas de água entre a superfície e o substrato, visto as diferenças na cinética de contaminação em nosso experimento com o que foi reportado na literatura, principalmente por não observarmos variação topográfica nas folhas de grafeno e pela contaminação aumentar a força lateral necessária para o movimento da ponta. 


\section{8 \\ Conclusões e perspectivas futuras}

No desenvolver desta tese, procuramos estudar o comportamento tribológico do grafeno e outros materiais atomicamente finos, como cristais de $\mathrm{MoS}_{2}$ e $\mathrm{WS}_{2}$ e amostras de mica em poucas camadas. Dada uma vasta literatura recente, esperamos que os resultados aqui encontrados possam contribuir de alguma forma no entendimento dos mecanismos de friç̧ão envolvidos neste tipo de materiais, podendo otimizar a utilidade tecnológica destes, de dispositivos eletromecânicos ao uso como lubrificante sólidos em sistemas micro ou nanoscópicos.

Para entender mecanismos de fricção em escala nanométrica, foram primeiro apresentados modelos de contato entre dois sólidos, particularmente entre uma esfera e um plano, representando a ponta de um microscópio de força atômica e a superfície da amostra a ser analisada, respectivamente. Além disso, o modelo de Prandtl-Tomlinson unidimensional também é introduzido, descrevendo uma interação ponta-superfície através de um potencial periódico, de forma simplificada. Esse modelo é estendido pelo modelo de PrandtlTomlinson termicamente ativado, o qual inclui influência da temperatura no processo de medição, tornando-o um processo probabilístico.

Uma breve caracterização dos materiais em análise é mostrada no Capítulo 4. Vimos que as folhas de grafeno esfoliado se apresenta em distribuição aleatórias de camadas, sendo estas identificadas numa conjunção do uso de técnicas como microscopia ótica, espectroscopia Raman e microscopia de força atômica. Vimos que a fricção no grafeno apresenta uma dependência com o número de camadas, sendo menor quanto maior a espessura da amostra, o que está ligado à deformação das folhas pela interação com as camadas abaixo ou ao substrato. A altura entre camadas e substrato foi medida, com os resultados indicando camadas de água entre as folhas de grafeno. Não foram encontradas correlações entre a rugosidade e o atrito medido, tampouco entre a adesão da ponta com a superfície e o atrito. Os cristais de TMD se formam geralmente com um aspecto triangular, porém outras formas como estrelas de seis pontas podem ser possíveis de formação pela fusão de pontos de nucleação durante o processo de crescimento por CVD. Ademais, a superfície mostra-se oxidada, contendo um acúmulo de material nas bordas dos cristais. As amostras de 
mica analisadas mostram a formação de bolhas nas superfícies, provavelmente provenientes pela presença e difusão de água entre camadas de mica pela exposição em ambientes de alta umidade relativa como o do laboratório. As bolhas apresentam características diferentes para regiões de poucas e muitas camadas, tanto em razão topográfica quanto tribológica. Em poucas camadas, notam-se bolhas mais elípticas e com maior altura, apresentando maior coeficiente de atrito do que as regiões contendo apenas mica. Já para as regiões em muitas camadas, vemos bolhas menores, tanto em raio como em altura, e mais bem distribuídas ao longo da superfície, apresentando menor coeficiente de atrito do que a mica.

A mecânica de contato para as diferentes amostras foi estimada com curvas de força de atrito em função da força normal aplicada pelo cantiléver, estimando parâmetros como o coeficiente de atrito não linear e a resistência ao cisalhamento. Vemos que tanto o grafeno quanto o $\mathrm{MoS}_{2}$ se assemelham ao modelo JKR, enquanto $\mathrm{WS}_{2}$ e mica seguem o modelo DMT. A diferença entre os dois TMDs é intrigante, dada tanta semelhança entre ambos materiais. Possíveis explicações se dão pelo espectro fonônico levemente diferente entre eles, com o $\mathrm{WS}_{2}$ apresentando picos na densidade de estados não presentes no $\mathrm{MoS}_{2}$, e também pelo efeito piezoelétrico. Estudos recentes publicados na literatura mostram relação entre piezoeletricidade e fricção. A deformação provocada pelo deslizamento da ponta do AFM pode resultar em indução de cargas nos materiais, modificando o coeficiente de atrito. Um estudo mais aprofundado entre piezoeletricidade e fricção nos parece particularente mais promissor, visto uma tendência de maior efeito de acordo com a posição dos elementos na tabela periódica. Assim, pode-se hipoteticamente manipular e facilitar o processo de fricção por aplicações de campos elétricos nas amostras, ou mesmo pela própria deformação das mesmas. A mica apresenta o maior coeficiente de atrito e também a maior resistência ao cisalhamento, em uma à duas ordens de grandeza maior que os outros materiais analisados.

O modelo de Prandtl-Tomlinson termicamente ativado foi ajustado aos dados do atrito em grafeno em função da velocidade relativa entre superfície e ponta do AFM. Tal análise foi feita para quatro diferentes camadas de grafeno. Nas curvas, o atrito apresenta uma relação linear com o logaritmo da velocidade até um ponto em que há saturação da fricção, dada por uma força crítica. Vimos que esse efeito é amplificado para mono e bicamada de grafeno, apresentando uma inclinação maior na parte linear da curva e saturando em forças mais altas. Parâmetros do modelo como força crítica, barreira de potencial e frequência dos pulos de um mínimo de potencial para o próximo são estimados. Camadas mais finas como mono e bicamadas apresentam uma maior 
barreira por causarem maior torção no cantiléver. A frequência é razoavelmente igual para as quatro camadas analisadas, e está associada à frequência de ressonância torcional do cantiléver, de modo que a fricção possa ser controlada ajustando parâmetros do cantiléver a ser usado, assim como vibrações por flutuações térmicas podem eventualmente facilitar o processo de fricção.

Por fim, foi feito um estudo da contaminação nas superfícies de grafeno pela exposição da amostra ao ar. Acreditamos que a contaminação se dá pela adsorção de moléculas orgânicas, hidrocarbonetos em especial, pela superfície de grafeno. A contaminação começa em locais como bordas da amostra com o substrato e defeitos na superfície, e então é espalhado ao longo de uma camada, para então repetir o processo em camadas adjacentes, alterando o comportamento tribológico das camadas e tornando-as indistinguíveis em termos de coeficiente de atrito. Vemos que a taxa de contaminação por área difere em ordens de grandeza entre mono e bicamada, sendo muito mais rápido para a primeira. Ademais, a contaminação muda o contato entre ponta e superfície, e o grafeno passa não mais a seguir o modelo JKR, e adesão entre ponta e superfície é aumentada com a contaminação. Tais resultados passam a ter relevância na aplicabilidade de lubrificantes em grafeno e ambiente ao qual será usado. Ademais, juntando-se ao resultado de caracterização da mica, um estudo ainda mais detalhado pode ser importante no entendimento da dinâmica de contaminação e papel do ambiente nos mecanismos de fricção em materiais esfoliados e transferidos para substratos de interesse tecnológico, como é o $\mathrm{SiO}_{2}$ usado em nossos estudos. 


\section{Referências bibliográficas}

[1] PHILIP WONG, H.-S.; AKINWANDE, D.. Carbon nanotube and graphene device physics. Cambridge University Press, 2010.

[2] WALLACE, P. R.. The band theory of graphite. Physical Review, 71(9):622-634, 1947.

[3] NOVOSELOV, K. S.; GEIM, A. K.; MOROZOV, S. V.; JIANG, D.; ZHANG, Y.; DUBONOS, S. V.; GRIGORIEVA, I. V. ; FIRSOV, A. A.. Electric field effect in atomically thin carbon films. Science, 306(5696):666-669, 2004.

[4] GEIM, A. K.; NOVOSELOV, K. S.. The rise of graphene. Nature Materials, 6(3):183-191, 2007.

[5] BALANDIN, A. A.. Thermal properties of graphene and nanostructured carbon materials. Nature Materials, 10(8):569-581, 2010.

[6] NAIR, R. R.; BLAKE, P.; GRIGORENKO, A. N.; NOVOSELOV, K. S.; BOOTH, T. J.; STAUBER, T.; PERES, N. M. R. ; GEIM, A. K.. Fine structure constant defines visual transparency of graphene. Science, 320(5881):1308, 2008.

[7] LEE, S. M.; KIM, J.-H. ; AHN, J.-H.. Graphene as a flexible electronic material: mechanical limitations by defect formation and efforts to overcome. Materials Today, 18(6):336-344, 2015.

[8] LEE, C.; WEI, X.; KYSAR, J. W. ; HONE, J.. Measurement of the elastic properties and intrinsic strength of monolayer graphene. Science, 321(5887):385-388, 2008.

[9] LEE, J.; HA, T.-J.; LI, H.; PARRISH, K. N.; HOLT, M.; DODABALAPUR, A.; RUOFF, R. S. ; AKINWANDE, D.. 25 ghz embedded-gate graphene transistors with high-k dielectrics on extremely flexible plastic sheets. ACS Nano, 7(9):7744-7750, 2013.

[10] VARGHESE, S. S.; LONKAR, S.; SINGH, K. K.; SWAMINATHAN, S. ; ABDALA, A.. Recent advances in graphene based gas sensors. Sensors and Actuators B: Chemical, 218:160-183, 2015. 
[11] ZANG, X.; ZHOU, Q.; CHANG, J.; LIU, Y. ; LIN, L.. Graphene and carbon nanotube (cnt) in mems/nems applications. Microelectronic Engineering, 132:192 - 206, 2015.

[12] CHEN, M.; HADDON, R. C.; YAN, R. ; BEKYAROVA, E.. Advances in transferring chemical vapour deposition graphene: a review. Materials Horizons, 4:1054-1063, 2017.

[13] LIU, H. F.; WONG, S. L. ; CHI, D. Z.. Cvd growth of mos2-based twodimensional materials. Chemical Vapor Deposition, 21(10-11-12):241$259,2015$.

[14] MAK, K. F.; LEE, C.; HONE, J.; SHAN, J. ; HEINZ, T. F.. Atomically thin $\operatorname{mos}_{2}$ : A new direct-gap semiconductor. Physical Review Letters, 105:136805, Sep 2010.

[15] CASTELLANOS-GOMEZ, A.; WOJTASZEK, M.; TOMBROS, N.; AGRAÏT, N.; VAN WEES, B. J. ; RUBIO-BOLLINGER, G.. Atomically thin mica flakes and their application as ultrathin insulating substrates for graphene. Small, 7(17):2491-2497, 2011.

[16] FILLETER, T.; MCCHESNEY, J. L.; BOSTWICK, A.; ROTENBERG, E.; EMTSEV, K. V.; SEYLLER, T.; HORN, K. ; BENNEWITZ, R.. Friction and dissipation in epitaxial graphene films. Phys. Rev. Lett., 102:086102, Feb 2009.

[17] LEE, C.; LI, Q.; KALB, W.; LIU, X.-Z.; BERGER, H.; CARPICK, R. W. ; HONE, J.. Frictional characteristics of atomically thin sheets. Science, 328(5974):76-80, 2010.

[18] LI, Q.; LEE, C.; CARPICK, R. W. ; HONE, J.. Substrate effect on thickness-dependent friction on graphene. physica status solidi (b), 247(11-12):2909-2914, 2010.

[19] CHO, D.-H.; WANG, L.; KIM, J.-S.; LEE, G.-H.; KIM, E. S.; LEE, S.; LEE, S. Y.; HONE, J. ; LEE, C.. Effect of surface morphology on friction of graphene on various substrates. Nanoscale, 5:3063-3069, 2013.

[20] DONG, Y.. Effects of substrate roughness and electron-phonon coupling on thickness-dependent friction of graphene. Journal of Physics D: Applied Physics, 47(5):055305, jan 2014.

[21] SPEAR, J. C.; CUSTER, J. P. ; BATTEAS, J. D.. The influence of nanoscale roughness and substrate chemistry on the frictional 
properties of single and few layer graphene. Nanoscale, 7:1002110029, 2015.

[22] YE, Z.; BALKANCI, A.; MARTINI, A. ; BAYKARA, M. Z.. Effect of roughness on the layer-dependent friction of few-layer graphene. Phys. Rev. B, 96:115401, Sep 2017.

[23] ALMEIDA, C. M.; CAROZO, V.; PRIOLI, R. ; ACHETE, C. A.. Identification of graphene crystallographic orientation by atomic force microscopy. Journal of Applied Physics, 110(8):086101, 2011.

[24] ALMEIDA, C. M.; PRIOLI, R.; FRAGNEAUD, B.; CANÇADO, L. G.; PAUPITZ, R.; GALVÃO, D. S.; DE CICCO, M.; MENEZES, M. G. ; ACHETE, C. A.. Giant and tunable anisotropy of nanoscale friction in graphene. Scientific Reports, 6:31569, 2016.

[25] CHOI, J. S.; CHANG, Y. J.; WOO, S.; YOUNG-WOO, S.; PARK, Y.; LEE, M. J.; BYUN, I.-S.; KIM, J.-S.; CHOI, C.-G.; BOSTWICK, A.; ROTENBERG, E. ; PARK, B. H.. Correlation between micrometer-scale ripple alignment and atomic-scale crystallographic orientation of monolayer graphene. Scientific Reports, 4:7263, 2015.

[26] PARK, Y.; CHOI, J. S.; CHOI, T.; LEE, M. J.; JIA, Q.; PARK, M.; LEE, H. ; PARK, B. H.. Configuration of ripple domains and their topological defects formed under local mechanical stress on hexagonal monolayer graphene. Scientific Reports, 5:9390, 2015.

[27] JANSEN, L.; HÖLSCHER, H.; FUCHS, H. ; SCHIRMEISEN, A.. Temperature dependence of atomic-scale stick-slip friction. Phys. Rev. Lett., 104:256101, Jun 2010.

[28] ZHANG, Y.; DONG, M.; GUEYE, B.; NI, Z.; WANG, Y. ; CHEN, Y.. Temperature effects on the friction characteristics of graphene. Applied Physics Letters, 107(1):011601, 2015.

[29] QU, W.; CHEN, X. ; KE, C.. Temperature-dependent frictional properties of ultra-thin boron nitride nanosheets. Applied Physics Letters, 110(14):143110, 2017.

[30] MEYER, E.; GYALOG, T.; OVERNEY, R. M. ; DRANSFELD, K.. Nanoscience: Friction and Rheology on the Nanometer Scale. WORLD SCIENTIFIC, 1998. 
[31] MATE, C. M.; MCCLELLAND, G. M.; ERLANDSSON, R. ; CHIANG, S.. Atomic-scale friction of a tungsten tip on a graphite surface. Phys. Rev. Lett., 59:1942-1945, Oct 1987.

[32] BABOUKANI, B. S.; YE, Z.; REYES, K. G. ; NALAM, P. C.. Prediction of nanoscale friction for two-dimensional materials using a machine learning approach. Tribology Letters, 68:57, 2020.

[33] LI, S.; LI, Q.; CARPICK, R. W.; GUMBSCH, P.; LIU, X. Z.; DING, X.; SUN, J. ; LI, J.. The evolving quality of frictional contact with graphene. Nature, 539:541, 2016.

[34] CHOI, J. S.; KIM, J.-S.; BYUN, I.-S.; LEE, D. H.; LEE, M. J.; PARK, B. H.; LEE, C.; YOON, D.; CHEONG, H.; LEE, K. H.; SON, Y.-W.; PARK, J. Y. ; SALMERON, M.. Friction anisotropy-driven domain imaging on exfoliated monolayer graphene. Science, 333(6042):607-610, 2011.

[35] GALLAGHER, P.; LEE, M.; AMET, F.; MAKSYMOVYCH, P.; WANG, J.; WANG, S.; LU, X.; ZHANG, G.; WATANABE, K.; TANIGUCHI, T. ; GOLDHABER-GORDON, D.. Switchable friction enabled by nanoscale self-assembly on graphene. Nature Communications, 7:10745, 2016.

[36] GNECCO, E.; BENNEWITZ, R.; GYALOG, T.; LOPPACHER, C.; BAMMERLIN, M.; MEYER, E. ; GÜNTHERODT, H.-J.. Velocity dependence of atomic friction. Phys. Rev. Lett., 84:1172-1175, Feb 2000.

[37] CHEN, J.; RATERA, I.; PARK, J. Y. ; SALMERON, M.. Velocity dependence of friction and hydrogen bonding effects. Phys. Rev. Lett., 96:236102, Jun 2006.

[38] SANG, Y.; DUBÉ, M. ; GRANT, M.. Thermal effects on atomic friction. Phys. Rev. Lett., 87:174301, Oct 2001.

[39] RIEDO, E.; GNECCO, E.; BENNEWITZ, R.; MEYER, E. ; BRUNE, H.. Interaction potential and hopping dynamics governing sliding friction. Phys. Rev. Lett., 91:084502, Aug 2003.

[40] FURLONG, O. J.; MANZI, S. J.; PEREYRA, V. D.; BUSTOS, V. ; TYSOE, W. T.. Kinetic monte carlo theory of sliding friction. Phys. Rev. B, 80:153408, Oct 2009 .

[41] TRAN-KHAC, B.-C.; KIM, H.-J.; DELRIO, F. W. ; CHUNG, K.-H.. Operational and environmental conditions regulate the frictional 
behavior of two-dimensional materials. Applied Surface Science, 483:34 - 44, 2019.

[42] ACIKGOZ, O.; BAYKARA, M. Z.. Speed dependence of friction on single-layer and bulk mos2 measured by atomic force microscopy. Applied Physics Letters, 116(7):071603, 2020.

[43] SMOLYANITSKY, A.; KILLGORE, J. P. ; TEWARY, V. K.. Effect of elastic deformation on frictional properties of few-layer graphene. Phys. Rev. B, 85:035412, Jan 2012.

[44] CARPICK, R. W.; OGLETREE, D. ; SALMERON, M.. A general equation for fitting contact area and friction vs load measurements. Journal of Colloid and Interface Science, 211(2):395 - 400, 1999.

[45] SOCOLIUC, A.; BENNEWITZ, R.; GNECCO, E. ; MEYER, E.. Transition from stick-slip to continuous sliding in atomic friction: Entering a new regime of ultralow friction. Phys. Rev. Lett., 92:134301, Apr 2004.

[46] GNECCO, E.; MEYER, E.. Fundamentals of friction and wear on the nanoscale. NanoScience and Technology. Springer International Publishing, 2015.

[47] CARPICK, R. W.; OGLETREE, D. F. ; SALMERON, M.. Lateral stiffness: A new nanomechanical measurement for the determination of shear strengths with friction force microscopy. Applied Physics Letters, 70(12):1548-1550, 1997.

[48] EVSTIGNEEV, M.; SCHIRMEISEN, A.; JANSEN, L.; FUCHS, H. ; REIMANN, P.. Force dependence of transition rates in atomic friction. Phys. Rev. Lett., 97:240601, Dec 2006.

[49] HELMAN, J. S.; BALTENSPERGER, W. ; HOL/YST, J. A.. Simple model for dry friction. Phys. Rev. B, 49:3831-3838, Feb 1994.

[50] JEON, J.; JANG, S. K.; JEON, S. M.; YOO, G.; JANG, Y. H.; PARK, J.-H. ; LEE, S.. Layer-controlled cvd growth of large-area twodimensional mos2 films. Nanoscale, 7:1688-1695, 2015.

[51] FUKUMA, T.; UEDA, Y.; YOSHIOKA, S. ; ASAKAWA, H.. Atomic-scale distribution of water molecules at the mica-water interface visualized by three-dimensional scanning force microscopy. Phys. Rev. Lett., 104:016101, Jan 2010. 
[52] MEYER, E.; HUG, H. J. ; BEnNeWITZ, R.. Scanning Probe Microscopy. The lab on a tip. Advanced texts in physics. Springer-Verlag Berlin Heidelberg, 2004.

[53] LIU, E.; BLANPAIN, B. ; CELIS, J.. Calibration procedures for frictional measurements with a lateral force microscope. Wear, 192(1):141 - 150, 1996.

[54] ZAMORA, R. R. M.. Influência da condensação capilar na fricção em nano escala. PhD thesis, PUC-Rio, 2005.

[55] Park Systems Corporation. NX-10 User's manual.

[56] SCHINDELIN, J.; ARGANDA-CARRERAS, I.; FRISE, E.; KAYNIG, V.; LOGAIR, M.; PIETZSCH, T.; PREIBISCH, S.; RUEDEN, C.; SAALFELD, S.; SCHMID, B.; TINEVEZ, J.-Y.; WHITE, D. J.; HARTENSTEIN, V.; ELICEIRI, K.; TOMANCAK, P. ; CARDONA, A.. Fiji: an open source platform for biological-image analysis. Nature Methods, 9(7):676682, 2012.

[57] THEVEnAZ, P.; RUTTIMANN, U. E. ; UNSER, M.. A pyramid approach to subpixel registration based on intensity. IEEE Transactions on Image Processing, 7(1):27-41, 1998.

[58] SEZGIN, M.; SANKUR, B.. Survey over image thresholding techniques and quantitative performance evaluation. Journal of Electronic Imaging, 13(1):146 - 165, 2004.

[59] FERRARI, A. C.; MEYER, J. C.; SCARDACI, V.; CASIRAGHI, C.; LAZZERI, M.; MAURI, F.; PISCANEC, S.; JIANG, D.; NOVOSELOV, K. S.; ROTH, S. ; GEIM, A. K.. Raman spectrum of graphene and graphene layers. Phys. Rev. Lett., 97:187401, Oct 2006.

[60] HONG, Y.; WANG, S.; LI, Q.; SONG, X.; WANG, Z.; ZHANG, X.; BESENBACHER, F. ; DONG, M.. Interfacial icelike water local doping of graphene. Nanoscale, 11:19334-19340, 2019.

[61] VAZIRISERESHK, M. R.; YE, H.; YE, Z.; OTERO-DE-LA ROSA, A.; ZHAO, M.-Q.; GAO, Z.; CHARLIE JOHNSON, A. T.; JOHNSON, E. R.; CARPICK, R. W. ; MARTINI, A.. Origin of nanoscale friction contrast between supported graphene, mos2, and graphene/mos2 heterostructure. Nano Letters, 19:5496-5505, July 2019. 
[62] CHE, Z.; VAZIRISRESHK, M. R.; KHAJEH, A.; MARTINI, A. ; KIM, S. H.. Effect of atomic corrugation on adhesion and friction: a model study with graphene step edges. The Journal of Physical Chemistry Letters, 10:6455-6461, October 2019.

[63] LEE, C.; WEI, X.; LI, Q.; CARPICK, R.; KYSAR, J. W. ; HONE, J.. Elastic and frictional properties of graphene. physica status solidi (b), 246(11-12):2562-2567, 2009.

[64] ARTYUKHOV, V. I.; HU, Z.; ZHANG, Z. ; YAKOBSON, B. I.. Topochemistry of bowtie- and star-shaped metal dichalcogenide nanoisland formation. Nano Letters, 16:3696-3702, May 2016.

[65] VAN DER ZENDE, A. M.; HUANG, P. Y.; CHENET, D. A.; BERKELBACH, T. C.; YOU, Y.; LEE, G.-H.; HEINZ, T. F.; REICHMAN, D. R.; MULLER, D. A. ; HONE, J. C.. Grains and grain boundaries in highly crystalline monolayer molybdenum disulphide. Nature Materials, 12(3):554-561, 2013.

[66] KANG, K. N.; GODIN, K. ; YANG, E.-H.. The growth scale and kiinetics of ws2 monolayers under varying h2 concentration. Scientific Reports, 5:13205, 2015.

[67] GAO, J.; LI, B.; TAN, J.; CHOW, P.; LU, T.-M. ; KORATKAR, N.. Aging of transition metal dichalcogenide monolayers. ACS Nano, 10:2628-2635, Jan 2016.

[68] SANTOSH, K. C.; LONGO, R. C.; WALLACE, R. M. ; CHO, K.. Surface oxidation energetics and kinetics on mos2 monolayer. Journal of Applied Physics, 117(13):135301, 2015.

[69] KOTSAKIDIS, J. C.; ZHANG, Q.; VAZQUEZ DE PARGA, A. L.; CURRIE, M.; HELMERSON, K.; GASKILL, D. K. ; FUHRER, M. S.. Oxidation of monolayer ws2 in ambient is a photoinduced process. Nano Letters, 19(8):5205-5215, 2019. PMID: 31287707.

[70] DIENWIEBEL, M.; VERHOEVEN, G. S.; PRADEEP, N.; FRENKEN, J. W. M.; HEIMBERG, J. A. ; ZANDBERGEN, H. W.. Superlubricity of graphite. Phys. Rev. Lett., 92:126101, Mar 2004.

[71] HULL, D.. The geometry of cracks and blisters in mica. Acta Materialia, 45(1):233 - 244, 1997. 
[72] SANCHEZ, D. A.; DAI, Z.; WANG, P.; CANTU-CHAVEZ, A.; BRENNAN, C. J.; HUANG, R. ; LU, N.. Mechanics of spontaneously formed nanoblisters trapped by transferred 2d crystals. Proceedings of the National Academy of Sciences, 115(31):7884-7889, 2018.

[73] CAO, P.; XU, K.; VARGHESE, J. O. ; HEATH, J. R.. The microscopic structure of adsorbed water on hydrophobic surfaces under ambient conditions. Nano Letters, 11(12):5581-5586, 2011. PMID: 22050080 .

[74] PIZZOCCHERO, F.; GAMMELGAARD, L.; JESSEN, B. S.; CARIDAD, J. M.; WANG, L.; HONE, J.; BOGGLID, P. ; BOOTH, T. J.. The hot pick-up technique for batch assembly of van der waals heterostructures. Nature Communications, 7:11894, 2016.

[75] MIRANDA, P. B.; XU, L.; SHEN, Y. R. ; SALMERON, M.. Icelike water monolayer adsorbed on mica at room temperature. Phys. Rev. Lett., 81:5876-5879, Dec 1998.

[76] DE BEER, S.; 'T MANNETJE, D.; ZANTEMA, S. ; MUGELE, F.. Instability of confined water films between elastic surfaces. Langmuir, 26(5):3280-3285, 2010. PMID: 20041680.

[77] MATLAB. version 9.4.0 (R2018a). The MathWorks Inc., Natick, Massachusetts, 2018.

[78] Computational Methods for Nonlinear Least Squares, p. 619660. John Wiley \& Sons, Ltd, 2005.

[79] LIU, K.; YAN, Q.; CHEN, M.; FAN, W.; SUN, Y.; SUH, J.; FU, D.; LEE, S.; ZHOU, J.; TONGAY, S.; JI, J.; NEATON, J. B. ; WU, J.. Elastic properties of chemical-vapor-deposited monolayer mos2, ws2, and their bilayer heterostructures. Nano Letters, 14(9):5097-5103, 2014. PMID: 25120033.

[80] CASTELLANOS-GOMEZ, A.; POOT, M.; AMOR-AMORÓS, A.; STEELE, G. A.; VAN DER ZANT, H. S. J.; AGRAIIT, N. ; RUBIO-BOLLINGER, G. Mechanical properties of freely suspended atomically thin dielectric layers of mica. Nano Research, 5(8):550-557, 2012.

[81] KIM, K.-S.; LEE, H.-J.; LEE, C.; LEE, S.-K.; JANG, H.; AHN, J.-H.; KIM, J.H. ; LEE, H.-J.. Chemical vapor deposition-grown graphene: The thinnest solid lubricant. ACS Nano, 5(6):5107-5114, 2011. PMID: 21545092 . 
[82] KWON, S.; KO, J.-H.; JEON, K.-J.; KIM, Y.-H. ; PARK, J. Y.. Enhanced nanoscale friction on fluorinated graphene. Nano Letters, 12(12):6043-6048, 2012. PMID: 22720882.

[83] DENG, Z.; KLIMOV, N. N.; SOLARES, S. D.; LI, T.; XU, H. ; CANNARA, R. J.. Nanoscale interfacial friction and adhesion on supported versus suspended monolayer and multilayer graphene. Langmuir, 29(1):235-243, 2013. PMID: 23215163.

[84] EBENSTEIN, D. M.. Nano-jkr force curve method overcomes challenges of surface detection and adhesion for nanoindentation of a compliant polymer in air and water. Journal of Materials Research, 26(8):1026-1035, 2011.

[85] NOTBOHM, J.; POON, B. ; RAVICHANDRAN, G.. Analysis of nanoindentation of soft materials with an atomic force microscope. Journal of Materials Research, 27(1):229-237, 2012.

[86] MOLINA-SÁNCHEZ, A.; WIRTZ, L.. Phonons in single-layer and few-layer $\operatorname{mos}_{2}$ and $\mathbf{w s}_{2}$. Phys. Rev. B, 84:155413, Oct 2011.

[87] AMANI, M.; CHIN, M. L.; MAZZONI, A. L.; BURKE, R. A.; NAJMAEI, S.; AJAYAN, P. M.; LOU, J. ; DUBEY, M.. Growth-substrate induced performance degradation in chemically synthesized monolayer mos2 field effect transistors. Applied Physics Letters, 104(20):203506, 2014.

[88] MCCREARY, K. K.; HANBICKI, A. T.; SING, S.; KAWAKAMI, R. K.; JERNIGAN, G. G.; ISHIGAMI, M.; NG, A.; BRINTLINGER, T. H.; STROUD, R. M. ; JONKER, B. T.. The effect of preparation conditions on raman and photoluminescence of monolayer ws2. Scientific Reports, 6:35154, 2016.

[89] ZHU, H.; WANG, Y.; XIAO, J.; LIU, M.; XIONG, S.; WONG, Z.; YE, Z.; YE, Y.; YIN, X. ; ZHANG, X.. Observation of piezoelectricity in free-standing monolayer mos2. Nature nanotechnology, 10:151-155, 122014.

[90] LAVINI, F.; CALÒ, A.; GAO, Y.; ALBISETTI, E.; LI, T.-D.; CAO, T.; LI, G.; CAO, L.; ARUTA, C. ; RIEDO, E.. Friction and work function oscillatory behavior for an even and odd number of layers in polycrystalline mos2. Nanoscale, 10:8304-8312, 2018. 
[91] PENG, J.; YANG, F.; HUANG, K.; DONG, H.; YAN, S. ; ZHENG, X.. Friction behavior of monolayer molybdenum diselenide nanosheet under normal electric field. Physics Letters A, 384:126166, 112019.

[92] HE, F.; YANG, X.; BIAN, Z.; XIE, G.; GUO, D. ; LUO, J.. In-plane potential gradient induces low frictional energy dissipation during the stick-slip sliding on the surfaces of $2 \mathrm{~d}$ materials. Small, 15:1904613, 102019.

[93] DUERLOO, K.-A.; ONG, M. ; REED, E.. Intrinsic piezoelectricity in two-dimensional materials. The Journal of Physical Chemistry Letters, 3:2871-2876, 092012.

[94] ALYORUK, M.; AIERKEN, Y.; ÇAKIR, D.; PEETERS, F. ; SEVIK, C.. Promising piezoelectric performance of single layer transitionmetal dichalcogenides and dioxides. The Journal of Physical Chemistry C, 119:23231-23237, 102015.

[95] HU, J.; D. XIAO, X.; OGLETREE, D. ; SAlMERON, M.. Atomic scale friction and wear of mica. Surface Science, 327(3):358 - 370, 1995.

[96] PTAK, F.; ALMEIDA, C. ; PRIOLI, R.. Velocity-dependent friction enhances tribomechanical differences between monolayer and multilayer graphene. Scientific Reports, 9:1-9, 102019.

[97] KILLGORE, J. P.; DELRIO, F. W.. Contact resonance force microscopy for viscoelastic property measurements: From fundamentals to state-of-the-art applications. Macromolecules, 51(18):69776996, 2018.

[98] COLCHERO, J.; BARÓ, A. M. ; MARTI, O.. Energy dissipation in scanning force microscopy-friction on an atomic scale. Tribology Letters, 2:327-343, 1996.

[99] SCHIRMEISEN, A.; JANSEN, L. ; FUCHS, H.. Tip-jump statistics of stick-slip friction. Phys. Rev. B, 71:245403, Jun 2005.

[100] ZHAO, X.; HAMILTON, M.; GREGORY SAWYER, W. ; PERRY, S. S.. Thermally activated friction. Tribology Letters, 27:113-117, 2007.

[101] LEENAERTS, O.; PARTOENS, B. ; PEETERS, F. M.. Adsorption of $\mathrm{h}_{2} \mathrm{O}, \mathrm{Nh}_{3}$, co, $\mathrm{No}_{2}$, and no on graphene: A first-principles study. Phys. Rev. B, 77:125416, Mar 2008. 
[102] LAZAR, P.; KARLICKÝ, F.; JURECKA, P.; KOCMAN, M.; OTYEPKOVA, E.; SAFAROVA, K. ; OTYEPKA, M.. Adsorption of small organic molecules on graphene. Journal of the American Chemical Society, 135:6372-6377, 042013.

[103] PENG, Z.; YANG, R.; KIM, M. A.; LI, L. ; LIU, H.. Influence of o2, h2o and airborne hydrocarbons on the properties of selected 2d materials. p. 27048-27057, 012017.

[104] LI, Z.; WANG, Y.; KOZBIAL, A.; SHENOY, G.; ZHOU, F.; MCGINLEY, R.; IRELAND, P.; MORGANSTEIN, B.; KUNKEL, A.; SURWADE, S.; LI, L. ; LIU, H.. Effect of airborne contaminants on the wettability of supported graphene and graphite. Nature materials, 12:925-931, 072013.

[105] ARIA, A.; KIDAMBI, P.; WEATHERUP, R.; XIAO, L.; WILLIAMS, J. ; HOFMANN, S.. Time evolution of the wettability of supported graphene under ambient air exposure. The Journal of Physical Chemistry C, 120:2215-2224, 012016.

[106] YAVARI, F.; KRITZINGER, C.; GAIRE, C.; SONG, L.; GULLAPALLI, H.; BORCA-TASCIUC, T.; AJAYAN, P. ; KORATKAR, N.. Tunable bandgap in graphene by the controlled adsorption of water molecules. Small (Weinheim an der Bergstrasse, Germany), 6:2535-2538, 112010.

[107] BALOG, R.; JØRGENSEN, B.; NILSSON, L.; ANDERSEN, M.; RIENKS, E.; BIANCHI, M.; FANETTI, M.; L/EGSGAARD, E.; BARALDI, A.; LIZZIT, S.; SLJIVANCANIN, Z.; BESENBACHER, F.; HAMMER, B.; PEDERSEN, T.; HOFMANN, P. ; HORNEKAER, L.. Bandgap opening in graphene induced by patterned hydrogen adsorption. Nature materials, 9:315-319, 032010.

[108] GONG, P.; YE, Z.; YUAN, L. ; EGBERTS, P.. Evaluation of wetting transparency and surface energy of pristine and aged graphene through nanoscale friction. Carbon, 132:749-759, 022018.

[109] LEE, M.; CHOI, J.; KIM, J.-S.; BYUN, I.-S.; LEE, D.; RYU, S.; LEE, C. ; PARK, B.. Characteristics and effects of diffused water between graphene and a sio2 substrate. Nano Research, 5:710-717, 102012.

[110] KIM, J.-S.; CHOI, J.; LEE, M. J.; PARK, B. H.; BUKHVALOV, D.; SON, Y. W.; YOON, D.; CHEONG, H.; YUN, J. N.; JUNG, Y.; PARK, J. Y. ; SALMERON, M.. Between scylla and charybdis: Hydrophobic 
graphene-guided water diffusion on hydrophilic substrates. Scientific Reports, 3:2309, 2013.

[111] LEE, H.; KO, J.-H.; CHOI, J. S.; HWANG, J. H.; KIM, Y.-H.; SALMERON, M. ; PARK, J. Y.. Enhancement of friction by water intercalated between graphene and mica. The Journal of Physical Chemistry Letters, 8(15):3482-3487, 2017. PMID: 28697599.

[112] LEE, D.; AHN, G. ; RYU, S.. Two-dimensional water diffusion at a graphene-silica interface. Journal of the American Chemical Society, 136:6634-6642, 042014.

[113] AMADEI, C.; LAI, C.-Y.; HESKES, D. ; CHIESA, M.. Time dependent wettability of graphite upon ambient exposure: The role of water adsorption. The Journal of chemical physics, 141:084709, 082014.

[114] YE, Z.; EGBERTS, P.; HAN, G.; JOHNSON, A. T. C.; CARPICK, R. ; MARTINI, A.. Load-dependent friction hysteresis on graphene. ACS Nano, 10:5161-5168, 042016.

[115] GIUSCA, C.; PANCHAL, V.; MUNZ, M.; WHEELER, V.; NYAKITI, L.; MYERS-WARD, R.; GASKILL, D. ; KAZAKOVA, O.. Water affinity to epitaxial graphene: The impact of layer thickness. Advanced Materials Interfaces, 2:1500252, 082015.

[116] SHARMA, R.; BAIK, J.; PERERA, C. ; STRANO, M.. Anomalously large reactivity of single graphene layers and edges toward electron transfer chemistries. Nano letters, 10:398-405, 022010.

[117] MARTÍNEZ-MARTÍN, D.; LONGUINHOS, R.; IZQUIERDO, J.; MARELE, A.; ALEXANDRE, S.; JAAFAR, M.; GÓMEZ-RODRÍGUEZ, J.; BAÑARES, L.; SOLER, J. ; GOMEZ-HERRERO, J.. Atmospheric contaminants on graphitic surfaces. Carbon, 61:33-39, 092013.

[118] KALATHINGAL, M.; C.H, O.; ROY, D. ; SWATHI, R.. Adsorption of monocyclic carbon rings on graphene: Energetics revealed via continuum modeling. ACS Omega, 3:7542-7554, 072018.

[119] DO, D.; DO, H.. Surface diffusion of hydrocarbons in activated carbon: Comparison between constant molar flow, differential permeation and differential adsorption bed methods. Adsorption, 7:189-209, 102001. 